OPEN ACCESS

Edited by:

Giovanna Longhi,

University of Brescia, Italy

Reviewed by:

Dong Chen,

Zhejiang University, China

Lorenzo Di Bari,

University of Pisa, Italy

*Correspondence:

Benjamin Doistau

Benjamin.Doistau@unige.ch

Juan-Ramón Jiménez

Juan.JimenezGallego@unige.ch

tThese authors have contributed equally to this work

Specialty section:

This article was submitted to

Physical Chemistry and Chemical

Physics,

a section of the journal

Frontiers in Chemistry

Received: 04 March 2020

Accepted: 29 May 2020

Published: 28 July 2020

Citation:

Doistau B, Jiménez J-R and Piguet C

(2020) Beyond Chiral Organic

(p-Block) Chromophores for Circularly

Polarized Luminescence: The

Success of $d$-Block and f-Block Chiral

Complexes. Front. Chem. 8:555.

doi: 10.3389/fchem.2020.00555

\section{Beyond Chiral Organic (p-Block) Chromophores for Circularly Polarized Luminescence: The Success of d-Block and f-Block Chiral Complexes}

\author{
Benjamin Doistau ${ }^{\star \dagger}$, Juan-Ramón Jiménez ${ }^{* \dagger}$ and Claude Piguet \\ Department of Inorganic and Analytical Chemistry, University of Geneva, Geneva, Switzerland
}

Chiral molecules are essential for the development of advanced technological applications in spintronic and photonic. The best systems should produce large circularly polarized luminescence (CPL) as estimated by their dissymmetry factor (glum), which can reach the maximum values of $-2 \leq g_{\text {lum }} \leq 2$ when either pure right- or left-handed polarized light is emitted after standard excitation. For matching this requirement, theoretical considerations indicate that optical transitions with large magnetic and weak electric transition dipole moments represent the holy grail of CPL. Because of their detrimental strong and allowed electric dipole transitions, popular chiral emissive organic molecules display generally moderate dissymmetry factors $\left(10^{-5} \leq g_{\mathrm{lum}} \leq 10^{-3}\right)$. However, recent efforts in this field show that glum can be significantly enhanced when the chiral organic activators are part of chiral supramolecular assemblies or of liquid crystalline materials. At the other extreme, chiral Eu III- and Sm III-based complexes, which possess intra-shell parity-forbidden electric but allowed magnetic dipole transitions, have yielded the largest dissymmetry factor reported so far with $g_{\text {lum }} \sim 1$ 1.38. Consequently, 4f-based metal complexes with strong $\mathrm{CPL}$ are currently the best candidates for potential technological applications. They however suffer from the need for highly pure samples and from considerable production costs. In this context, chiral earth-abundant and cheap d-block metal complexes benefit from a renewed interest according that their CPL signal can be optimized despite the larger covalency displayed by d-block cations compared with $4 \mathrm{f}$-block analogs. This essay thus aims at providing a minimum overview of the theoretical aspects rationalizing circularly polarized luminescence and their exploitation for the design of chiral emissive metal complexes with strong CPL. Beyond the corroboration that $\mathrm{f}-\mathrm{f}$ transitions are ideal candidates for generating large dissymmetry factors, a special attention is focused on the recent attempts to use chiral $\mathrm{Cr}^{\mathrm{III}}$-based complexes that reach values of glum up to 0.2. This could pave the way for replacing high-cost rare earths with cheap transition metals for CPL applications.

Keywords: circularly polarized luminescence (CPL), coordination complexes, lanthanides, chromium(III), dissymmetry factor 


\section{INTRODUCTION}

Chirality has raised human interest probably because of its ubiquity in nature (Barron, 2008), which originates from stereoselective reactions affording proteins, DNA, or more generally natural compounds (Mori, 2011). Chemists have then invested major efforts and energy to reproduce the nature efficiency with the artificial preparation of a plethora of chiral molecules and structures, such as curved aromatics (Rickhaus et al., 2017; Dhbaibi et al., 2019), coordination compounds (Knof and von Zelewsky, 1999; Seeber et al., 2006; Crassous, 2009, 2012), polyoxometalates (Hasenknopf et al., 2008), topologically complex architectures (Chambron et al., 1993; Jamieson et al., 2018), self-assembled systems (MateosTimoneda et al., 2004; Hembury et al., 2008; Liu et al., 2015), dynamics motors, and shuttles, to name a few (Leigh and Pérez, 2006; Feringa, 2007; Kudernac et al., 2011; van Leeuwen et al., 2017). In optics, the appeal for chiral systems is justified by their ability to rotate the plane of polarized light, a phenomenon that was discovered by the French scientist Jean-Baptiste Biot in collaboration with Jean-François Persoz in 1812. Subsequently, the physicist Aimé Cotton discovered the optical rotatory dispersion in 1895 and highlighted that chiral molecules displayed different absorption coefficients for right- and left-handed circularly polarized light, the amplitudes of which depend on the light wavelengths (Cotton effect). The latter feature gave birth to circular dichroism (CD) spectroscopy (Beychok, 1968; Schellman, 1975; Woody, 1995). The CD technique was extensively used to study the conformation and the configuration of enantiopure organic compounds (Berova et al., 2007; Pescitelli et al., 2011) and permitted to analyze the chirality and helicity of sophisticated supramolecular selfassembled architectures in solution (Pescitelli et al., 2014). Similarly to CD, which is based on the selective absorption of circularly polarized photons, some emissive chiral compounds may display a difference in intensity between right- and lefthanded circularly polarized emitted light upon excitation with non-polarized light (Richardson, 1979; Riehl and Richardson, 1986; Riehl and Muller, 2004; Zinna and Di Bari, 2015; Longhi et al., 2016). The first circularly polarized luminescence (CPL) emission was observed in 1948 by Samoilov for a sodium uranyl acetate crystal. In 1960, Oosterhof reported the first CPL measurement in solution for an organic compound, namely, trans-b-hydrindanone, and for a coordination complex $\left[\mathrm{Cr}(\mathrm{en})_{3}\right]^{3+}$ where en stands for ethylenediamine (Emeis and Oosterhoff, 1967). Several decades later, the development of CPL was promoted by the need for chiroptical features in versatile technological fields ( $\mathrm{Wu}$ et al., 2015; Brandt et al., 2017), such as optoelectronics (Han et al., 2018), nanomaterials (Sang et al., 2019), chiral molecular conductors (Réthoré et al., 2005), magnetochiral devices (Rikken and Raupach, 1997; Train et al., 2011), chiral molecular switches (Feringa et al., 2000; Browne and Feringa, 2011; Isla and Crassous, 2016; Isla et al., 2016), macrostructure solvers (Roose et al., 2016), unidirectional motion controllers (Huck et al., 1996), semiconductor transistors (Yang et al., 2013), and CP-OLEDs (Gilot et al., 2010; Zinna et al., 2017).

\section{PHYSICAL BASIS OF CPL AND STRATEGIES TO ACHIEVE STRONG CPL EMISSION}

The development of CPL techniques required a quantificative parameter for comparing the amount of circularly polarized light emitted by a specific chromophore, the latter factor being independent of the non-polarized photophysical features. The dissymmetry factor $g_{\text {lum }}\left(-2<g_{\text {lum }}<2\right)$ was thus set as the ratio between the difference of left and right circularly polarized emission and the global emitted intensity (Equation 1). Although this value is defined for each wavelength of the CPL spectrum, it is usually reported for the maximum intensity of the emission band.

$$
g_{\text {lum }}=\frac{\Delta I}{\frac{1}{2} I}=\frac{I_{\mathrm{L}}-I_{\mathrm{R}}}{\frac{1}{2}\left(I_{\mathrm{L}}+I_{\mathrm{R}}\right)}
$$

The time-dependent intensity difference of emitted light $\Delta I$ depends on the orientation of molecules regarding the selected polarization of the emitted light. Moreover, the excitation process is affected as well by molecule orientation since the transition probability depends on the relative orientation of the molecule transition dipole moment with respect to the incident electric field (Riehl and Muller, 2004). Consequently, working with crystals, solid samples, or more generally anisotropic media requires the explicit consideration of anisotropy in theoretical models. For matters of simplicity, the following review is restricted (i) to studies performed in isotropic media (solution) and (ii) to molecules showing excited-state lifetime one order of magnitude longer than their rotational correlation time, in order to allow relaxation to randomize the orientations of the molecules after selection of some preferential orientations upon excitation (Riehl and Muller, 2004). At room temperature, this latter criterion is fulfilled for excited-state lifetimes longer than $10 \mathrm{~ns}$ for molecules around $1 \mathrm{kD}$ (Tóth et al., 1996).

The amplitude of the CPL signal for a $i \rightarrow j$ transition is governed by its rotatory strength $\left(R_{\mathrm{ij}}\right)$, which represents the probability of emitting (or absorbing for $\mathrm{CD}$ ) a circularly polarized photon. In an isotropic medium, $R_{\mathrm{ij}}$ can be expressed by Equation (2), where $\psi_{\mathrm{i}}$ and $\psi_{\mathrm{j}}$ are the wave functions of the initial and final states, respectively. $\widehat{\mu}$ and $\widehat{m}$ are the electric and magnetic perturbation Hamiltonians, while $\overrightarrow{\mu_{i j}}$ and $\overrightarrow{\mathbf{m}_{\mathrm{ij}}}$ are respectively the electric transition dipole moment (ED) and magnetic transition dipole moment (MD) and $\theta$ is the angle between those two latter vectors.

$$
R_{\mathrm{ij}}=-i\left\langle\psi_{\mathrm{i}}|\widehat{\mu}| \psi_{\mathrm{j}}\right\rangle\left\langle\psi_{\mathrm{i}}|\widehat{m}| \psi_{\mathrm{j}}\right\rangle=-i \overrightarrow{\mu_{\mathrm{ij}}} \cdot \overrightarrow{\mathbf{m}_{\mathrm{ij}}}=\left|\overrightarrow{\mu_{\mathrm{ij}}}\right|\left|\overrightarrow{\mathbf{m}_{\mathrm{ij}}}\right| \cos \theta
$$

Any contribution arising from the coupling between the electric dipole (ED) and electric quadrupole (EQ) moments is neglected in the rotatory strength equation since the consideration of an isotropic medium implies the orientation average (Gendron et al., 2019). The comparison of CPL intensities of different compounds showing different quantum yields requires some normalization of the rotatory strength by the global emission contribution which is ruled by the dipole strength $\left(D_{\mathrm{ij}}\right)$ depicted in Equation (3), where 
$\overrightarrow{\mathbf{Q}_{\mathrm{ij}}}$ is the electric transition quadrupole moment (Gendron et al., 2019).

$$
D_{\mathrm{ij}}=\left|\overrightarrow{\boldsymbol{\mu}_{\mathrm{ij}}}\right|^{2}+\left|\overrightarrow{\mathbf{m}_{\mathrm{ij}}}\right|^{2}+\left|\overrightarrow{\mathbf{Q}_{\mathrm{ij}}}\right|^{2}
$$

The electric transition quadrupole moment being several orders of magnitude weaker than its dipole counterpart, it is often negligible and will be omitted in the following. The dissymmetry factor can now be related to the theoretical features with Equation (4).

$$
g_{\text {lum }}=\frac{4 R_{\mathrm{ij}}}{D_{\mathrm{ij}}}=4 \frac{\left|\overrightarrow{\boldsymbol{\mu}_{\mathrm{ij}}}\right|\left|\overrightarrow{\mathbf{m}_{\mathbf{i j}}}\right| \cos \theta}{\left|\overrightarrow{\boldsymbol{\mu}_{\mathbf{i j}}}\right|^{2}+\left|\overrightarrow{\mathbf{m}_{\mathbf{i j}}}\right|^{2}}
$$

For organic chromophores involving parity-allowed ED- and MD-forbidden transitions, the contribution of the magnetic transition dipole moment is often neglected in the denominator $\left(\left|\overrightarrow{\boldsymbol{\mu}_{\mathrm{ij}}}\right|>\left|\overrightarrow{\mathbf{m}_{\mathrm{ij}}}\right|\right)$, and the dissymmetry factor reduces to $g_{\text {lum }}=4\left(\left|\overrightarrow{\mathbf{m}_{\mathbf{i j}}}\right| /\left|\overrightarrow{\boldsymbol{\mu}_{\mathbf{i j}}}\right|\right) \cos \theta$. However, this latter equation is too restrictive and cannot be applied for magnetic dipole-allowed and electric dipole-forbidden transitions, such as those found in $\mathrm{f}-\mathrm{f}$ transitions, for which the amplitude of magnetic transition dipole moment can overpass its electric counterpart (Metcalf and Richardson, 1994). The introduction of a ratio $r=\left|\overrightarrow{\boldsymbol{\mu}_{\mathbf{i j}}}\right| /\left|\overrightarrow{\mathbf{m}_{\mathbf{i j}}}\right|$ into Equation (4) permits its rewriting as Equation (5), which highlights that a maximum value of $g_{\text {lum }}$ is reached when the electric and magnetic transition dipole moments are (i) colinear $\left(\theta=0\right.$ or $\left.180^{\circ}\right)$ and (ii) of the same amplitude $\left(\left|\overrightarrow{\boldsymbol{\mu}_{\mathrm{ij}}}\right|=\right.$ $\left|\overrightarrow{\mathbf{m}_{\mathrm{ij}}}\right| ; r=1$ ) (Wada et al., 2018). The latter criterion contrasts with the usual misleading statement saying that $\left|\overrightarrow{\mathbf{m}}_{\mathbf{i j}}\right|$ should be maximized while $\left|\overrightarrow{\mu_{i j}}\right|$ is minimized, a situation encountered for organic chromophores upon neglecting $\left|\overrightarrow{\mathbf{m}_{\mathbf{i j}}}\right|$ at the denominator of Equation (4). Nevertheless, the weak magnitude of magnetic dipole compared to electric dipole transition moments $\left(\left|\overrightarrow{\mu_{\mathrm{ij}}}\right|=\right.$ $\left.10^{6}\left|\overrightarrow{\mathbf{m}_{\mathbf{i j}}}\right|\right)$ indicates the ED-forbidden/MD-allowed transitions are promising for equalizing both transition dipole moments.

$$
g_{\text {lum }}=4 \frac{r}{r^{2}+1} \cos \theta
$$

From a theoretical point of view, the organic chromophores thus appear to be not particularly promising for CPL. However, their low cost, their easy synthetic accessibility, and the chemical inertness of carbon chemistry bring substantial advantages which (i) allow chiral resolution, (ii) afford enantiomerically pure compounds, and (iii) provide easy processability for material applications. As a consequence, CPL was systematically recorded and explored for myriads of organic chromophores exploiting central, axial, planar, or helical chirality (SánchezCarnerero et al., 2015; Chen and Yan, 2018; Tanaka et al., 2018a) with record values for 1,8-naphthalimide ( $\left|g_{\text {lum }}(450 \mathrm{~nm})\right|$ $=0.014)$ (Sheng et al., 2016), oligothiophenes $\left(\left|g_{\text {lum }}(520 \mathrm{~nm})\right|\right.$ $=0.0093$ ) (Benincori et al., 2018; Dhbaibi et al., 2019) cyclo2,8-chrysenylene $\left(\left|g_{\text {lum }}(443 \mathrm{~nm})\right|=0.152\right)$ (Sato et al., 2017), and $1,1^{\prime}$-bitriphenylenes $\left(\left|g_{\text {lum }}(449 \mathrm{~nm})\right|=0.032\right)$ (Sawada et al.,
2012). Planar and helical chiralities, as found in helicenes, were highlighted to promote important dissymmetry factors because of the larger magnetic transition dipole moments induced by aromatic distortion. Hence, important efforts were made to rationalize this observation with the calculation of $\left|\overrightarrow{\mu_{i j}}\right|$ and $\left|\overrightarrow{\mathbf{m}_{\mathrm{ij}}}\right|$ and the determination of the $\theta$ angle (Sato et al., 2017; Ito et al., 2018; Tanaka et al., 2018b,c). The outstanding $\left|g_{\text {lum }}\right|$ value of 0.152 reported for the single-wall carbon nanotubes (Dhbaibi et al., 2019) cyclo-2,8-chrysenylene by Isobe and Sato was attributed to the unusually important magnetic transition dipole moment originating from a cyclic aromatic structure which allows and facilitates a magnetic field-induced current loop (Sato et al., 2017). In addition, due to the circular shape of the molecule, the first individual singlet-state electric transition dipole moments of the four chromophoric moieties might result in some compensation effects, as stated by Anderson for achiral nanorings (Sprafke et al., 2011). Hence, the combination of peculiar MD strength and ED weakness provides a large $g_{\text {lum }}$ value. Apart from this exceptional chiral single-wall carbon nanotube, the dissymmetry factors lie in the $10^{-5}-10^{-2}$ range for most of organic compounds (Sánchez-Carnerero et al., 2015; Chen and Yan, 2018; Tanaka et al., 2018a).

Despite the chemical advantages of organic molecules for application in material sciences (easy synthetic access, low cost, easy incorporation into devices, and processability) (Yang et al., 2013; Brandt et al., 2017; Han et al., 2018; Sang et al., 2019), the need for important dissymmetry factors prompted chemists to look into d-block chemistry. In particular, the second- and third-row metal complexes have attracted important attention due to (i) the synthetic accessibility, (ii) the chemical inertness due to large ligand-field strengths, (iii) the processability, and (iv) some easy characterization by NMR techniques for common diamagnetic $\mathrm{Ir}^{\mathrm{III}}, \mathrm{Pt}^{\mathrm{II}}, \mathrm{Ru}^{\mathrm{II}}$, or $\mathrm{Os}^{\mathrm{II}}$ complexes. In addition, the important covalency in those complexes produces highly emissive charge transfer states which are not quenched by $\mathrm{d}-\mathrm{d}$ states located at much higher energies. However, the associated dissymmetry factors still cover the expected range for $\mathrm{ED}$-allowed/MD-forbidden transitions $\left(10^{-5}-10^{-2}\right)$ (Han et al., 2018).

It is worth noting here that significant enhancement of $g_{\text {lum }}$ could be observed occasionally in nano-assemblies or in aggregated systems as a result of the formation of chiral microstructural materials or films (Geng et al., 2003; Kumar et al., 2015; Roose et al., 2016; Sang et al., 2019), in particular for few electroluminescent systems, such as OLEDs (Brandt et al., 2016; Song F. et al., 2018). In addition, the incorporation of emissive moieties into anisotropic media, such as chiral liquid crystals displaying helical macrostructures, proved to be an efficient strategy for the generation of strong CPL emission (Watanabe and Akagi, 2014; Goto, 2018; Gao et al., 2019; Kim et al., 2019; Li et al., 2019; Yang X. et al., 2019). Focusing on isotropic solutions, some recent up-converted CPL studies evidenced enhanced $g_{\text {lum }}$ compared to their downshifted counterparts. This observation suggests that triplet-triplet annihilation could be an innovative and unexpected approach to increase the CPL emission of organic compounds showing weak $g_{\text {lum }}$ (Han et al., 2017a; Yang D. et al., 2019; Yang X. et al., 2019). 
Further optimization of the dissymmetry factors requires the operation of $\mathrm{MD}$-allowed/ED-forbidden transitions in complexes showing little covalence to avoid the relaxation of the parity rules due to the mixing of metal and ligand wave functions. In this context, the lanthanide $\mathrm{f}-\mathrm{f}$ transitions and the first-row $\mathrm{d}-\mathrm{d}$ transitions, for which covalence is still reasonably weak, appear as promising candidates to generate important $g_{\text {lum }}$. The high potential of these coordination compounds led to extensive theoretical studies in order to tackle potential spectral/structure relationships (Richardson, 1979; Riehl and Richardson, 1986; Riehl and Muller, 2004). The most comprehensive model used for rationalizing the influence of stereogenic centers on the optical activity (CD or CPL) is referred to as the independent systems/perturbation model (ISP) (Mason, 1971; Richardson, 1971; Mason and Seal, 1975, 1976; Strickland and Richardson, 1976). According to this approach, the rotatory strength emerges from two distinct mechanisms: the static coupling (SC) and the dynamic coupling (DC). The rotary strength due to SC arises from the intrinsic chirality of the emissive center which is, in the case of the coordination complexes, restricted to the metal and the ligand donor atoms. Intrinsic chirality of the first coordination sphere is ensured, for instance, for a $D_{3}$ symmetric transition metal or for a lanthanide complex displaying a distorted square anti-prismatic geometry with an optimal computed twist angle of $22.5^{\circ}$ (Carr et al., 2012; Zinna and Di Bari, 2015). If the chromophore (i.e., the coordination sphere) is achiral, while a stereogenic center is located on a remote site (i.e., a chiral ligand), the optical activity is driven by the DC mechanism. In this case, the optical activity of the metal center derives from a multipole (metal)-dipole (ligand) interaction between the emissive metal's transition density and the stereogenic center's induced dipole moment. This coupling provides a non-orthogonal contribution of the electric transition dipole moment with respect to its magnetic counterpart, the scalar product of which affords non-zero terms for the rotatory strength. When the DC mechanism is solely active, the CPL intensity mainly depends on the electrostatic quadripole-dipole interaction, which is optimized for (i) highly polarizable stereogenic centers, (ii) short metalstereogenic center distance (the quadripole-dipole interaction distance decreases as $1 / r^{8}$ ), and (iii) energy matching between the optical transitions of the aromatic stereogenic center and those centered on the metal (Richardson, 1979; Zinna and Di Bari, 2015). Although the intrinsic chirality of the metal coordination sphere (SC) might appear to neophyte as the best tool for maximizing $g_{\text {lum }}$, the DC mechanism appears to be very efficient and may provide considerable rotatory strength. To date, the record $g_{\text {lum }}=1.38$ belongs to the $\mathrm{Cs}\left[\mathrm{Eu}(\mathrm{hfbc})_{4}\right](\mathrm{hfbc}=$ heptafluorobutyrylcamphorate) complex, in which an essentially achiral square anti-prismatic coordination sphere (twist angle of $-41.4^{\circ}$ ) results in a weak SC contribution, whereas the location of a camphor unit on the bound ligand is responsible for the impressive dissymmetry factor via the DC mechanism (Lunkley et al., 2008, 2011; Zinna and Di Bari, 2015).

Nonetheless, harnessing the potential of lanthanide $f-f$ or of first-row $\mathrm{d}-\mathrm{d}$ transitions requires overcoming the kinetic lability of the associated complexes, which hampers enantiomeric separations and/or provides efficient racemization pathways. In a first attempt to exploit labile lanthanide complexes, a chiral ligand is simply used to induce solely a DC mechanism. Actually, this approach is at the origin of the record dissymmetry factor reported to date (Aspinall, 2002; Lunkley et al., 2008, 2011). An alternative strategy to generate enantiomerically pure systems takes advantage of chiral ligands for inducing stereoselectivity within the coordination process (Cantuel et al., 2004; Gregolinski et al., 2008; Kotova et al., 2013). In this latter case, both SC and DC mechanisms should be active. Finally, the selection of some (rare) inert coordination complexes followed by chiral resolution and separation may afford enantiomerically pure complexes. Inert lanthanides complexes can be obtained for polydentate ligands (i.e., cryptates, DOTA) (Gregolinski et al., 2008; Walton et al., 2011; Carr et al., 2012; Dai et al., 2019) or via the design of supramolecular assemblies, in which the lanthanide is sequestered within inert stoppers (Zare et al., 2017a). Although the first-row transition metals are known to produce labile complexes, the preparation of inert complexes is possible with $\mathrm{Cr}^{\mathrm{III}}\left(\mathrm{d}^{3}\right)$ or $\mathrm{Co}^{\mathrm{III}}$ (low-spin $\mathrm{d}^{6}$ ) metals which possess large ligand-field stabilization energies, and with small and highly charged Fe ${ }^{\mathrm{III}}$ centers (Hilmes et al., 1977; Cantuel et al., 2004; Dee et al., 2019; Jiménez et al., 2019). When emissive states can be implemented, those latter cheap transition metal complexes should be good candidates to provide large dissymmetry factors after chiral resolution.

\section{THE SUCCESS OF LANTHANIDE COMPLEXES USING CHIRAL ORGANIC LIGANDS AND (SUPRA)MOLECULAR CONTROL}

\section{Theoretical Aspects of $\mathbf{f}-\mathbf{f}$ Transitions}

The absorption and emission properties of $\mathrm{Ln}^{3+}$-based complexes arise from the parity-forbidden and spin-forbidden metal-centered $\mathrm{f}-\mathrm{f}$ transitions, the proscribed character of which can be relaxed by spin-orbit coupling and by crystal-field effects (see below). Consequently, these transitions have generally low but no negligible molar absorption coefficients $\left(<10 \mathrm{M}^{-1} \cdot \mathrm{cm}^{-1}\right)$ and limited radiative rate constants $\left(k_{\text {rad }}<10^{3} \mathrm{~s}^{-1}\right)$. This results in long-lived excited states that give extended emissions reaching up to $10 \mathrm{~ms}$ for $\mathrm{Ln}^{3+}$ doped in low-phonon materials but reduced by one to four orders in magnitudes in $\mathrm{Ln}^{3+}$. based molecular complexes possessing high-energy oscillators. According to quantum mechanics, in the absence of spin-orbit coupling, any electronic wave functions can be separated into two independent contributions arising from the spin wave function and the orbital wave function. Since the interaction between an electromagnetic wave responsible for the electronic transition only involves the orbital wave function, the orthogonal and normalized character of the non-perturbated spin wave functions implies that an electronic transition between two states is only possible when the spin does not change $(\Delta S=0)$, a first condition known as the spin rule. The interaction between the electromagnetic wave and the orbital part of the electronic wave functions further implies that an electric-dipole-allowed 
electronic transition between two states requires a parity change between the two incriminated orbital wave functions $(\Delta L= \pm 1$, $\pm 3 .$. ), a condition often referred to as Laporte's rule. However, magnetic dipole transitions are allowed in the absence of change in parity $(\Delta L=0, \pm 2 \ldots)$. Accordingly, $\mathrm{f}-\mathrm{f}$ transitions obeying the spin rule are electric dipole forbidden but magnetic dipole allowed. The considerable spin-orbit coupling constants which characterize the $4 \mathrm{f}$-block series indeed mix orbital and spin wave functions so that the spin-selection rule $(\Delta S=0)$ is relaxed for $4 \mathrm{f}-4 \mathrm{f}$ transitions. Concerning the parity rules controlling the electronic transitions, two different situations have to be considered. For centrosymmetric systems, the electronic f-f transitions are electric-dipole (ED) forbidden by the Laporte selection rule, but some intensity can be gained through the operation of symmetry-allowed but weak magnetic-dipole (MD, oscillator strength $10^{-6}$, Table 1) transitions and electric quadrupole (EQ, oscillator strength $10^{-10}$, Table 1) transitions. In molecular complexes, minor vibronic coupling mechanisms cannot be completely ruled out. For non-centrosymmetric systems produced by weak static crystal-field effects, the Laporte rule is partially relaxed and the mixing of electronic configurations with opposite parity gives rise to the so-called Judd-Ofelt forced ED transitions, possessing oscillator strength in the order of $10^{-4}$ (note that allowed ED transitions have oscillator strengths in the 0.01-1 range) (Malta and Carlos, 2003; Tanner, 2013). Altogether, the original selection rules based on spin $S$ and orbital $L$ quantum numbers should be replaced with some looser versions of them, which rely on the total momentum $J$ quantum number (Table 1, column 5). In this context, the $\mathrm{f}-\mathrm{f}$ transitions with $\Delta J=0, \pm 1$ (except $0 \leftrightarrow 0$ ) are MD allowed and can benefit from the large magnetic moments displayed by these ions. Consequently, the weak ED transition mechanisms do not always dominate the transition dipole moment, as it does in organic molecules and in the major part of d-block complexes. This can lead to large rotatory strengths comparable with the dipole strength, and in the context of CPL that can afford large dissymmetry factors, $g_{\text {lum }}$ (Equation 4). For instance, the ${ }^{5} \mathrm{D}_{0} \rightarrow{ }^{7} \mathrm{~F}_{1}$ transition of $\mathrm{Eu}^{3+}$ is an example of an MD-allowed and ED-forbidden transition that leads to large $g_{\text {lum }}$, typically, $g_{\text {lum }}>0.1$ (Harada et al., 2009; Dai et al., 2016; Neil et al., 2016; Uchida et al., 2016; Zercher and Hopkins, 2016; Kono et al., 2017; Leonzio et al., 2017). Exceptionally, the complex Cs[Eu[(+)-(hfbc) $\left.)_{4}\right]$ displays $g_{\text {lum }}=+1.38$ at $595 \mathrm{~nm}$ $\left({ }^{5} \mathrm{D}_{0} \rightarrow{ }^{7} \mathrm{~F}_{1}\right)$, which represents the highest dissymmetric factor reported to date (Lunkley et al., 2008). The emissive ${ }^{5} \mathrm{D}_{0} \rightarrow{ }^{7} \mathrm{~F}_{2}$ and ${ }^{5} \mathrm{D}_{0} \rightarrow{ }^{7} \mathrm{~F}_{3}$ transitions of the aforementioned complex that do not satisfy the MD selection rule indeed yield lower but still remarkable dissymmetry factors of $>0.2$. Surprisingly, the $\mathrm{Sm}^{3+}$ based complexes possessing two MD-allowed ${ }^{4} \mathrm{G}_{5 / 2} \rightarrow{ }^{6} \mathrm{H}_{5 / 2}$ and ${ }^{4} \mathrm{G}_{5 / 2} \rightarrow{ }^{6} \mathrm{H}_{7 / 2}$ transitions have been considerably less exploited for CPL although the analog $\operatorname{Cs}\left[\operatorname{Sm}\left[(+)-(h f b c)_{4}\right]\right.$ has been shown to produce large dissymmetry factors of +1.15 and -1.15 at 553 and $598 \mathrm{~nm}$, respectively (Lunkley et al., 2011). Other chiral $\mathrm{Sm}^{3+}$ complexes have been also reported (Petoud et al., 2007; Kreidt et al., 2018; Cotter et al., 2019). Aside from $\mathrm{Eu}^{3+}$ and $\mathrm{Sm}^{3+}$, other lanthanides ions, such as $\mathrm{Nd}^{3+}, \mathrm{Tb}^{3+}, \mathrm{Dy}^{3+}$, and $\mathrm{Yb}^{3+}$ have been used in chiral complexes as optically active
TABLE 1 | Selection rules for electronic transitions of lanthanides ions (Eliseeva and Bünzli, 2010; Tanner, 2013).

\begin{tabular}{|c|c|c|c|c|c|}
\hline $\begin{array}{l}\text { Type of } \\
\text { transition }\end{array}$ & Parity | & $|\Delta S|$ & $|\Delta L|$ & $|\Delta \boldsymbol{J}|$ & $\begin{array}{c}\text { Order of } \\
\text { magnitude of the } \\
\text { oscillator strength }\end{array}$ \\
\hline $\begin{array}{l}\text { Electric dipole } \\
\text { (ED) }\end{array}$ & Opposite & 0 & $\leq 1^{a}$ & $\leq 1^{b}$ & $\sim 0.01-1$ \\
\hline $\begin{array}{l}\text { Judd forced } \\
\text { ED }\end{array}$ & Same & $0=$ & $\begin{array}{l}=0,1,3,5^{a, c} \\
=2,4,6^{a, d}\end{array}$ & $\begin{array}{l}=0,1,3,5^{b, c} \\
=2,4,6^{b, d}\end{array}$ & $\sim 10^{-4}$ \\
\hline $\begin{array}{l}\text { Magnetic dipole } \\
\text { (MD) }\end{array}$ & Same & 0 & 0 & $\leq 1^{b}$ & $\sim 10^{-6}$ \\
\hline $\begin{array}{l}\text { Electric } \\
\text { quadrupole } \\
\text { (EQ) }\end{array}$ & Same & 0 & $\leq 2^{\mathrm{e}}$ & $\leq 2^{f}$ & $\sim 10^{-10}$ \\
\hline
\end{tabular}

${ }^{a} L=0 \leftrightarrow L^{\prime}=0$ are forbidden.

bJ $=0 \leftrightarrow J^{\prime}=0$ are forbidden.

c/f $J$ and $J^{\prime} \neq 0$.

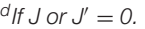

${ }^{e} L=0 \leftrightarrow L^{\prime}=0,1$ are forbidden.

${ }^{f} J=0 \leftrightarrow J^{\prime}=0,1$ are forbidden.

luminescence-polarized emitters, and they will be described in the following section (Maupin et al., 1998, 2000; Dickins et al., 1999; Morita et al., 2000; Petoud et al., 2007; Casanovas et al., 2017; Leonzio et al., 2017; Górecki et al., 2018; Zinna et al., 2019). Concerning the MD contribution to the total transition dipole moment in a $\mathrm{f}-\mathrm{f}$ transition, Richardson classified those into types DI, DII, and DIII where DI is expected to exhibit the largest dissymmetric factor (e.g., ${ }^{5} \mathrm{D}_{0} \rightarrow{ }^{7} \mathrm{~F}_{1}$ in $\mathrm{Eu}^{3+}$ ) and DII and DIII lower values, for instance, ${ }^{4} \mathrm{G}_{5 / 2} \rightarrow{ }^{6} \mathrm{H}_{5 / 2}$ and ${ }^{5} \mathrm{D}_{4} \rightarrow{ }^{7} \mathrm{~F}_{5}$ in $\mathrm{Sm}^{3+}$ and $\mathrm{Tb}^{3+}$, respectively, which are type DII transitions (Richardson, 1980). With this in mind, the trivalent lanthanide $\mathrm{Ln}^{3+}$ ions gathered in Figure 1 represent a straightforward choice, within the periodic table, to induce strong $g_{\text {lum }}$ in molecular complexes and materials. However, several key requirements must be fulfilled in order to obtain efficient (high quantum yields) luminescent chiral complexes with a strong dissymmetry factor for realistic applications.

\section{Strategy for Achieving Highly Luminescent CPL Emission Using Ln $^{3+}$}

A classical strategy to overcome the low molar absorptivity of $\mathrm{f}-$ $\mathrm{f}$ transitions relies on the coordination of trivalent lanthanides, $\mathrm{Ln}^{3+}$, to an organic chromophore, which can act as an efficient antenna, when excited, followed by an energy transfer onto the close lanthanide metal ion. This mechanism results in an efficient population of the lanthanide excited states that can relax to the ground state via radiative (luminescence) or nonradiative pathways. Therefore, to prepare highly luminescent chiral $\mathrm{Ln}^{\mathrm{III}}$-based complexes, the following points should be kept in mind. (i) The organic chromophore should be able to harvest a considerable amount of energy by absorbing UV-Vis light and to efficiently transfer it onto the lanthanide-excited states. (ii) The ligand should favor high coordination numbers for protecting $\mathrm{Ln}^{\mathrm{III}}$ from interactions with solvent molecules and subsequent non-radiative de-excitation pathways. (iii) The kinetic inertness 


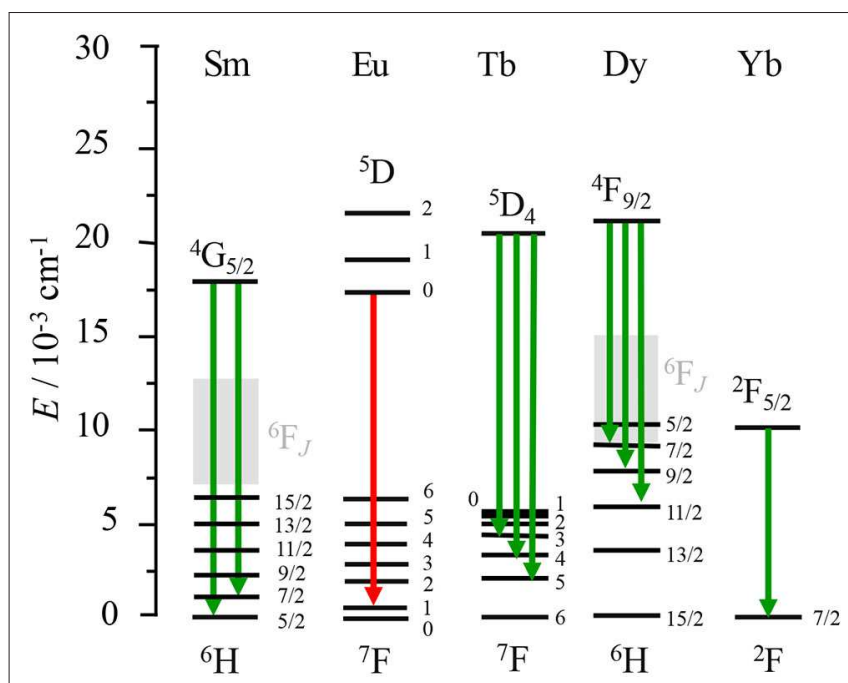

FIGURE 1 | Dieke diagram of the energy of the spectroscopic levels $\left({ }^{2 S+1} L J\right)$ for some $\mathrm{Ln}^{3+}$. Green arrows represent the magnetic dipole (MD)-allowed and electric dipole (ED)-allowed transitions whereas the red one represents the optimal case of an MD-allowed and ED-forbidden transition.

and thermodynamic stability of the resulting complex is of major importance since dissociation could lead to the formation of several luminescent species in solution and to a decrease in the luminescence intensity. (iv) The resulting complex should preferably not be fluxional or at least it should display a slow racemization rate constant compared to the time scale of the experiment (Metcalf et al., 1990). (v) Enantiopure species are desired in order to get unambiguous structure/property relationships and to induce maximum CPL performances. On the other hand, the chirality of lanthanide complexes may arise from (i) the helical twist of the ligands around the metal ions, (ii) the stereochemical orientation of the ligating arms of multidentate ligands, or (iii) the incorporation of stereocenters directly onto the ligand scaffold. As regards the first two options, the coordination of an achiral ligand (e.g., DPA = dipicolinic acid or tpy $=$ terpyridine) to a lanthanide ion indeed produces the $\Delta$ or $M$ (right-handed) and $\Lambda$ or $P$ (left-handed) isomers in racemic proportions. However, chiral resolution with the help of chromatographic techniques are quite challenging because of the kinetically fast interconversion (racemization) occurring between the two enantiomers (Kreidt et al., 2017). Therefore, the use of enantiopure chiral ligands (point iii, above) appeared to be the most promising strategy to prepare chiral lanthanide complexes, although the chiral induction of the Ln coordination sphere is not always quantitative and the associated stereoisomeric excess is only sporadically reported. In this context, Raymond and coworkers reported on a chiral octadentate ligand (L1) that strongly binds $\mathrm{Ln}^{3+}$ and protects it from interactions with solvent molecules (Figure 2A) (Petoud et al., 2007). The authors were able to prepare a family of luminescent complexes emitting in the visible range $\left(\mathrm{Sm}^{3+}, \mathrm{Eu}^{3+}, \mathrm{Tb}^{3+}\right.$, and $\left.\mathrm{Dy}^{3+}\right)$ with modest to reasonable quantum yields $(0.8-62 \%)$ and $\mathrm{CPL}$ activities. Remarkable dissymmetry factors could be measured for these complexes with $g_{\text {lum }}(\mathrm{Eu}(\mathbf{L 1}))= \pm 0.296(2)$ at $596 \mathrm{~nm}$, $g_{\text {lum }}(\mathrm{Tb}(\mathbf{L} \mathbf{1}))= \pm 0.046(2)$ at $543 \mathrm{~nm}, g_{\text {lum }}(\operatorname{Sm}(\mathbf{L} \mathbf{1}))=-0.027$ at $565 \mathrm{~nm}$ and -0.028 at $597 \mathrm{~nm}$, and $g_{\text {lum }}(\operatorname{Dy}(\mathbf{L} \mathbf{1}))=0.013$ at $669 \mathrm{~nm}$. It is worth noting that this contribution reported on the first chiral $\mathrm{Sm}^{3+}$ complex showing CPL activity. From a more application-oriented point of view, Parker and coworkers provided numerous examples of versatile macrocycles (e.g., cyclen and triazacyclononane) bearing different coordinating side arms decorated with $\mathrm{N}$-donors, amides, phosphinates, and carboxylate groups that are able to both complex and sensitize lanthanide ions for ultimate biomolecule sensing. Chirality elements can be introduced within the ring or within the side arms of these versatile scaffolds (L2 and L3 in Figure 2A).

These nitrogen-containing macrocycles served as starting materials for the synthesis of a huge number of $\mathrm{Ln}^{3+}$ complexes with remarkable thermodynamic stabilities and kinetic inertness. The most famous is probably 1,4,7,10-tetraazacyclododecane1,4,7,10-tetraacetic acid (DOTA) (Figure 2A, L2) which usually gives nine-coordinated complexes when one additional water molecule is bound to the lanthanide (Parker et al., 2002). However, lanthanide complexes based on DOTA derivatives exist as four dynamically interconvertible stereoisomers which can be best described as two enantiomeric pairs (Aime et al., 1999). This has an unfavorable effect on the CPL performance. The introduction of chiral substituents into the cyclen ring and/or into the pendant arms of the DOTA derivative drives the formation of one stereoisomer over the others (Dickins et al., 1997, 1999; Ranganathan et al., 2002; Woods et al., 2003). This is of crucial importance for controlling the degree of local helicity and the associated dissymmetry factor (Carr et al., 2012; Dai et al., 2019). These complexes have been widely used as CPL probes for sensing small molecules and proteins thanks to the great sensitivity of the CPL signals of $\mathrm{Tb}^{3+}, \mathrm{Eu}^{3+}, \mathrm{Dy}^{3+}, \mathrm{Yb}^{3+}$, and $\mathrm{Nd}^{3+}$ to conformational and structural modifications (Beeby et al., 2000). Dissymmetry factors $\left|g_{\text {lum }}\right|$ around 0.5 correspond to the largest values reported for $\mathrm{Eu}^{3+}$ and $\mathrm{Tb}^{3+}$ chiral DOTA-based complexes. Triazonanebased europium complexes based on L3 (Figure 2A) and L3 derivatives are powerful tools for anion sensing (Neil et al., 2016). It is worth noticing that $\mathbf{L 3}$ in its tautomeric form (tautomery between $\mathrm{P}-\mathrm{OH}$ and $\mathrm{P}=\mathrm{O}$ ) is achiral, but it becomes a persistent stereochemical element when coordinated to a metal. In fact, Parker's group prepared a family of highly emissive Eu complexes, the chiroptical properties of which could be induced upon addition of chiral anions. Furthermore, the same authors exploited this property for the analysis of enantiomeric purity. Other complexes with interesting chiroptical properties have been reported, and most of them belong to the family of $\beta$-diketonate ligands. These bidentate anionic ligands are efficient to coordinate $\mathrm{Ln}^{3+}$ because of both the oxophilicity of $\mathrm{Ln}^{3+}$ and the electrostatic attraction between the cationic $\mathrm{Ln}^{3+}$ and the anionic ligands. Furthermore, $\beta$-diketonates are good sensitizers for inducing $\mathrm{Ln}^{3+}$ emission since they possess strong $\pi \rightarrow \pi^{*}$ transitions usually located in the UV region. The introduction of different substituents at the 1 or 3 position allows some energy tuning of the ligand triplet state of the antenna effect but also of the crystal field splitting affecting the ${ }^{2 S+1} \mathrm{~L}_{J}$ 
A

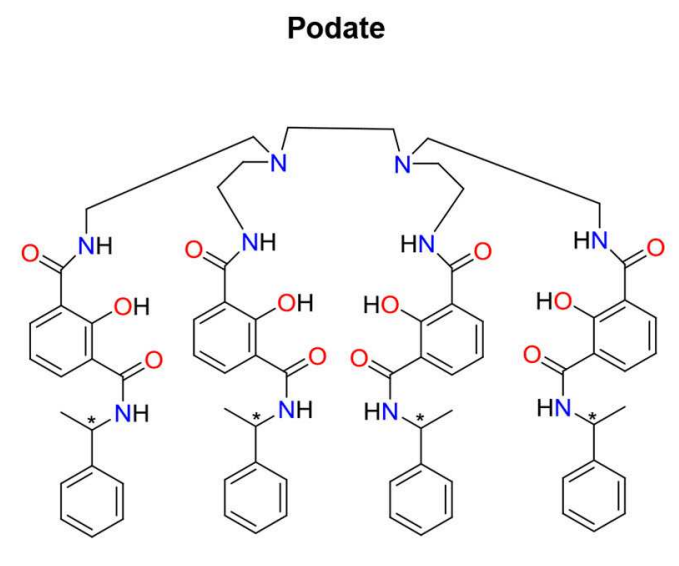

L1

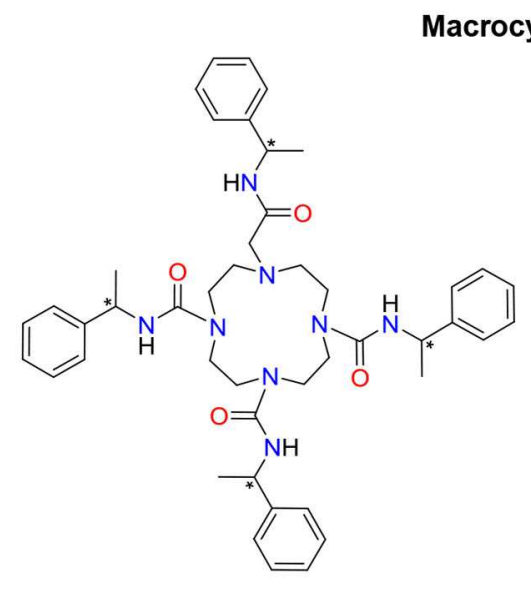

L2<smiles>O=P(O)(c1ccccc1)c1cccc(CN2CCN(Cc3cccc(P(=O)(O)c4ccccc4)n3)CCN(Cc3cccc(P(=O)(O)P(=O)(O)c4ccccc4)n3)CC2)n1</smiles>

L3

B

Camphor-based complexes

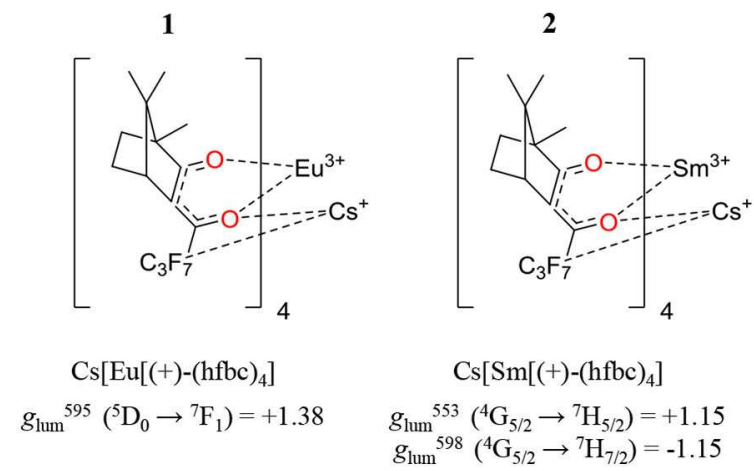

FIGURE 2 | (A) Structure of the podate ligand (L1) reported by Raymond and coworkers for the preparation of chiral Sm, Eu, Tb, and Dy complexes. Macrocycle-based cyclen (L2) and triazacyclononane (L3) used by Parker and coworkers for the preparation of chiral lanthanide-based CPL probes (Parker et al.,

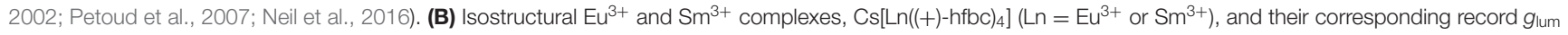
values associated with their MD-allowed transitions.

terms of the coordinated lanthanide complexes (Gálico et al., 2019). Taking advantage of the versatility of $\beta$-diketonate ligands, chiral derivatives can be easily prepared using cheap enantiopure ketones. Hence, the $\mathrm{Eu}^{3+}$ and $\mathrm{Sm}^{3+}$ complexes based on the hfbc ligand $[\mathrm{hfbc}=(+)$-3-heptafluorobutylyrylcamphorato, Figure $2 \mathbf{B}$ ] were straightforwardly prepared. They gave rise to extraordinary chiroptical properties affording the highest $g_{\text {lum }}$ reported to date $\left(+1.38\right.$ at $595 \mathrm{~nm}$ for the $\mathrm{Eu}^{3+}$ derivative). This value exceeds the previous record of -0.78 at $588 \mathrm{~nm}$ found for a similar camphor-based ligand, $\mathrm{Cs}\left[\mathrm{Eu}((-) \text {-facam })_{4}\right]$ where facam is 3-trifluoroacetyl-d-camphorato (Riehl and Richardson, 1986; Riehl and Muller, 2004). In its pivotal work, Muller and coworkers examined the CPL properties of $\mathrm{M}^{\mathrm{I}}\left[\mathrm{Eu}((+)-\mathrm{hfbc})_{4}\right]$ complexes $\left(\mathrm{M}^{\mathrm{I}}=\mathrm{Cs}\right.$ and $\left.\mathrm{Na}\right)$ in $\mathrm{CHCl}_{3}$ and $\mathrm{EtOH}$. They found that the magnitude of $\left|g_{\text {lum }}\right|$ is affected by the size of the alkali counter-ion and, to a less extend, by the nature of the solvent. In going from $\mathrm{Cs}^{+}$to $\mathrm{Na}^{+},\left|g_{\text {lum }}\right|$ drops to 0.15 , a 9-fold reduction compared to 1.38 found for the $\mathrm{Cs}^{+}$derivative. This difference has been associated with a decrease in the degree of helical twist and hence of the chiral environment of the complex, upon reducing the size of the interacting alkali cation (Lunkley et al., 2011). Last but not least, a solvent dependence was also observed in going from $\mathrm{CHCl}_{3}$ to $\mathrm{EtOH}$, thus giving rise to lower dissymmetry factors of +1.32 and +0.06 at $595 \mathrm{~nm}$ for the $\mathrm{Cs}^{+}$and $\mathrm{Na}^{+}$derivatives. Subsequently, Di Bari and coworkers pointed out the crucial role played by the centered $\beta$-diketonane $\pi \rightarrow \pi^{*}$ transitions on the dynamic coupling mechanism (DC) operating in these complexes (Di Pietro and Di Bari, 2012). Alternatively, the combination of achiral $\beta$-diketonate antenna, including acetylacetonate (acac) or hexafluoracetylacetonate (hfac), with commercially available chiral tridentate ligands, such as 2,6-bis[(4R)-4-phenyl-2-oxazolinyl]pyridine (L6, Ph-Pybox) 
or analogous L5 (iPr-Pybox) and L7 (Me-Ph-Pybox) represents an efficient approach for preparing enantiopure heteroleptic chiral trivalent lanthanides with high emission properties and interesting CPL properties (Figure 3, top) (Górecki et al., 2018). For instance, by changing the nature of the ancillary ligand in going from $\left[\mathrm{Eu}(\mathbf{L 5})(\mathrm{hfbc})_{3}\right]$ to $\left[\mathrm{Eu}(\mathbf{L 7})(\mathrm{hfbc})_{3}\right]$ (Figure 3, bottom), glum remains similar. However, the replacement of the chiral $\beta$-diketonate co-ligand (facam) with achiral acac in $\left[\mathrm{Eu}(\mathrm{L6})(\mathrm{acac})_{3}\right]$ resulted in a considerable drop in magnitude of the dissymmetry factor (Figure 3, bottom). This points out empirically the importance of having a large amount of chiral centers around the $\mathrm{Ln}^{3+}$ coordination environment for enhancing the dissymmetry factor. By replacing $\mathrm{Eu}^{3+}$ with $\mathrm{Yb}^{3+}$, Di Bari and coworkers obtained $\left[\mathrm{Yb}(\mathbf{L} \mathbf{5})(\mathrm{tta})_{3}\right]$ and $\left[\mathrm{Yb}(\mathbf{L 6})(\mathrm{tta})_{3}\right]\left(\mathrm{tta}=\right.$ thenoyltrifluoroacetone), for which $\left|g_{\text {lum }}\right|$ values of 0.019 and 0.029 could be recorded for the ${ }^{2} \mathrm{~F}_{7 / 2} \rightarrow{ }^{2} \mathrm{~F}_{5 / 2}$ transition (Zinna et al., 2019), one of the rare examples of the NIR-CPL signal reported up to date.

Axial chiral ligands, such as $(R / S)-2,2^{\prime}$ bis(diphenylphosphoryl)-1, $1^{\prime}$-binaphthyl (BINAPO) have been also proven to be appropriate for inducing CPL (Harada et al., 2009; Liu et al., 2018; Cotter et al., 2019). Chiral terpyridine (tpy) ligands allowed Muller and coworkers to prepare helical complexes $\left(\mathrm{Ln}=\mathrm{Eu}^{3+}\right.$ and $\mathrm{Tb}^{3+}$ ) which showed poor quantum yields (4\% and $0.022 \%)$ and moderate $g_{\text {lum }}$ of 0.028 and 0.020 for $\mathrm{Eu}^{3+}$ and $\mathrm{Tb}^{3+}$, respectively (Muller et al., 2002). Along this line, the same authors used enantiopure dipicolinic acid-based ligands, which produce helical arrangements around the metal center mirroring those previously described for tpy-based complex ligands (Golesorkhi et al., 2018). At this occasion, they observed a considerable improvement of the chiroptical properties by measuring a $g_{\text {lum }}$ of -0.18 for the $\mathrm{Eu}^{3+}$ derivative (Bonsall et al., 2007). Other important works using dipicolinic acid-based ligands have been reported, some of them leading to supramolecular structures (Leonard et al., 2007; Lincheneau et al., 2011; Kitchen et al., 2012; Bradberry et al., 2015; Zhang G. et al., 2015).

So far, we have focused our analysis on small chiral complexes, but more sophisticated structures, such as helicates, cages, or wheels showing interesting CPL properties have also been reported (Figure 4). For instance, Piguet and coworkers prepared the first enantiomerically pure inert nonadentate receptor $\left[\mathrm{Cr}(\mathbf{L} \mathbf{9})_{3}\right]^{3+}$ (Cantuel et al., 2004). Its complexation to $\mathrm{Ln}^{3+}$ generates the triple-stranded helicates $\left[\operatorname{LnCr}(\mathbf{L} 9)_{3}\right]^{6+}$ (e.g., $\mathrm{Ln}=\mathrm{Eu}, \mathrm{Tb}$ ), the $\mathrm{CPL}$ spectrum of which revealed a dual polarized emission for $\left[\operatorname{EuCr}(\mathbf{L} \mathbf{9})_{3}\right]^{6+}$ arising from the spin-flip $\mathrm{Cr}^{\mathrm{III}}\left({ }^{2} \mathrm{E} \rightarrow{ }^{4} \mathrm{~A}_{2}\right)$ transition with $\left|g_{\text {lum }}\right|=0.01$ at $744 \mathrm{~nm}$ and from the $\mathrm{Eu}^{\mathrm{III}}\left({ }^{5} \mathrm{D}_{0} \rightarrow{ }^{7} \mathrm{~F}_{1}\right)$ transition with $\left|g_{\text {lum }}\right|$ $=0.16$ at $594 \mathrm{~nm}$. Due to the quantitative intramolecular $\mathrm{Tb}$ $\rightarrow$ Cr energy transfer, $\left[\mathrm{TbCr}(\mathbf{L} \mathbf{9})_{3}\right]^{6+}$ showed exclusively the polarized emission of $\mathrm{Cr}^{3+}$ with a $g_{\text {lum }}$ value identical to that observed for the Eu derivative. Mamula et al. were able to prepare a trinuclear $\mathrm{Eu}_{3}(\mathbf{L} \mathbf{1 0})_{2}$ array through a diastereoselective assembly process harnessing the so-called chiral cooperativity approach and using an enantiopure bipyridine-carboxylate ligand (L10, $\left|g_{\text {lum }}\right|=0.16$ for the $\mathrm{Eu}\left({ }^{5} \mathrm{D}_{0} \rightarrow{ }^{7} \mathrm{~F}_{1}\right)$ transition) (Mamula et al., 2005). Similarly, Gunnlaugsson and coworkers prepared the $\left[\mathrm{Eu}_{2}(\mathbf{L 8})_{3}\right]^{6+}$ triple-stranded helicate by selfassembly of enantiomerically pure $\mathbf{L 8}$ and $\mathrm{Eu}\left(\mathrm{CF}_{3} \mathrm{SO}_{3}\right)_{3}$ salts (Stomeo et al., 2009). CPL measurements showed a large $g_{\text {lum }}$ of -0.23 at $593 \mathrm{~nm}$ corresponding to the magnetic allowed ${ }^{5} \mathrm{D}_{0} \rightarrow{ }^{7} \mathrm{~F}_{1}$ transition. Mazzanti and coworkers prepared a chiral heptanuclear $\mathrm{Eu}^{3+}$ wheel using the dissymmetric tetradentate ligand L11 (Bozoklu et al., 2012). This system showed a reasonable quantum yield of $27 \%$ with a $\left|g_{\text {lum }}\right|$ of 0.1 for the ${ }^{5} \mathrm{D}_{0} \rightarrow{ }^{7} \mathrm{~F}_{1}$ transition. Other assemblies, such as tetrahedral and cubic cages, triangles, wheels, and clusters have been also reported, most of them based on $\mathrm{Eu}^{3+}$ with $\left|g_{\text {lum }}\right|$ ranging from 0.04 to 0.20 (Mamula et al., 2006; Tang et al., 2009; Yan et al., 2015; Li X.-Z. et al., 2017; Yeung et al., 2017; Bing et al., 2018; Zhou et al., 2019).

Although far to be comprehensive, the selected contributions commented above represent important and illustrative results in the field of lanthanide's CPL. The usual strategy to prepare chiral $\mathrm{Ln}^{3+}$-based complexes deals with the introduction of stereogenic centers in the ligand skeleton that itself should (i) act as an efficient antenna for inducing the lanthanide emission and (ii) provide a DC mechanism for inducing considerable CPL. Thus, chiral $\mathrm{Eu}^{3+}, \mathrm{Tb}^{3+}$, and $\mathrm{Sm}^{3+}$ complexes have been largely exploited and they are now well-recognized for having strong CPL in the visible range whereas $\mathrm{Yb}^{3+}$ and $\mathrm{Nd}^{3+}$ centers have also been proven to show remarkable CPL emission in the NIR. This has led to the preparation of a plethora of optically active complexes with reasonable quantum yields. Despite the many examples reported to date, the relationship between the structure of the complex and the value of $g_{\text {lum }}$, which is of fundamental importance for molecular programming, remains challenging. This weakness mainly relies on the difficulties of performing theoretical CPL studies accessible to synthetic coordination chemists (Gendron et al., 2019). The potential applications of CPL arising from chiral $\mathrm{Ln}^{3+}$ systems is of considerable importance in biology and biochemistry because they have shown to be very sensitive to small changes in the molecular structure which can be detected as a change in the CPL emission. Therefore, they can be used as molecular probe for amino acid, anion, and biomolecule sensing. However, the high cost owed to the difficult purification of lanthanides and the theoretical complications associated with the operation of intermediate to strong spin-orbit coupling are non-negligible limitations for applications. Therefore, alternatives regarding the replacement of the optically active lanthanide center with transition metals might be of interest. Furthermore, the chemical lability of most of lanthanide complexes (apart from cryptates or anionic multidentate podates) is a severe drawback that usually prevents chiral resolution.

\section{SECOND- AND THIRD-ROW TRANSITION METAL COMPLEXES FOR CPL}

The $4 \mathrm{~d}$ and $5 \mathrm{~d}$ metal complexes benefit from their kinetic inertness, which allows their stereoisomeric separation, purification, and easy incorporation into devices. Those chemical advantages are supplemented by the strong and 
<smiles>CC(C)[C@H]1COC(c2cccc(C3=N[C@@H](C(C)C)CO3)n2)=N1</smiles>

L5 - iPr-Pybox

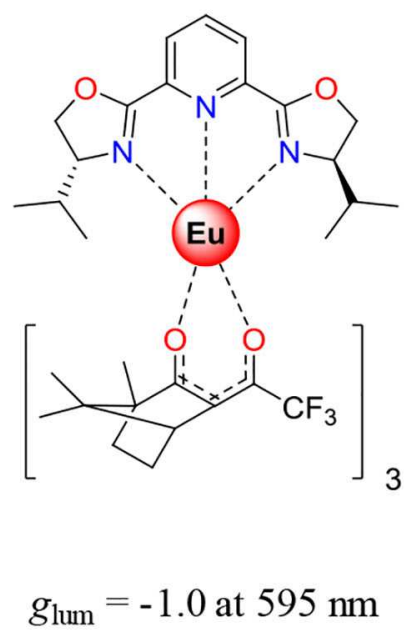

3<smiles>c1ccc([C@H]2COC(c3cccc(C4=N[PbH](c5ccccc5)CO4)n3)=N2)cc1</smiles>

L6 - Ph-Pybox

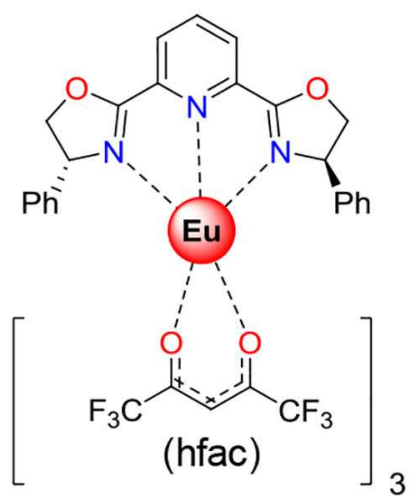

$g_{\text {lum }}=0.15$ at $595 \mathrm{~nm}$<smiles>C[C@@H]1N=C(c2cccc(C3=N[C@H](C)[C@@H](c4ccccc4)O3)n2)O[C@H]1c1ccccc1</smiles>

L7 - Me-Ph-PyBox

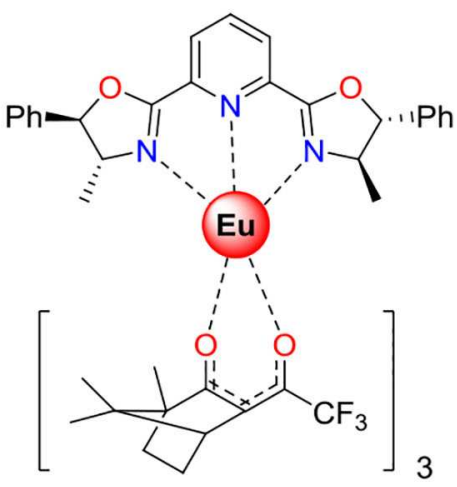

$g_{\text {lum }}=-1.0$ at $595 \mathrm{~nm}$

FIGURE 3 | (Top) Widely used enantiomerically pure ligand (L5, L6, and L7) used for the preparation of (bottom) chiral lanthanide complexes with the corresponding glum associated with the Eulll $\left({ }^{5} D_{0} \rightarrow{ }^{7} F_{1}\right)$ transition.

tunable emission properties covering the visible part of the electromagnetic spectrum with sometimes impressive quantum yields, which are important advantages for modern applications (i.e., OLED or bio-probes) (Guerchais and Fillaut, 2011; Zhou et al., 2011). The efficient emission from the ${ }^{3} \mathrm{LC}$ or ${ }^{3} \mathrm{MLCT}$ transitions is due to the strong ligand field of complexes holding large metal ions and showing important covalence. In particular, the low spin $\mathrm{d}^{6}\left(\mathrm{Ru}^{\mathrm{II}}, \mathrm{Os}^{\mathrm{II}}, \mathrm{Rh}^{\mathrm{III}}, \mathrm{Ir}^{\mathrm{III}}\right)$ or $\mathrm{d}^{8}\left(\mathrm{Pt}^{\mathrm{II}}\right)$ configurations in octahedral and square planar geometries, respectively, promote the ${ }^{3} \mathrm{MC}$ quencher levels to high energy, which prevents ${ }^{3} \mathrm{LC} /{ }^{3} \mathrm{MLCT} \rightarrow{ }^{3} \mathrm{MC}$ energy transfers (Figure 5). Increasing the emission quantum yield is thus indebted to the ligand field increase, a concept often harnessed to generate more efficient $\mathrm{Ru}^{\mathrm{II}}$ emitters.

Among the $\mathrm{d}^{6}$ metals, the strong-field and chiral emissive Ir ${ }^{\mathrm{III}}$ cyclometallated complexes cover the visible spectral range and have been thus widely used as CPL emitters (Han et al., 2018). This important feature together with their appealing total luminescence properties have opened new perspectives for life science applications (Caporale and Massi, 2018), bioimaging (Lo et al., 2011), electroluminescence (Kapturkiewicz,
2016), phototherapy (Zamora et al., 2018), and OLEDs (Zhou et al., 2011). The emission of the Ir ${ }^{\mathrm{III}}$ cyclometallated complexes arised from a ${ }^{3} \mathrm{LC} /{ }^{3} \mathrm{MLCT}$ manifold displaying excited states lifetimes around 50 and $5 \mu \mathrm{s}$, respectively (Flamigni et al., 2007). Harnessing the Ir $^{\mathrm{III}}$ emission for CPL requires chiral complexes, and apart from a sole example of a chiral complex $\left[\operatorname{Ir}\left(\mathrm{N}^{\wedge} \mathrm{C}^{\wedge} \mathrm{N}^{\prime}\right)\left(\mathrm{C}^{\wedge} \mathrm{N}\right) \mathrm{X}\right]\left(\mathrm{X}^{-}=\mathrm{Cl}^{-}\right.$or $\left.\mathrm{CN}^{-}\right)$holding a tridentate, a bidentate, and a monodentate ligand, the enantiomers of which were separated by chiral HPLC ( $g_{\text {lum }}$ $=4 \times 10^{-3}$ ) (Ashizawa et al., 2009), the chiral environments of $\mathrm{Ir}^{\mathrm{III}}$ complexes were mainly produced with the help of pseudo-octahedral ter-bidentate environments leading to $\Delta / \Lambda$ stereoisomers in the $\left[\operatorname{Ir}\left(\mathrm{X}^{\wedge} \mathrm{X}\right)_{3}\right]^{n+}$ complexes. Moreover, the use of unsymmetrical cyclometalated ligands in ter-bidentate $\left[\operatorname{Ir}\left(\mathrm{X}^{\wedge} \mathrm{Y}\right)_{3}\right]^{n+}$ complexes induces the potential formation of fac/mer configurational isomers (Figure 6A); a synthetic issue that could be partially overcome thanks to the so-called trans effect since mer and fac isomers can be quantitatively formed, respectively at low (meridional conformation, kinetic product) and high temperatures (facial isomer, thermodynamic product) (Tamayo et al., 2003). The formation of heteroleptic 
<smiles>CC(NC(=O)c1cccc(C(=O)Nc2ccc(C(=O)NC(C)c3cccc4ccccc34)cc2)n1)c1cccc(C(=O)Nc2ccc(C(=O)NC(C)c3cccc4ccccc34)cc2)n1</smiles><smiles></smiles><smiles>CC1(C)C2CC1[C@H](C(=O)O)c1nc(-c3ccccn3)ccc12</smiles>

L11

FIGURE 4 | Multidentate ligands L8, L9, L10, and L11 that have been used for the preparation of chiral supramolecular assemblies, such as helicates (L8 and L9), trinuclear assemblies (L10), and wheels (L11) mainly by complexation to $\mathrm{Eu}^{3+}$.

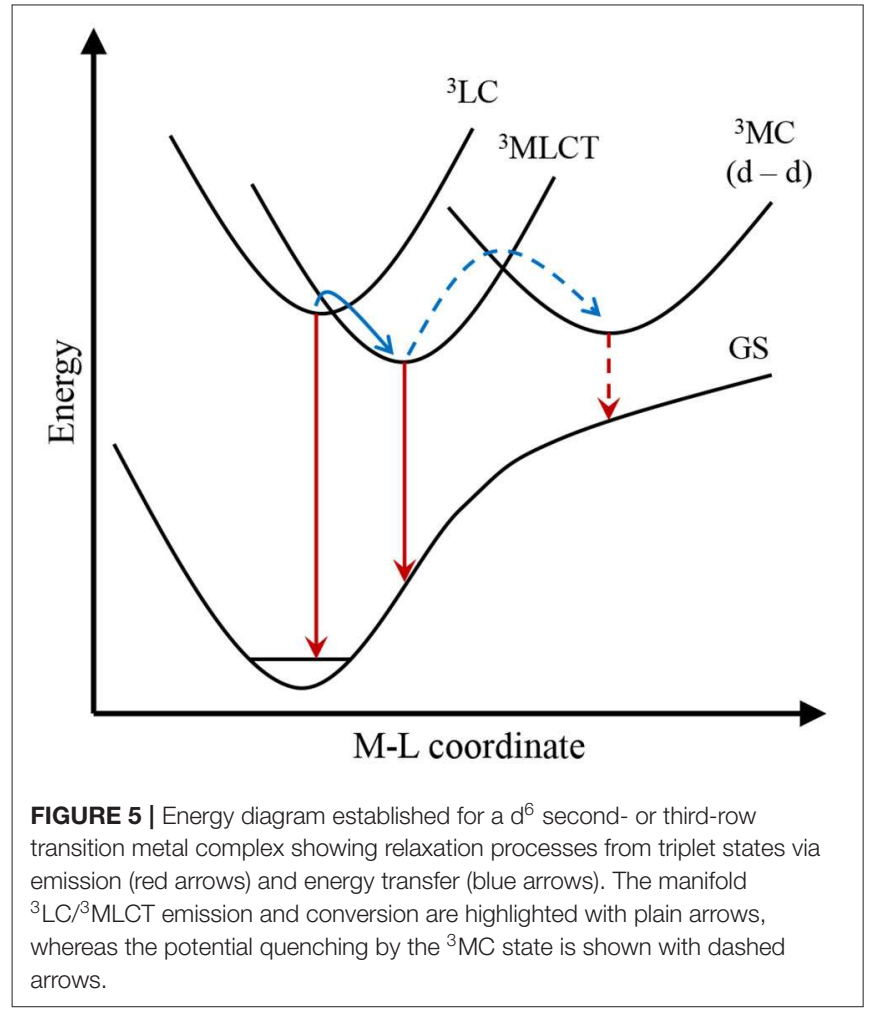

complexes $\left[\operatorname{Ir}\left(\mathrm{C}^{\wedge} \mathrm{N}\right)_{2}\left(\mathrm{X}^{\wedge} \mathrm{Y}\right)\right]^{n+}$ further increases the number of available isomers (Figure 6B). Owing to the easy access to the intermediates $\left[\operatorname{Ir}\left(\mathrm{C}^{\wedge} \mathrm{N}\right)_{2} \mathrm{Cl}_{2}\right]^{-}$or $\left[\left(\operatorname{Ir}\left(\mathrm{C}^{\wedge} \mathrm{N}\right)_{2} \mathrm{Cl}\right)_{2}\right]$ showing
$\mathrm{N}-\mathrm{Ir}-\mathrm{N}$ trans configuration (Figure 6C), all heteroleptic $\mathrm{Ir}^{\mathrm{III}}$ complexes of $\left[\operatorname{Ir}\left(\mathrm{C}^{\wedge} \mathrm{N}\right)_{2}\left(\mathrm{X}^{\wedge} \mathrm{Y}\right)\right]^{n+}$ type reported to date for $\mathrm{CPL}$ investigations have been designed to possess a $\mathrm{N}-\mathrm{Ir}-\mathrm{N}$ trans configuration in order to avoid mixture of isomers.

In order to obtain enantiopure ter-bidentate $\mathrm{Ir}^{\mathrm{III}}$ complexes for CPL, a first strategy relies on a unique source of chirality induced by the metal taken as the stereogenic center and using achiral bidentate ligands. Such method produces a pair of helical enantiomers as a racemate which should be further resolved by chiral HPLC. The latter separation technique was successfully achieved for simple mixtures of fac/mer$\left[\operatorname{Ir}(\mathrm{ppy})_{3}\right](\mathbf{6})(\mathrm{ppy}=2$-phenylpyridine) complexes to give mer$\Lambda$-[Ir(ppy $\left.)_{3}\right]$, mer- $\Delta-\left[\operatorname{Ir}(\mathrm{ppy})_{3}\right]$, fac- $\Lambda$-[Ir(ppy $\left.)_{3}\right]$, and fac- $\Delta$ [Ir(ppy) $)_{3}$ (Li et al., 2015), as well as for the more sophisticated complex 7 (Figure 7A) (Coughlin et al., 2008). Interestingly, the dissymmetry factor of fac-6 is one order of magnitude superior to its mer counterpart, which might explain the popularity of $f a c$ isomers in CPL.

The previously introduced synthetic method for preparing $\left[\operatorname{Ir}\left(\mathrm{C}^{\wedge} \mathrm{N}\right)_{2}\left(\mathrm{X}^{\wedge} \mathrm{Y}\right)\right]^{n+}$ afforded some heteroleptic complexes holding different achiral ligands (Figure 7B). Because of the use of unresolved $\left[\operatorname{Ir}\left(\mathrm{C}^{\wedge} \mathrm{N}\right)_{2} \mathrm{Cl}_{2}\right]^{-}$or $\left[\left(\operatorname{Ir}\left(\mathrm{C}^{\wedge} \mathrm{N}\right)_{2} \mathrm{Cl}\right)_{2}\right]$ precursors, chiral resolution of the synthetized $\Delta / \Lambda-\left[\operatorname{Ir}\left(\mathrm{C}^{\wedge} \mathrm{N}\right)_{2}\left(\mathrm{X}^{\wedge} \mathrm{Y}\right)\right]^{\mathrm{n}+}$ racemate 8 (Hellou et al., 2017), 9, 10 (Li et al., 2015), and 11, 12 (Coughlin et al., 2008) was performed by chiral supercritical fluid chromatography, before CPL measurement. Since the isolation of pure enantiomers requires sophisticated chiral resolution, the latter method is neither the most popular nor the first exploited to generate enantiopure Ir ${ }^{\mathrm{III}}$ complex for CPL. An alternative strategy exploits the coordination of an 


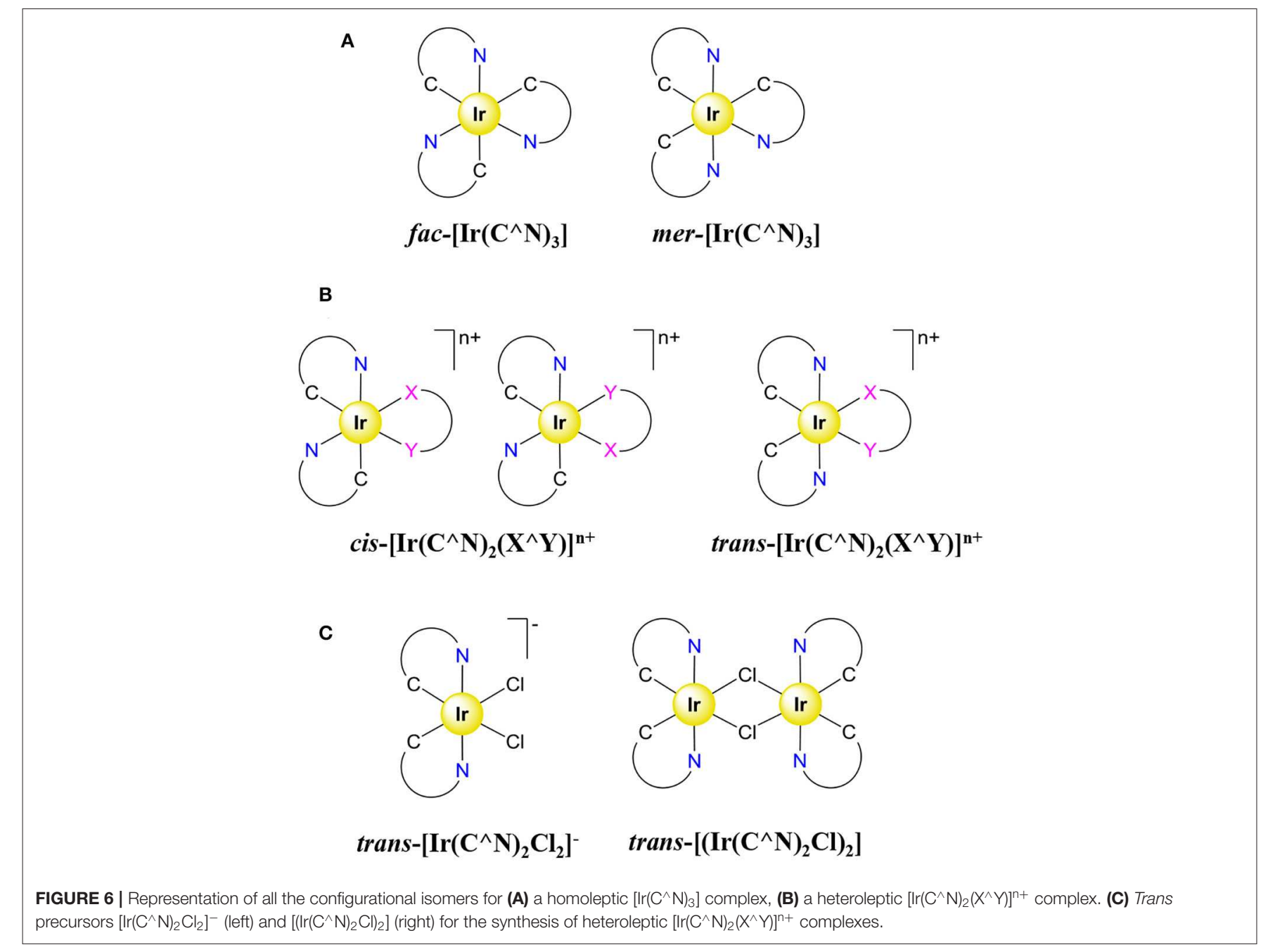

enantiopure chiral ligand to $\mathrm{Ir}^{\mathrm{III}}$, which provides a pair of diastereoisomers allowing (i) chiral induction, (ii) quantification of diastereomeric excess by NMR, and (iii) diastereoisomer separation by conventional chemical techniques, such as crystallization, precipitation, or chromatography. Actually, the first CPL measurement performed on an $\mathrm{Ir}^{\mathrm{III}}$ complex used an homoleptic [Ir(pppy) 3 ] (12) complex (pppy $=(8 \mathrm{R}, 10 \mathrm{R})-2-\left(2^{\prime}-\right.$ phenyl)-4,5-pinenopyridine) synthetized according to the chiral induction methodology (Figure 8A) (Schaffner-Hamann et al., 2004). The reaction of $\operatorname{Ir}(\mathrm{acac})_{3}$ with pppy at $190^{\circ} \mathrm{C}$ in glycerol afforded pure $f a c$ - $\left[\operatorname{Ir}(\text { pppy })_{3}\right]$ with a diastereomeric $\Lambda / \Delta$ ratio of $2 / 3$. Further separation of the two diastereoisomers was achieved on a silica plate and afforded $g_{\text {lum }}$ of $-3.2 \times 10^{-3}$ and $+2.8 \times$ $10^{-3}$ for $f a c-\Delta$ - $\left[\operatorname{Ir}(\text { pppy })_{3}\right]$ and $f a c-\Lambda$ - $\left[\operatorname{Ir}(\text { pppy })_{3}\right]$, respectively.

Apart from 13, the chemical attention usually focused on heteroleptic $\left[\operatorname{Ir}\left(\mathrm{C}^{\wedge} \mathrm{N}\right)_{2}\left(\mathrm{X}^{\wedge} \mathrm{Y}\right)\right]^{n+}$ complexes probably because they are obtained by the simple reaction of the aforementioned $\mathrm{Ir}^{\mathrm{III}}$ intermediates $\left(\left[\operatorname{Ir}\left(\mathrm{C}^{\wedge} \mathrm{N}\right)_{2} \mathrm{Cl}_{2}\right]^{-}\right.$or $\left.\left[\left(\operatorname{Ir}\left(\mathrm{C}^{\wedge} \mathrm{N}\right)_{2} \mathrm{Cl}\right)_{2}\right]\right)$ with enantiopure ligands, a versatile strategy which produces a library of complexes with various chiral ligands. In particular, the combination of achiral $\mathrm{C}^{\wedge} \mathrm{N}$ ligands with a chiral $\mathrm{X}^{\wedge} \mathrm{Y}$ one afforded the most important library of $\left[\operatorname{Ir}\left(\mathrm{C}^{\wedge} \mathrm{N}\right)_{2}\left(\mathrm{X}^{\wedge} \mathrm{Y}\right)\right]^{n+}$ complexes for CPL, mainly based on central chirality (14-17) $(\mathrm{Li}$ et al., 2016; Mazzeo et al., 2016; Li L.-P. et al., 2017; Manguin et al., 2019), albeit axial chirality was occasionally exploited with ligands containing 1, $1^{\prime}$-bi-2-naphthol derivatives (18-19) (Figure 8B) (Han et al., 2017b; Yan et al., 2019a). Although a few examples report on full chiral induction (14) (Li L.P. et al., 2017), in most cases the separation of the formed diastereoisomer pair was achieved by selective diasteroisomer precipitation (15) (Mazzeo et al., 2016), by HPLC (16) (Li et al., 2016), or by silica column chromatography (17-19) (Manguin et al., 2019; Yan et al., 2019a). Alternatively, the ligand chirality can be introduced on the $\mathrm{C}^{\wedge} \mathrm{N}$ ligand held by the precursor $\operatorname{Ir}^{\mathrm{III}}$ complex prepared as an unresolved diasteroisomeric mixture. Hence, the coordination of $\operatorname{acac}\left(\mathrm{X}^{\wedge} \mathrm{Y}\right)$ to a precursor containing enantiopure 2-phenyl-5,6-pinenepyridine $\left(\mathrm{C}^{\wedge} \mathrm{N}\right)$ resulted in a surprising full chiral induction with the exclusive formation of the $\Delta$ compound (20) (Figure 8C) (Yang et al., 2009). Finally, the introduction of both enantiopure $\mathrm{C}^{\wedge} \mathrm{N}$ and $\mathrm{X}^{\wedge} \mathrm{Y}$ ligands provided 8 stereoisomers from the overall 3 stereogenic centers (21) (Figure 8D) (Yan et al., 2018). The various mixtures of 
A<smiles></smiles>

\section{6-fac}

$\left|g_{\text {lum }}\right|=3.3 \times 10^{-3}$

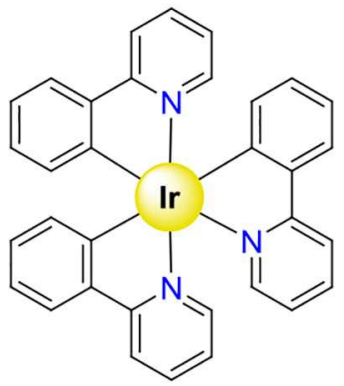

6-mer

$\left|g_{\text {lum }}\right|=3 \times 10^{-4}$<smiles></smiles>

7

$\left|g_{\text {lum }}\right|=2.0 \times 10^{-3}$

B

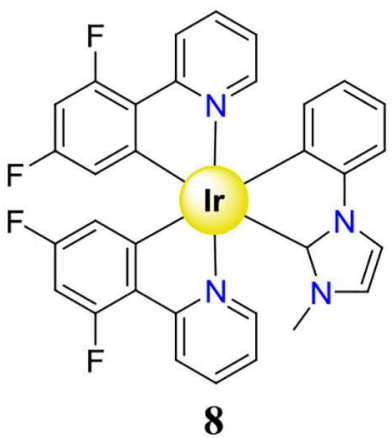

$\left|g_{\text {lum }}\right|=9 \times 10^{-4}$<smiles></smiles>

9<smiles></smiles>

10

$\left|g_{\text {lum }}\right|=1.3 \times 10^{-3}$

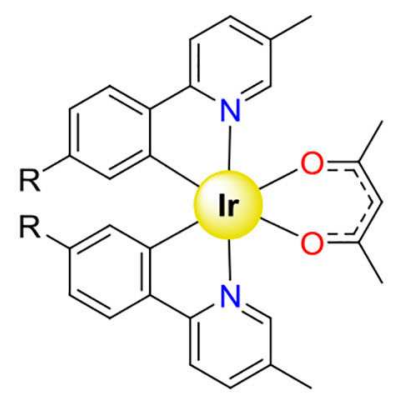

11

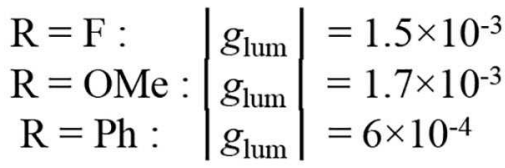

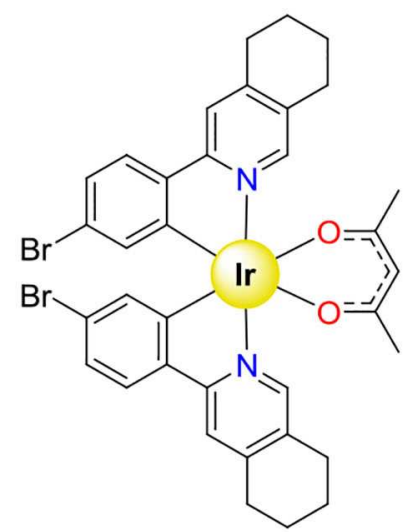

12

FIGURE 7 | (A) Homoleptic [Ir $\left.\left(C^{\wedge} N\right)_{3}\right]$ (Coughlin et al., 2008; Li et al., 2015) and (B) heteroleptic [Ir( $\left.\left.C^{\wedge} N\right)_{2}\left(X^{\wedge} Y\right)\right]$ (Coughlin et al., 2008; Li et al., 2015; Hellou et al., 2017), cyclometallated Irll! complexes holding achiral ligands displaying CPL, and associated dissymmetry factor glum. 
A

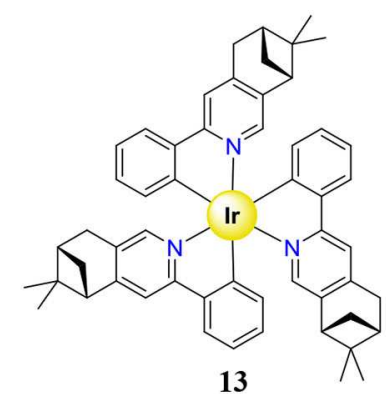

fac- $-1\left[\operatorname{Ir}(\text { pppy })_{3}\right]: g_{\text {lum }}=-3.2 \times 10^{-3}$

fac- $A$-[Ir(pppy $\left.)_{3}\right]: g_{\text {lum }}=+2.8 \times 10^{-3}$

B

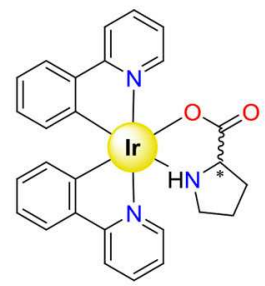

14

$\left|g_{\text {lum }}\right| \sim 10^{-3}$

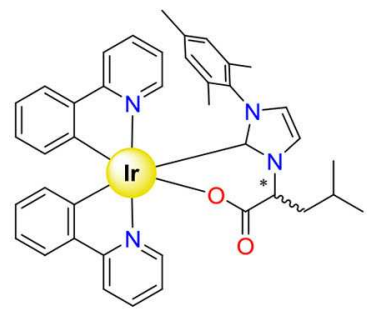

17

$\left|g_{\text {lum }}\right| \sim 1.5 \times 10^{-3}$

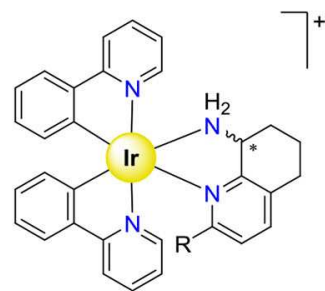

15

$\left|g_{\text {lum }}\right| \sim 10^{-3}$

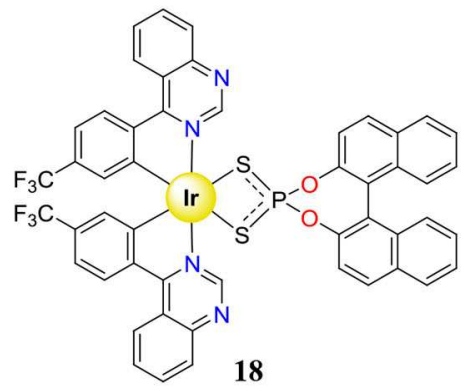

$$
\begin{aligned}
& R-\Lambda: g_{\text {lum }}=+9 \times 10^{-4} \\
& R-\Lambda: g_{\operatorname{lum}}=-4 \times 10^{-4} \\
& S-\triangle: g_{\operatorname{lum}}=+5 \times 10^{-4} \\
& S-\Lambda: g_{\operatorname{lum}}=-8 \times 10^{-4}
\end{aligned}
$$

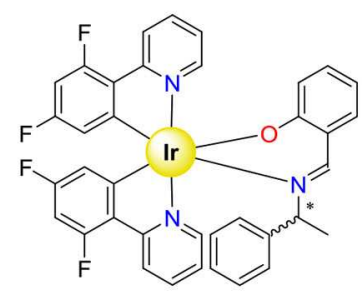

16

$\left|g_{\text {lum }}\right| \sim 5 \times 10^{-3}$

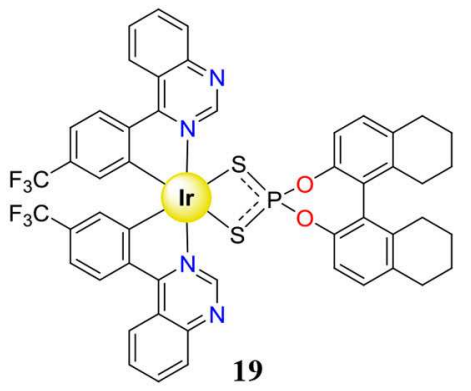

$R-\Lambda: g_{\text {lum }}=+7 \times 10^{-4}$
$R-\Lambda: g_{\text {lum }}=-4 \times 10^{-4}$
$S-\triangle: g_{\text {lum }}=+5 \times 10^{-4}$
$S-\Lambda: g_{\text {lum }}=-6 \times 10^{-4}$
C

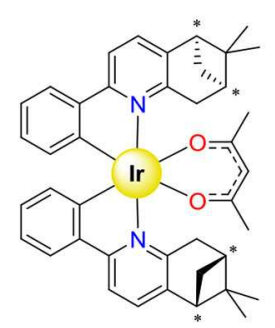

20

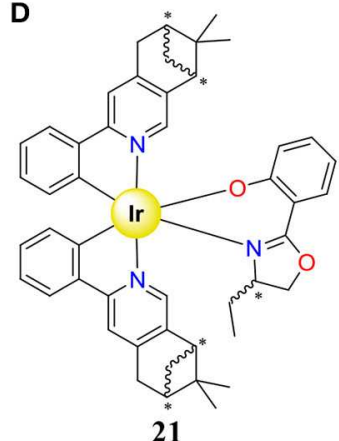

21

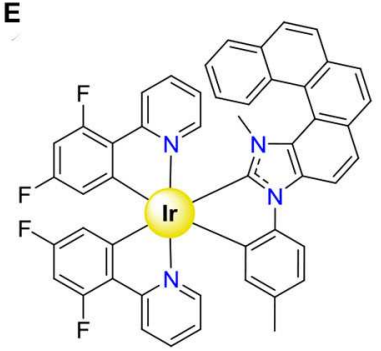

22

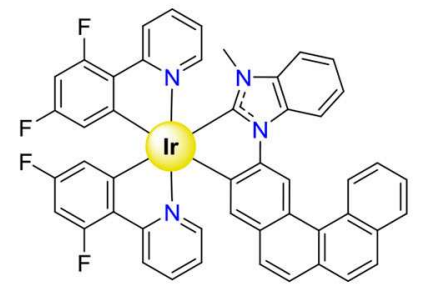

23

$(R, R)-\triangle:\left|g_{\text {lum }}\right|=2 \times 10^{-3}$

$\left|g_{\text {lum }}\right| \sim 3 \times 10^{-3}$

A: $g_{\mathrm{lum}}=-2.6 \times 10^{-3}$

A: $g_{\text {lum }}=+3.1 \times 10^{-3}$

FIGURE 8 | Cyclometallated IrIII complexes holding chiral ligands, displaying CPL, and associated dissymmetry factor glum. (A) Homoleptic fac-[Ir(pppy) 3 ] complex (Schaffner-Hamann et al., 2004). Heteroleptic complexes $\left[\operatorname{lr}\left(C^{\wedge} N\right)_{2}\left(X^{\wedge} Y\right)\right]^{n+}$ holding (B) achiral $C^{\wedge} N$ and chiral $X^{\wedge} Y$ ligands (Li et al., 2016; Mazzeo et al., 2016; Li L.-P. et al., 2017; Manguin et al., 2019; Yan et al., 2019a), (C) chiral $C^{\wedge} N$ and achiral $X^{\wedge} Y$ ligands (Yang et al., 2009), (D) chiral $C^{\wedge} N$ and $X^{\wedge} Y$ ligands (Yan et al., 2018), and (E) helicenic-NHC chiral ligand $X^{\wedge} Y$ (Hellou et al., 2017; Macé et al., 2019). 
diastereoisomers could be successfully separated by silica column chromatography. Even if chiral induction is an outstanding strategy for the easy preparation of stereoisomerically pure $\mathrm{Ir}^{\mathrm{III}}$ complexes, this method requires kinetically inert enantiopure ligands. Nevertheless, the synthesis of a $\left[\operatorname{Ir}\left(\mathrm{C}^{\wedge} \mathrm{N}\right)_{2}\left(\mathrm{X}^{\wedge} \mathrm{Y}\right)\right]^{n+}$. type complex with a helicenic-NHC as ligand $\mathrm{X}^{\wedge} \mathrm{Y}(\mathbf{2 2 - 2 3})$ was conducted despite the observed racemization of the unbound helicene (Figure 8E) (Hellou et al., 2017; Macé et al., 2019). Since racemization is inhibited upon coordination, the chiral resolution of the four stereoisomers could be performed by chiral HPLC. In spite of all the remarkable synthetic efforts made for generating libraries of enantiopure $\mathrm{Ir}^{\mathrm{III}}$ emissive complexes, the CPL measurements always show weak and comparable dissymmetry factors in the range of $10^{-4}-5 \times$ $10^{-3}$, an observation which is consistent with the nature of the electric-dipole allowed transitions characterizing mixed ${ }^{3} \mathrm{LC} /{ }^{3}$ MLCT manifolds.

Recently, neutral $\mathrm{Pt}^{\mathrm{II}}$ complexes received increasing attention as CPL emitters because they combine (i) chemical and kinetic advantages similar to $\mathrm{Ir}^{\mathrm{III}}$ complexes, (ii) important emission quantum yield from ${ }^{3}$ MLCT state or even ${ }^{3}$ MMLCT state due to $\mathrm{Pt}-\mathrm{Pt}$ bonds, and (iii) emission in the red-to-NIR region, which is an asset for biological applications. $\mathrm{Pt}^{\mathrm{II}}\left(\mathrm{d}^{8}\right)$ complexes usually display square planar geometry with a coordination number of 4 compatible with additional intermolecular axial interactions produced by molecule pilling which permit the tuning of the ${ }^{3}$ MMLCT emission energy via $\mathrm{Pt}-\mathrm{Pt}$ bond formation. Contrary to aforementioned pseudo-octahedral $\mathrm{Ir}^{\mathrm{III}}$ ter-bidentate complexes, the square planar $\mathrm{Pt}^{\mathrm{II}}$ ones possess an intrinsically achiral first coordination sphere, which affords an easy route for the preparation of enantiopure complexes. Indeed, the coordination of chiral enantiopure ligands generates the corresponding complex without the appearance of an additional stereogenic center upon coordination-a convenient synthetic pathway, which makes $\mathrm{Pt}^{\mathrm{II}}$ complexes particularly appealing for CPL. The first CPL of a $\mathrm{Pt}^{\mathrm{II}}$ complexes was thus reported by Crassous and coworkers in 2014. They correspond to the coordination of cyclometalated bidentate helicene ligands, with an acac anion completing the coordination sphere (24-26) (Figure 9A) (Shen et al., 2014). While 24 and 25 display weak dissymmetry factors, the related complex 26 shows $g_{\text {lum }}$ one order of magnitude higher than that measured for the $\mathrm{Ir}^{\mathrm{III}}$ analogs, this despite the simple ligand-centered chirality. This confirms the efficiency of the DC mechanism and the option of avoiding metal-centered chirality for producing large CPL signals. Owing to its outstanding $g_{\text {lum }}=1.3 \times 10^{-2}$ for a d-block complex, 26 was recently incorporated into an electroluminescent device which provided an electroluminescent dissymmetry factor $\left(g_{\mathrm{el}}\right)$ one order of magnitude higher than its photoluminescent counterpart $\left(g_{\text {lum }}\right)$ - a result probably due to an additional helical arrangement in the condensed phase (Brandt et al., 2016). The impressive $g_{\text {el }}$ is sensitive to weak structural modifications since the similar complex 27 showed much weaker values (Yan et al., 2019b). Motivated by the seminal work of Crassous and coworkers, numerous chiral $\mathrm{Pt}^{\mathrm{II}}$ complexes for CPL studies were synthesized with the help of bidentate ligands possessing helical chirality (27-28, Figure 9A) (Biet et al.,
2017), central chirality (29-31, Figure 9B) (Ionescu et al., 2017; Lu et al., 2017; Usuki et al., 2019), or axial chirality (32-33, Figure 9C) (Song J. et al., 2018; Song et al., 2019).

The fluorinated version of the bimetallic complex 33 shows a $g_{\text {lum }}$ of $10^{-2}$ due to the helical shape induced by the BINOL ligand, which highlights that the pilling of complexes in an overall helical architecture is a promising strategy for $g_{\text {lum }}$ enhancement (Song et al., 2019). The latter strategy was repeated with complex 34, which is used as a dopant in achiral analog for the formation of helical co-assemblies with improved $g_{\text {lum }}$ for the ${ }^{3}$ MMLCT transition via Pt-Pt bonding interactions (Figure 10A) (Park et al., 2019).

In order to provide efficient stacking and intermolecular PtPt bonding interactions, $\mathrm{Pt}^{\mathrm{II}}$ complexes holding a tridentate and a monodentate ligand were developed $(35,36,38$, Figure 10) (Ikeda et al., 2015, 2018; Zhang X.-P. et al., 2015; Tanaka et al., 2016). Despite positioning the stereogenic centers on the ligand far from the emissive moiety, the resulting aggregates and helical supramolecular structures often display important dissymmetry factor around $10^{-2}$. Moreover, the reversible entropic control of the aggregation process transforming CPL active assemblies (at low $T$ ) into discrete molecules with no CPL signal (at high $T$ ) provides a noteworthy CPL switch (36-38, Figure 10B) (Ikeda et al., 2015, 2018; Zhang X.-P. et al., 2015; Fu et al., 2016). The tuning of the CPL property can nonetheless be achieved in solution by controlling the intermetallic distance in a bimetallic architecture via the choice of the spacer length between complexes (39, Figure 11A) (Zhang et al., 2018).

A remarkable modulation of the CPL property in solution could be achieved with the cyclometallated $\mathrm{Pt}^{\mathrm{II}}$-helicene complex (40, Figure 11A), for which reversible protonation of the bidentate helical ligand provided a modification of $g_{\text {lum }}$ albeit its absolute value remains weak (Saleh et al., 2015a). Aside from complexes owing their chirality to stereogenic centers located on the ligand, Clever and coworkers reported in 2017 a remarkable $\mathrm{Pt}^{\mathrm{II}}$ cyclometallated complex built with an achiral ligand and showing metal-centered chirality despite the square planar geometry of the first coordination sphere (41, Figure 11B) (Schulte et al., 2017). In this complex, the chirality arises from an appropriate choice of the ligand coordination vectors, which permit the unusual orthogonal coordination of the two bidentate ligands.

Beyond the most popular $\mathrm{Ir}^{\mathrm{III}}$ and $\mathrm{Pt}^{\mathrm{II}}$ neutral complexes, the CPL of second- and third-row transition metal complexes is currently restricted, to the best of our knowledge, to three reports dealing with chiral and charged $\mathrm{Ru}^{\mathrm{II}}$ (42) (Oyler et al., 2007), $\operatorname{Re}^{I}$ (43) (Saleh et al., 2015b), and Os ${ }^{I I}$ (44) (Gunde et al., 1997) complexes (Figure 12).

The use of $\left[\mathrm{Ru}^{\mathrm{II}}(\mathrm{R} \text {-bipy })_{3}\right]$ chromophores restores the difficulties associated with the prospective formation of $\Delta / \Lambda$ stereoisomers as well as fac/mer regioisomers. Nevertheless, those synthetic drawbacks were finally overcome by the use of enantiopure ter-bidentate podand, the coordination of which solely provides the fac isomer 42 (Oyler et al., 2007). Moreover, the three stereogenic centers located on the hexadentate ligand induce the complete diastereoselective formation of the $\Delta-(-)-42$ and $\Lambda$-(+)-42 complexes which showed weak $g_{\text {lum }}$ value of 7.7 
A

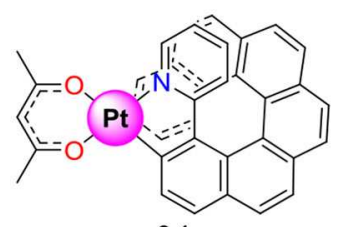

24

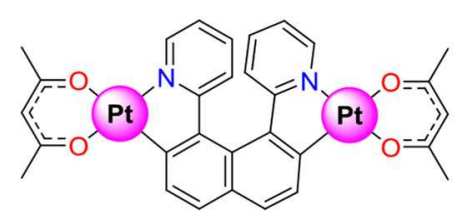

25

$$
\begin{aligned}
& P: g_{\text {lum }}=+4 \times 10^{-3} \\
& M: g_{\text {lum }}=-5 \times 10^{-3}
\end{aligned}
$$

$P: g_{\operatorname{lum}}=+5 \times 10^{-3}$

$M: g_{\text {lum }}=-5 \times 10^{-3}$

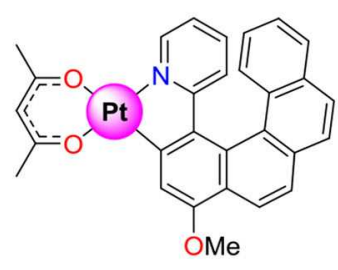

26

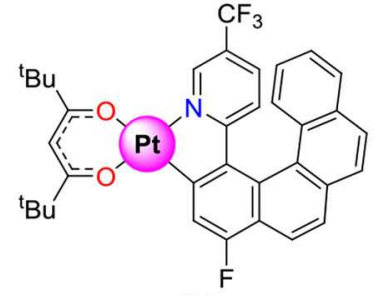

27

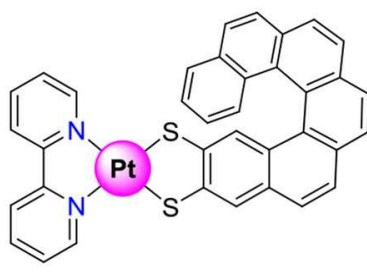

28
$P: g_{\text {lum }}=+1.3 \times 10^{-2}$
$M: g_{\text {lum }}=-1.1 \times 10^{-2}$
$(+): g_{\mathrm{el}}=0.22$
$(-): g_{\mathrm{el}}=0.38$

$\left|g_{\text {lum }}\right|=3.7 \times 10^{-3}$

$P: \quad g_{\text {el }}=-3.7 \times 10^{-3}$

$M: g_{\mathrm{el}}=5.1 \times 10^{-3}$

B

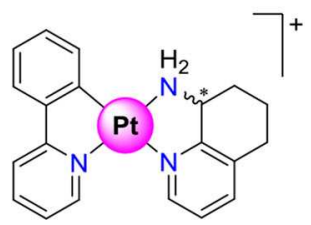

29a

Weak $\left|g_{\text {lum }}\right|$

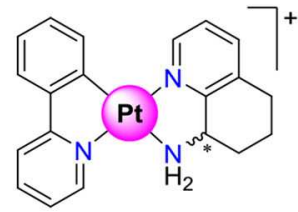

29b

Weak $\left|g_{\text {lum }}\right|$

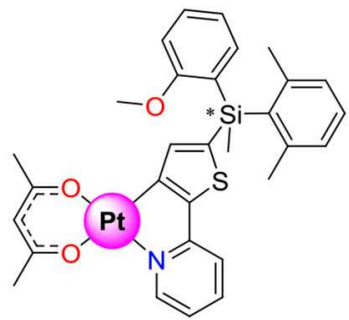

30

$\left|g_{\text {lum }}\right|=9 \times 10^{-4}$

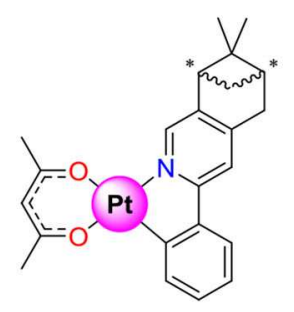

31

Weak $\left|g_{\text {el }}\right|$

C

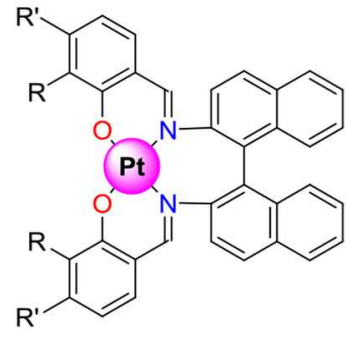

32

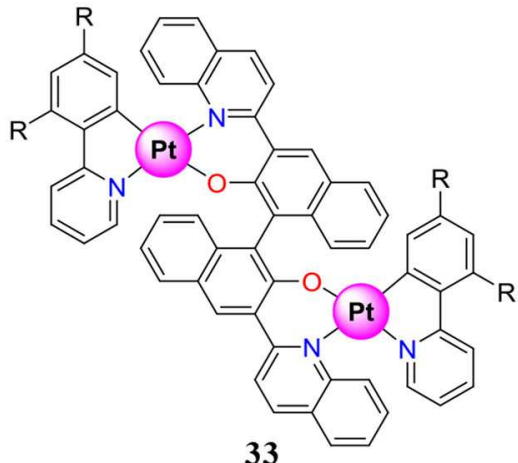

33

$$
\begin{array}{ll}
\mathrm{R}=\mathrm{F} ; \mathrm{R}^{\prime}=\mathrm{H}: \quad\left|g_{\text {lum }}\right|=3.0 \times 10^{-3} & \mathrm{R}=\mathrm{H}:\left|g_{\text {lum }}\right|=6 \times 10^{-3} \\
\mathrm{R}=\mathrm{H} ; \mathrm{R}^{\prime}=\mathrm{NEt}_{2}:\left|g_{\text {lum }}\right|=5.0 \times 10^{-3} & \mathrm{R}=\mathrm{F}:\left|g_{\text {lum }}\right|=1 \times 10^{-2}
\end{array}
$$

FIGURE 9 | Pt" complexes coordinated by (A) helicene ligands (Shen et al., 2014; Brandt et al., 2016; Biet et al., 2017; Yan et al., 2019b), (B) bidentate ligands showing central chirality (lonescu et al., 2017; Lu et al., 2017; Usuki et al., 2019), and (C) bidentate ligands showing axial chirality (Song J. et al., 2018; Song et al., 2019), and associated luminescence dissymmetry factor $g_{\text {lum }}$ and electroluminescence dissymmetry factor $g_{\mathrm{el}}$. 
A<smiles>CC(C)(c1ccccc1-c1ccccc1)c1c(-c2ccccc2)c(-c2ccccc2)n(-c2ccccc2)c1-c1ccccc1</smiles>

Co-assemblies

$(R, R): g_{\text {lum }}=-6.4 \times 10^{-2}$

$(S, S): g_{\text {lum }}=+5.0 \times 10^{-2}$

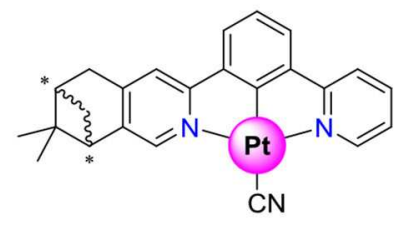

35

Excimers:

$\left|g_{\text {lum }}\right|=5 \times 10^{-4}$
B

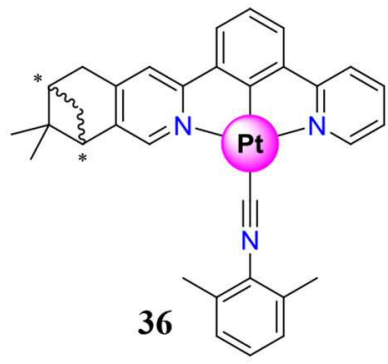

$295 \mathrm{~K}$ (aggregates):

$(-): g_{\text {lum }}=-1.8 \times 10^{-3}$

$(+): g_{\text {lum }}=+1.2 \times 10^{-3}$

$353 \mathrm{~K}$ : No CPL<smiles></smiles>

$185 \mathrm{~K}$ (aggregates):

$\left|g_{\text {lum }}\right|=4 \times 10^{-2}$

$273 \mathrm{~K}$ : No CPL

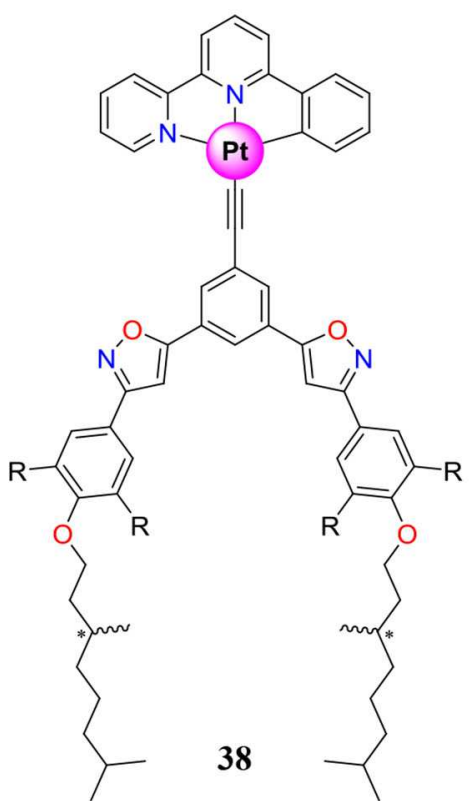

$\underline{\mathrm{R}=\mathrm{OC}_{18}} \underline{\mathrm{H}}_{37}$

$273 \mathrm{~K}$ (gel): $\left|g_{\text {lum }}\right|=1.1 \times 10^{-2}$

$323 \mathrm{~K}$ : $\quad$ No CPL

$\mathbf{R}=\mathbf{H}$ :

Helical assemblies: $\left|g_{\text {lum }}\right|=1 \times 10^{-2}$ Molecule:

FIGURE 10 | Pt" complexes (A) showing aggregation (Tanaka et al., 2016; Park et al., 2019), (B) showing reversible aggregation and switchable CPL and associated dissymmetry factor glum (Ikeda et al., 2015, 2018; Zhang X.-P. et al., 2015; Fu et al., 2016).

$\times 10^{-4}$. More recently, the complex 43 was obtained through the coordination of a helicenic ligand to a $\mathrm{Re}^{\mathrm{I}}$ metal center with intrinsic achiral coordination sphere (Saleh et al., 2015b). Although this straightforward method provides enantiopure complexes, the associated dissymmetry factors remain weak, and only few further synthesis were performed for CPL application (Gauthier et al., 2020). Finally ligand-centered CPL were casually tuned or switched by a closed shell d-block metal like $\mathrm{Ag}^{\mathrm{I}}$ or $\mathrm{Au}^{\mathrm{I}}$. While $\mathrm{Au}^{\mathrm{I}}$ can be used to rigidify and organize organic chromophores to enhance its emission (Zhang J. et al., 2019), the interaction of $\mathrm{Ag}^{\mathrm{I}}$ with organic moieties provides CPL switch and ratiometric CPL probe (Reiné et al., 2018a; Resa et al., 2018). Furthermore, CPL emission can be observed from nanoclusters of silver or gold in their metallic state (Kumar et al., 2017; Shi et al., 2017).

Excluding the outstanding electroluminescence of 26 , the CPL-active $4 \mathrm{~d}$ and $5 \mathrm{~d}$ metal complexes reported to date display a systematically weak dissymmetry factor $\left(<7 \times 10^{-2}\right)$ in line with the limitations ascribed to ED-allowed and MD-forbidden charge transfer or ligand-centered transitions. Similarly to the lanthanide-based $\mathrm{f}-\mathrm{f}$ transitions, the $\mathrm{d}-\mathrm{d}$ transitions in the second and third-row metal complexes should display strong CPL, albeit there are non-emissive because of the low-lying MLCT. In order to observe emissive metal centered $\mathrm{d}-\mathrm{d}$ transitions, the strong ligand field of $4 \mathrm{~d}$ and $5 \mathrm{~d}$ metal complexes should be reduced until the energy of MC states becomes lower than those of MLCT states, a criterion more easily fulfilled with $3 \mathrm{~d}$ metal complexes.

\section{EXTENSION TOWARD 3D METAL COMPLEXES. THE PROMISING CASE OF EARTH-ABUNDANT CHROMIUM CENTERS}

The earth-abundant first-row d-block metals seem appealing in the field of CPL because of their low cost and the theoretically promising dissymmetry factors arising from the $\mathrm{d}-\mathrm{d}$ transitions. Assuming very weak spin-orbit coupling and pure metal character of $\mathrm{d}$ orbitals, the $\mathrm{d}-\mathrm{d}$ transitions with $\Delta L=0$ are indeed $\mathrm{ED}$-forbidden and $\mathrm{MD}$-allowed. However, pure metalcentered emission in $3 \mathrm{~d}$ coordination complexes, as found in $4 \mathrm{f}$-block analogs, is rare because of the considerable covalencies of the $\mathrm{M}-\mathrm{L}$ bonds that promote mixing with ligand-based wave functions, efficient coupling with vibration modes, and some significant quenching of the luminescence. Regarding this last point, a favorable situation for an emissive $3 \mathrm{~d}$ metal excited level requires (i) a minimum perturbation by the ligand field in order 


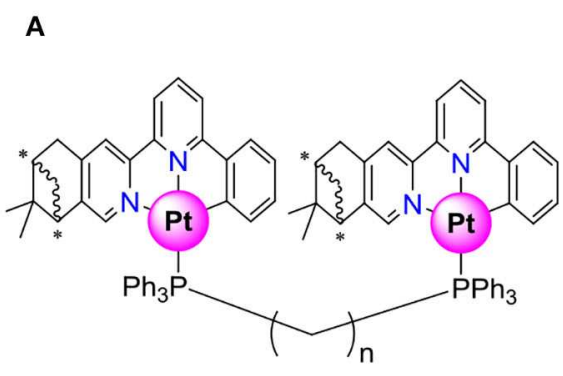

39

$$
\begin{aligned}
& \mathrm{n}=1: \\
& \mathrm{n}=2:
\end{aligned}\left|\begin{array}{l}
g_{\text {lum }} \\
g_{\text {lum }}
\end{array}\right|=5 \times 10^{-3}
$$

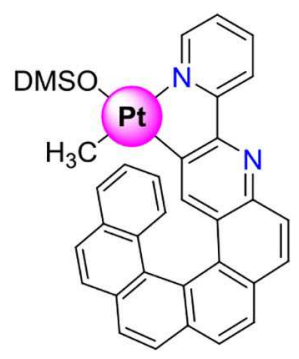

40

Unprotonated:

$P$ - $(+): g_{\text {lum }}=+1.0 \times 10^{-3}$

$M-(-): g_{\text {lum }}=-1.1 \times 10^{-3}$

Protonated:

$P$-(+): $g_{\text {lum }}=+1.8 \times 10^{-3}$

$M-(-): g_{\text {lum }}=-2.2 \times 10^{-3}$

B

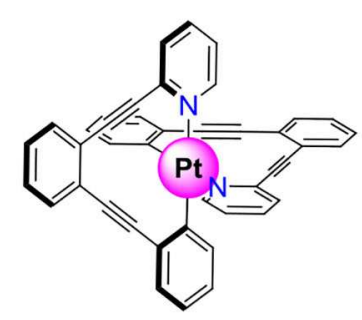

41

$\left|g_{\text {lum }}\right| \sim 10^{-3}$

FIGURE 11 | (A) Pt" complexes showing CPL signals tunable by spacer length (left) or switchable by protonation/deprotonation (right) (Saleh et al., 2015a; Zhang et al., 2018). (B) Ptll cyclometallated complexes holding achiral ligands and showing metal centered chirality (Schulte et al., 2017), and associated dissymmetry factor glum.

to retain the almost pure $\mathrm{d}-\mathrm{d}$ character of the transition and (ii) an important energy gap with upper excited levels in order to prevent deleterious back inter system crossing (BISC). Because of those sophisticated conditions, the use of first-row metals is mainly restricted to closed shell ions with $\mathrm{d}^{10}$ configuration, such as $\mathrm{Zn}{ }^{\mathrm{II}}$ complexes showing ligand-based emission (Isla et al., 2016; Kögel et al., 2016; Aoki et al., 2017; Reiné et al., 2018b; Maeda et al., 2019), or in $\mathrm{Cu}^{\mathrm{I}}$ complexes displaying MLCT emission (Zhang M.-M. et al., 2019; Deng et al., 2020). In the first case, the $\mathrm{Zn}{ }^{\mathrm{II}}$ ions are responsible, upon their coordination to an organic ligand, for conformational changes affecting the optical and chiroptical properties, particularly in the CPL emission. However, $g_{\text {lum }}$ remains low ranging from $10^{-2}$ to $10^{-4}$ as it arises from the organic moiety of the complex. One can note that chiral porphyrin-based ligand platforms have been widely used for such purposes. Interestingly, $\mathrm{Cu}^{\mathrm{I}}$ has been recently exploited for the preparation of enantiopure organometallic complexes based on chiral carbene ligands. These complexes have the advantage of being prepared directly from enantiopure ligands and so there is no need for chiral resolution. However, the highest $g_{\text {lum }}$ value recorded up to now reaches only $10^{-3}$, but this strategy opens a new way to prepare enantiopure complexes based on earthabundant metals acting as CPL emitters.

Significant $g_{\text {lum }}$ enhancement thus requires moving from charge transfer to ED-forbidden/MD-allowed metal-centered transitions operating in $3 \mathrm{~d}$ open-shell metal ions, but only few studies were reported on first-row transition metals, mainly on $\mathrm{Cr}^{\mathrm{III}}$ and once on $\mathrm{Mn}^{\mathrm{II}}$ showing CPL in the solid state (Zhao et al., 2019). Although the use of labile $\mathrm{Mn}^{\mathrm{II}}$ is compatible with chiral induction produced by enantiopure ligands, the ideal metal complexes should be inert enough to tolerate separation techniques, such as chromatogaphy, a criterion only fulfilled with $\mathrm{Co}^{\mathrm{III}}, \mathrm{Fe}^{\mathrm{III}}$, or $\mathrm{Cr}^{\mathrm{III}}$. While the two former ions are known to be non-emissive, $\mathrm{Cr}^{\mathrm{III}}$ complexes are known to show NIR emission in the $600-800 \mathrm{~nm}$ region, arising from the two lowlying $\mathrm{Cr}^{\mathrm{III}}\left({ }^{2} \mathrm{E}\right)$ and $\mathrm{Cr}^{\mathrm{III}}\left({ }^{2} \mathrm{~T}_{1}\right)$ spin-flip excited states (Figure 13) (Jamieson et al., 1981; Kirk, 1981, 1999; Forster, 1990, 2002; Buldt and Wenger, 2017; Otto et al., 2018). In fact, $\mathrm{Cr}^{\mathrm{III}}$ complexes 


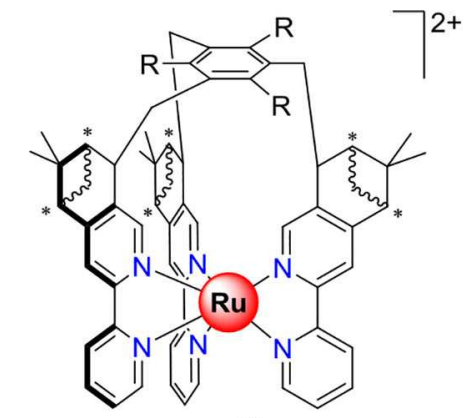

42

$\mathbf{R}=\mathbf{H}:$

$\Delta-(-): g_{\text {lum }}=-7.3 \times 10^{-4}$

$\Lambda$-(+): $g_{\text {lum }}=+7.7 \times 10^{-4}$

$\mathbf{R}=\mathbf{M e}:$

$\Delta-(-): g_{\text {lum }}=-5.3 \times 10^{-4}$

$\Lambda$-(+): $g_{\text {lum }}=+5.5 \times 10^{-4}$

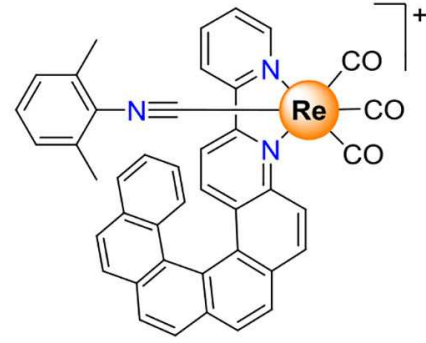

43

$M: g_{\text {lum }}=-1.5 \times 10^{-3}$
$P: g_{\text {lum }}=+1.3 \times 10^{-3}$

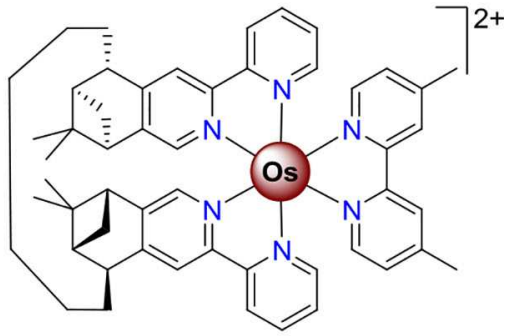

44

FIGURE 12 | Ru" (left) (Oyler et al., 2007), Rel (center) (Saleh et al., 2015b), and Os"l (right) (Gunde et al., 1997) complexes showing CPL, and associated dissymmetry factor glum.

have long been known to exhibit interesting photophysical and photochemical properties as illustrated by the archetypal terbidentate $\left[\mathrm{Cr}(\text { phen })_{3}\right]^{3+}$ (Serpone et al., 1979; Ryu and Endicott, 1988; Isaacs et al., 2006; Donnay et al., 2007; Vandiver et al., 2010; Vasudevan et al., 2010; Doistau et al., 2018, 2020), bisterdentate $\left[\mathrm{Cr}(\mathrm{tpy})_{2}\right]^{3+}$ (Serpone et al., 1979; Scarborough et al., 2012; Constable et al., 2014; Schönle et al., 2015a,b; Barbour et al., 2017), and analogs (Zare et al., 2017b; Jiménez et al., 2018). In all cases, the ligand-field strength induced by the phen and tpy ligands is strong enough to induce near-infrared phosphorescence arising from the lowest-lying $\left.\mathrm{Cr}^{2} \mathrm{~T}_{1}\right)$ and $\mathrm{Cr}\left({ }^{2} \mathrm{E}\right)$ excited states, but the associated very low quantum yields $(<0.2 \%)$ are strong limitations for their use as CPL probes. Thus, much effort was focused on the optimization of the $\mathrm{Cr}^{\mathrm{III}}$ complexes in order to improve their photophysical properties. The introduction of six-membered chelated rings in the terdetante ligands (ddpd $=N, N^{\prime}$-dimethyl- $N, N^{\prime}$-dipyridin2-ylpyridine-2,6-diamine or dqp $=2,6$-di(quinolin-8-yl) ligands) has proven to be an efficient approach to increase both the quantum yield and the lifetimes of the $\operatorname{Cr}\left({ }^{2} \mathrm{~T}_{1}\right)$ and $\mathrm{Cr}\left({ }^{2} \mathrm{E}\right)$ excited states in $\left[\mathrm{Cr}(\mathrm{ddpd})_{2}\right]^{3+}$ and $\left[\mathrm{Cr}(\mathrm{dqp})_{2}\right]^{3+}$ (Otto et al., 2015; Wang et al., 2017; Jiménez et al., 2018, 2019; Treiling et al., 2019).

In the frame of $\mathrm{CPL}, \mathrm{Cr}{ }^{\mathrm{III}}$ complexes holding strong nitrogen donors as ligands are valuable candidates because the energy gap with the upper ligand field state $\left({ }^{4} \mathrm{~T}_{2}\right)$ is large enough to prevent BISC and subsequent quenching (Fucaloro et al., 1983; Doistau et al., 2018; Otto et al., 2018). In addition, the Tanabe-Sugano diagram pertinent to a $\mathrm{d}^{3}$ electronic configuration indicates that the $\mathrm{Cr}^{\mathrm{III}}\left({ }^{2} \mathrm{~T}_{1},{ }^{2} \mathrm{E}\right)$ energy levels are almost insensitive to the ligand field strength, which preserve the ED-forbidden/MD-allowed character of the $\mathrm{Cr}^{\mathrm{III}}\left({ }^{2} \mathrm{~T}_{1},{ }^{2} \mathrm{E} \rightarrow{ }^{4} \mathrm{~A}_{2}\right)$ transitions (Lever, 1984; Zare et al., 2017b; Jiménez et al., 2018). Hence, the $\mathrm{Cr}^{\mathrm{III}} \mathrm{N}_{6}$ complex NIR emission seems to fulfill the established criteria

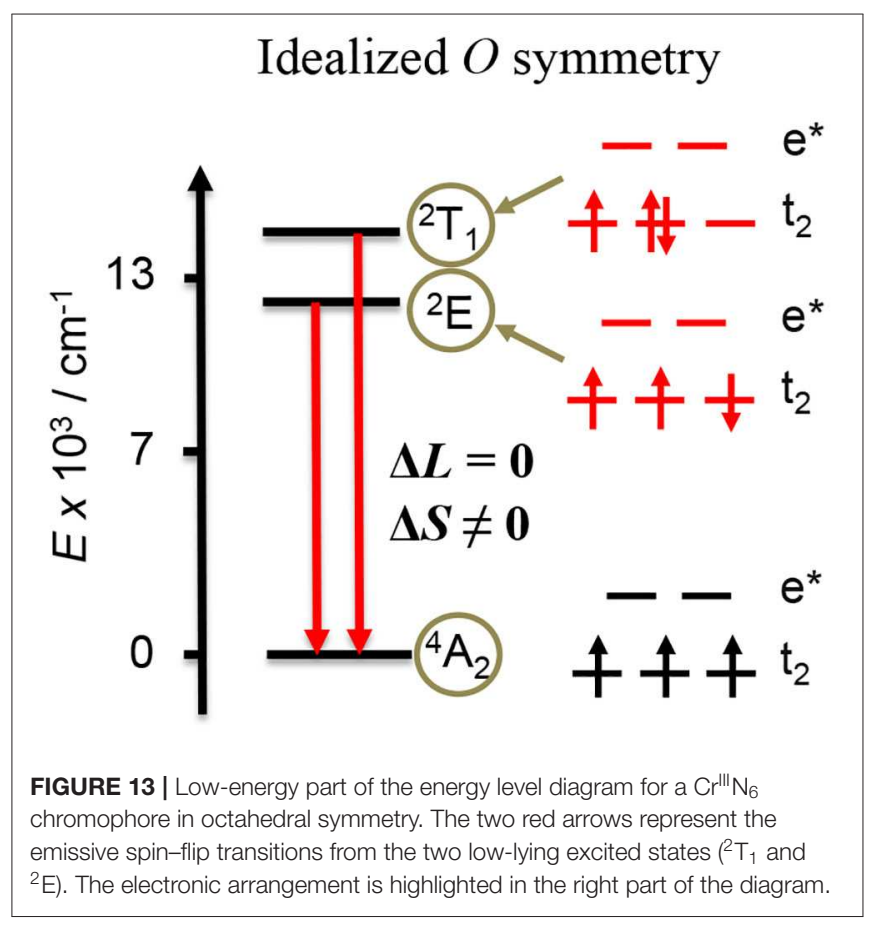

for exhibiting strong CPL with high $g_{\text {lum. }}$. It is however worth stressing here that, although the spin-flip $\mathrm{Cr}{ }^{\mathrm{III}}\left({ }^{2} \mathrm{~T}_{1},{ }^{2} \mathrm{E} \rightarrow{ }^{4} \mathrm{~A}_{2}\right)$ emissive transitions are both strictly Laporte and spin-forbidden, the former rule is released in non-centrosymmetric systems and considerable intensity can be also gained through the vibronic coupling with unsymmetrical modes. Hence, the distortion from a perfect centrosymmetric octahedral should have a deleterious 
effect on the $\mathrm{ED} / \mathrm{MD}$ ratio because of increasing covalence in the $t_{2 g}$ orbitals- $\mathrm{a}$ consequence also triggered by strong $\pi$ interactions and by strong nephelauxetic effect. Finally, the $\mathrm{Cr}^{\mathrm{III}} \mathrm{N}_{6}$ complexes may allow discriminating the contribution of both ligand-field splitting and Racah parameters to the magnitude of $g_{\text {lum }}-$ a feature which remains unexplored. During the early seventies, there was an ephemeral interest for chiral $\mathrm{Cr}^{3+}$ complexes that gave rise to the first reports on the circularly polarized emission arising from first raw transition metal complexes. In their seminal work, Emeis and Oosterhoff reported in 1967 that the simple chiral complexes $\left[\mathrm{Cr}(\mathrm{en})_{3}\right]^{3+}$ (en = ethylenediamine) showed, despite a weak quantum yield, a remarkable $\left|g_{\text {lum }}\right|=0.028$ for the spin-flip $\mathrm{Cr}^{\mathrm{III}}\left({ }^{2} \mathrm{E} \rightarrow{ }^{4} \mathrm{~A}_{2}\right)$ transition (Emeis and Oosterhoff, 1967), a result boosted to 0.046 in an ethylene glycol/water solution by Richardson and coworkers 10 years later (Hilmes et al., 1977). This $\left|g_{\text {lum }}\right|$ value is quite high compared with p-block systems and with $4 \mathrm{~d}$ - and 5d-block-based complexes, which confirms the potential of $\mathrm{Cr}^{\mathrm{II}}$ ions for inducing large $g_{\text {lum }}$. Despite those promising results, only scarce studies focused on $\mathrm{Cr}^{\mathrm{III}}$ complexes reported $\mathrm{CPL}$ measurements in condensed phases (Manson and Shah, 1977; Yamaga et al., 1990; Nobuhiro et al., 2001; Anzai et al., 2003, 2006; Seyler et al., 2018), or in solution except for some triple helical complexes $\left[\mathrm{Cr}(\mathrm{en})_{3}\right]^{3+}$ (Madaras and Brittain, 1980; Morita et al., 1984; Herren et al., 1996), $\left[\mathrm{Cr}(\mathrm{ox})_{3}\right]^{3+}$ (ox = oxalate) (Herren et al., 1996), $\left[\mathrm{Cr}(\mathrm{pn})_{3}\right]^{3+}(\mathrm{pn}=1,2$-propanediamine) (Morita et al., 1984; Herren et al., 1996), and [Cr(ala) 3 ] (ala = alaninato) (Tsubomura et al., 1988; Taro et al., 1991).

In 2001, Piguet and coworkers took advantage of the $\mathrm{Cr}$ complex inertness to prepare and resolve the enantiomerically pure triple-stranded helicates $\left[\operatorname{LnCr}(\mathbf{L} 9)_{3}\right]^{6+}$ (e.g., $\left.\mathrm{Ln}=\mathrm{Eu}, \mathrm{Tb}\right)$ (Figure 14A) which revealed $\mathrm{Cr}^{\mathrm{III}}$-centered polarized emission arising from the spin-flip $\mathrm{Cr}^{\mathrm{III}}\left({ }^{2} \mathrm{E} \rightarrow{ }^{4} \mathrm{~A}_{2}\right)$ transition with a $\left|g_{1 \text { um }}\right|$ of 0.01 at $744 \mathrm{~nm}$ (Cantuel et al., 2004). More recently, the chiral resolution of the cationic kinetically inert $\left[\mathrm{Cr}(\mathrm{dqp})_{2}\right]^{3+}$ complex $(\mathrm{dqp}=2,6-\operatorname{di}($ quinolin-8-yl $)$ ) displaying extraordinary dual CPL emission was achieved. The wrapped arrangement of the dqp ligand around the $\mathrm{Cr}^{\mathrm{III}}$ provides a helical configuration which generates a chiral bisterdentate monometallic $\mathrm{Cr}^{\mathrm{III}}$ helix as a racemic mixture. The two enantiomers $P P$ - $\left[\mathrm{Cr}(\mathrm{dqp})_{2}\right]^{3+}$ and $M M-\left[\mathrm{Cr}(\mathrm{dqp})_{2}\right]^{3+}$ (Figure 14C) were separated by chromatography and isolated by cation exchange. The CPL spectra recorded in $\mathrm{CH}_{3} \mathrm{CN}$ solutions showed two polarized emission bands at $724 \mathrm{~nm}$ and $747 \mathrm{~nm}$ corresponding to the spin-flip $\mathrm{Cr}^{\mathrm{III}}\left({ }^{2} \mathrm{~T}_{1} \rightarrow{ }^{4} \mathrm{~A}_{2}\right)$ and $\mathrm{Cr}{ }^{\mathrm{III}}\left({ }^{2} \mathrm{E} \rightarrow{ }^{4} \mathrm{~A}_{2}\right)$ transitions with $g_{\text {lum }}$ values of \pm 0.1 and \pm 0.2 , respectively (Jiménez et al., 2019). These values are the highest reported up to date for any transition metal complex, and they are comparable to those found in chiral lanthanide-based $f-f$ complexes. Subsequently, Heinze and coworkers were able to partially resolve the chiral complex $\left[\mathrm{Cr}(\mathrm{ddpd})_{2}\right]^{3+}$ by HPLC (Figure 14B). CPL measurements displayed $g_{\text {lum }}$ values as high as 0.098 for the $\mathrm{Cr}^{\mathrm{III}}\left({ }^{2} \mathrm{E} \rightarrow{ }^{4} \mathrm{~A}_{2}\right)$ transition (Dee et al., 2019).

Interestingly, the $\left[\mathrm{EuCr}(\mathbf{L} 9)_{3}\right]^{6+}$ and $\left[\mathrm{Cr}(\mathrm{en})_{3}\right]^{3+}$ complexes, which show intrinsic chirality of the $\mathrm{CrN}_{6}$ coordination sphere due to $\mathrm{D}_{3}$ local symmetry, display $g_{\text {lum }}$ significantly lower than the $\left[\mathrm{Cr}(\mathrm{dqp})_{2}\right]^{3+}$ and $\left[\mathrm{Cr}(\mathrm{ddpd})_{2}\right]^{3+}$ complexes where their chirality arises from the helical disposition of the coordination ligands and not from the metal environment. The latter feature highlights the efficiency of the DC mechanism compared to SC. Nevertheless, the distortion from perfect octahedral can be also incriminated since it reduces the pure metal character of the $t_{2 g}$ orbitals in the $D_{3}$ symmetric coordination sphere holding five-membered chelate rings, while the $\left[\mathrm{Cr}(\mathrm{dqp})_{2}\right]^{3+}$ and $\left[\mathrm{Cr}(\mathrm{ddpd})_{2}\right]^{3+}$ complexes show a nearly undistorted octahedral first-coordination sphere (Perkovic et al., 1991). Finally, the importance for strong CPL due to a helical wrapping of the ligands around the metal should not be underestimated.

In summary, binding semirigid achiral bis six-membered chelate rings (dqp or ddpd) to form helical $\mathrm{Cr}^{\mathrm{III}}$ complexes and further chiral resolution to generate enantiopure samples makes these systems promising candidates for working as

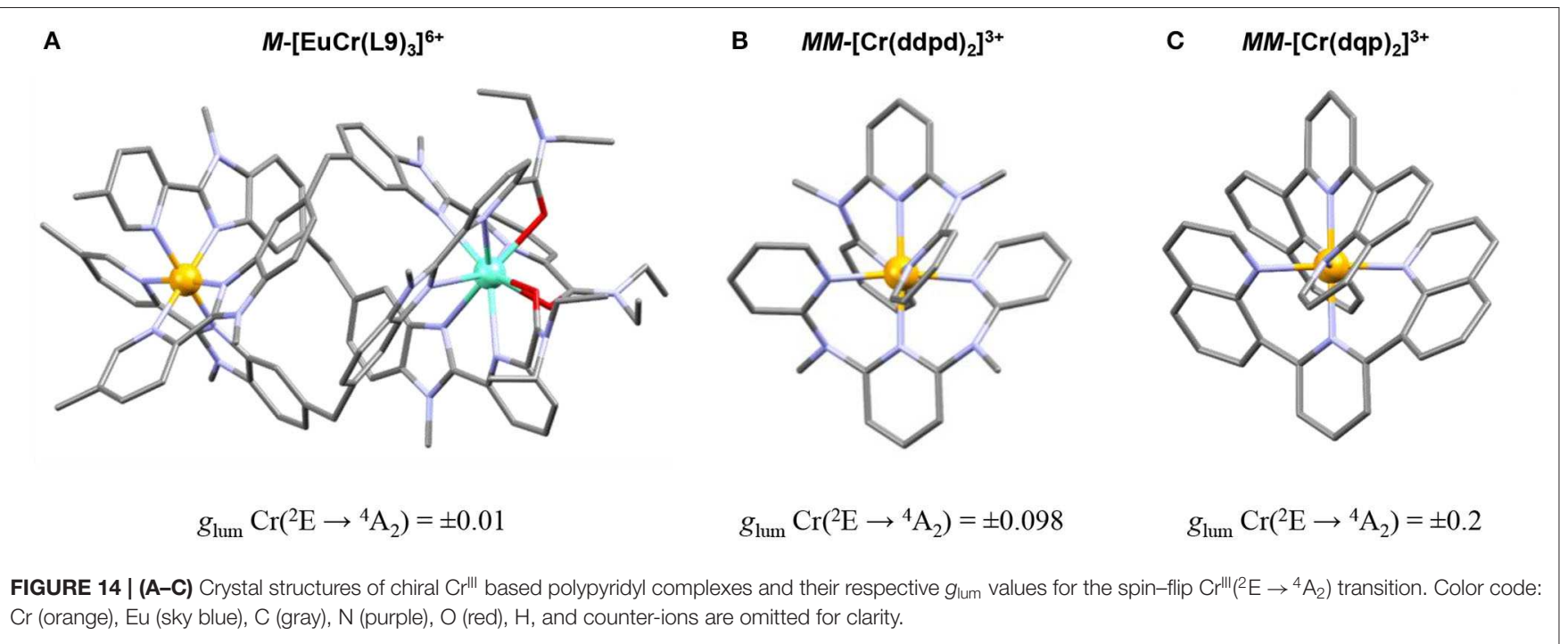


NIR CPL emitters. In these conditions, this earth-abundant metal could become a good competitor to rare earths for chiroptical applications.

\section{CONCLUSION}

Since the beginning of the twenty-first century, increasing efforts have been devoted to the synthesis of molecules or materials

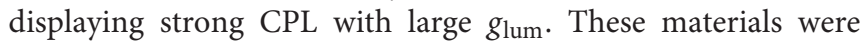
found appealing for the design of devices, such as CP-OLEDs, the brightness of which can be enhanced compared with their linearly polarized counterparts, or for bio-imaging because of the lower scattering of the circularly polarized light. In terms of processability and adaptability to specific applications, the kinetically inert organic chromophores, as well as $4 \mathrm{~d}$ and $5 \mathrm{~d}$ coordination complexes, were systematically exploited despite the rather weak dissymmetry factors $\left(g_{\text {lum }}<7 \times 10^{-2}\right)$ associated with electric dipole allowed $\pi \rightarrow \pi^{*}$ and charge transfer transitions. Chiral single-wall carbon nano-ring and $\mathrm{Pt}^{\mathrm{II}}$-helicene complexes have been shown to exhibit the largest $g_{\text {lum }}$ and $g_{\text {el }}$ within that family of CPL materials. Improving $g_{\text {lum }}$ requires ED-forbidden/MD-allowed transition; thus, pure metal-centered transitions $(\Delta L=0)$ are probably the best choice. In this context, the $\mathrm{f}-\mathrm{f}$ transitions benefit from low covalence due to the inner character of the f orbitals, which are responsible for weak crystal field splittings $\left(100-1,000 \mathrm{~cm}^{-1}\right)$ and almost pure intrashell character for the $f-f$ transitions. Because of the strong spin-orbit coupling, all $\mathrm{f}-\mathrm{f}$ transitions are not equally promising for displaying large $g_{\text {lum }}$ and the target MDallowed transitions obey specific selection rules applied on $\Delta J$ values. A large number of chiral lanthanide complexes showing important dissymmetric factors in the range $0.01-2$ have been reported with a record value of 1.38 at $595 \mathrm{~nm}$ for a europium complex. Nevertheless, the costly lanthanides metals and the kinetic lability of most of $\mathrm{Ln}^{\mathrm{III}}$-based complexes are severe drawbacks for the preparation of inert enantiopure complexes and their subsequent applications in material science. In order to combine large $g_{\text {lum }}$, kinetic inertness, and low cost, some $3 \mathrm{~d}$ metal complexes represent a valuable alternative since the $\mathrm{d}-\mathrm{d}$ transitions should display similar advantages as those described for $\mathrm{f}-\mathrm{f}$, except that they suffer from more important covalence and vibronic coupling. In particular, some $\mathrm{Cr}^{\mathrm{III}}$ inert complexes have been shown to be compatible with enantiomeric resolution and strong CPL emission due to the spin-flip $\mathrm{Cr}^{\mathrm{III}}\left({ }^{2} \mathrm{~T}_{1},{ }^{2} \mathrm{E}\right.$

\section{REFERENCES}

Aime, S., Barge, A., Bruce, J. I., Botta, M., Howard, J. A. K., Moloney, J. M., et al. (1999). NMR, relaxometric, and structural studies of the hydration and exchange dynamics of cationic lanthanide complexes of macrocyclic tetraamide ligands. J. Am. Chem. Soc. 121, 5762-5771. doi: 10.1021/ja990225d

Anzai, N., Kurihara, H., Sone, M., Furukawa, H., Watanabe, T., Horie, K., et al. (2006). Light-induced formation of curved needle texture by circularly polarized light irradiation on a discotic liquid crystal containing a racemic chromium complex. Liq. Cryst. 33, 671-679. doi: 10.1080/02678290600647998

Anzai, N., Machida, S., and Horie, K. (2003). Light-induced control of textures and cholesteric pitch in liquid crystals containing chromium complexes, $\left.\rightarrow{ }^{4} \mathrm{~A}_{2}\right)$ transitions. The pure $\mathrm{d}-\mathrm{d}$ character of the latter transitions is respected as long as the $\mathrm{Cr}^{\mathrm{III}}$ coordination sphere is close to a perfect octahedron (no distortion) - a geometry observed for the $\left[\mathrm{Cr}(\mathrm{dqp})_{2}\right]^{3+}$ complex which possesses the record $g_{\text {lum }}$ value of 0.2 within the family of transition metal complexes. Although a deep theoretical understanding of the $g_{\text {lum }} /$ structure relationship remains somehow elusive, this review dealing with CPL emitters allows the identification of empirical strategies for inducing large $g_{\text {lum }}$. Firstly, the SC mechanism induced by the intrinsic chirality of the chromophore does not provide the strongest CPL signals. On the contrary, introducing chirality on an aside moiety provides efficient DC mechanism, which has been proven to be an efficient tool for inducing important $g_{\text {lum }}$-an effect often enhanced when the number of stereogenic moieties increases. Secondly, the favorable MD transition can be enhanced upon implementing (i) helicity via aggregate formation or helical ligand coordination/wrapping or (ii) circular skeleton permitting current loop. Finally, in chiral coordination complexes, it is important to reduce the covalence and the mixing of the metal/ligand wave functions in order to retain the Laporte rule $(\Delta L=0)$ which controls the intensity of ED and MD transitions. This latter feature is fulfilled for (i) f-f transitions in weak crystal field complexes and for (ii) $\mathrm{d}$-d transitions operating on in close-to perfect centrosymmetrical complexes.

\section{AUTHOR CONTRIBUTIONS}

$\mathrm{BD}$ and J-RJ equally contributed to both bibliography and writing of the manuscript. CP got the financial support for the project, supervised the research group, and corrected the manuscript. All authors contributed to the article and approved the submitted version.

\section{FUNDING}

This work was financially supported by the University of Geneva and by the Swiss National Science Foundation (grant numbers 200020_178758 and 206021_183324).

\section{ACKNOWLEDGMENTS}

CP thanks Professor Oliver Wenger (University of Basel) for fruitful discussions. by means of circular and linear polarized light. Liq. Cryst. 30, 359-366. doi: 10.1080/0267829031000083740

Aoki, R., Toyoda, R., Kögel, J. F., Sakamoto, R., Kumar, J., Kitagawa, Y., et al. (2017). Bis(dipyrrinato)zinc(II) complex chiroptical wires: exfoliation into single strands and intensification of circularly polarized luminescence. J. Am. Chem. Soc. 139, 16024-16027. doi: 10.1021/jacs.7b07077

Ashizawa, M., Yang, L., Kobayashi, K., Sato, H., Yamagishi, A., Okuda, F., et al. (2009). Syntheses and photophysical properties of optical-active bluephosphorescent iridium complexes bearing asymmetric tridentate ligands. Dalton Trans. 2009, 1700-1702. doi: 10.1039/B820821M

Aspinall, H. C. (2002). Chiral lanthanide complexes: coordination chemistry and applications. Chem. Rev. 102, 1807-1850. doi: 10.1021/cr010288q 
Barbour, J. C., Kim, A. J. I., deVries, E., Shaner, S. E., and Lovaasen, B. M. (2017). Chromium(III) bis-arylterpyridyl complexes with enhanced visible absorption via incorporation of intraligand charge-transfer transitions. Inorg. Chem. 56, 8212-8222. doi: 10.1021/acs.inorgchem.7b00953

Barron, L. D. (2008). Chirality and life. Space Sci. Rev. 135, 187-201. doi: 10.1007/s11214-007-9254-7

Beeby, A., Dickins, R. S., FitzGerald, S., Govenlock, L. J., Maupin, C. L., Parker, D., et al. (2000). Porphyrin sensitization of circularly polarised near-IR lanthanide luminescence: enhanced emission with nucleic acid binding. Chem. Commun. 2000, 1183-1184. doi: 10.1039/B002452J

Benincori, T., Appoloni, G., Mussini, P. R., Arnaboldi, S., Cirilli, R., Quartapelle Procopio, E., et al. (2018). Searching for models exhibiting high circularly polarized luminescence: electroactive inherently chiral oligothiophenes. Chem. Eur. J. 24, 11082-11093. doi: 10.1002/chem.201801158

Berova, N., Bari, L. D., and Pescitelli, G. (2007). Application of electronic circular dichroism in configurational and conformational analysis of organic compounds. Chem. Soc. Rev. 36, 914-931. doi: 10.1039/B515476F

Beychok, S. (1968). Rotatory dispersion and circular dichroism. Annu. Rev. Biochem. 37, 437-462. doi: 10.1146/annurev.bi.37.070168.002253

Biet, T., Cauchy, T., Sun, Q., Ding, J., Hauser, A., Oulevey, P., et al. (2017). Triplet state CPL active helicene-dithiolene platinum bipyridine complexes. Chem. Commun. 53, 9210-9213. doi: 10.1039/C7CC05198K

Bing, T. Y., Kawai, T., and Yuasa, J. (2018). Ligand-to-ligand interactions that direct formation of D2-symmetrical alternating circular helicate. J. Am. Chem. Soc. 140, 3683-3689. doi: 10.1021/jacs.7b12663

Bonsall, S. D., Houcheime, M., Straus, D. A., and Muller, G. (2007). Optical isomers of $N, N^{\prime}$-bis(1-phenylethyl)-2,6-pyridinedicarboxamide coordinated to europium(iii) ions as reliable circularly polarized luminescence calibration standards. Chem. Commun. 2007, 3676-3678. doi: 10.1039/B704346E

Bozoklu, G., Gateau, C., Imbert, D., Pécaut, J., Robeyns, K., Filinchuk, Y., et al. (2012). Metal-controlled diastereoselective self-assembly and circularly polarized luminescence of a chiral heptanuclear europium wheel. J. Am. Chem. Soc. 134, 8372-8375. doi: 10.1021/ja3020814

Bradberry, S. J., Savyasachi, A. J., Peacock, R. D., and Gunnlaugsson, T. (2015). Quantifying the formation of chiral luminescent lanthanide assemblies in an aqueous medium through chiroptical spectroscopy and generation of luminescent hydrogels. Faraday Discuss. 185, 413-431. doi: 10.1039/C5FD00105F

Brandt, J. R., Salerno, F., and Fuchter, M. J. (2017). The added value of small-molecule chirality in technological applications. Nat. Rev. Chem. 1:45. doi: 10.1038/s41570-017-0045

Brandt, J. R., Wang, X., Yang, Y., Campbell, A. J., and Fuchter, M. J. (2016). Circularly polarized phosphorescent electroluminescence with a high dissymmetry factor from PHOLEDs based on a platinahelicene. J. Am. Chem. Soc. 138, 9743-9746. doi: 10.1021/jacs.6b02463

Browne, W. R., and Feringa, B. L. (eds.). (2011). "Chiroptical molecular switches," in Molecular Switches (Wiley-VCH Verlag GmbH \& Co. KGaA), 121-179. doi: 10.1002/9783527634408.ch5

Buldt, L. A., and Wenger, O. S. (2017). Chromium complexes for luminescence, solar cells, photoredox catalysis, upconversion, and phototriggered NO release. Chem. Sci. 8, 7359-7367. doi: 10.1039/C7SC03372A

Cantuel, M., Bernardinelli, G., Muller, G., Riehl, J. P., and Piguet, C. (2004). The first enantiomerically pure helical noncovalent tripod for assembling nine-coordinate lanthanide(III) podates. Inorg. Chem. 43, 1840-1849. doi: 10.1021/ic035292u

Caporale, C., and Massi, M. (2018). Cyclometalated iridium(III) complexes for life science. Coord. Chem. Rev. 363, 71-91. doi: 10.1016/j.ccr.2018.02.006

Carr, R., Evans, N. H., and Parker, D. (2012). Lanthanide complexes as chiral probes exploiting circularly polarized luminescence. Chem. Soc. Rev. 41, 7673-7686. doi: 10.1039/C2CS35242G

Casanovas, B., Zinna, F., Di Bari, L., El Fallah, M. S., Font-Bardía, M., and Vicente, R. (2017). Circularly polarized luminescence on dinuclear $\mathrm{Tb}$ (iii) and Eu(iii) complexes with (S-) and (R-) 2-phenylpropionate. Dalton Trans. 46, 6349-6357. doi: 10.1039/C6DT04686J

Chambron, J.-C., Dietrich-Buchecker, C., and Sauvage, J.-P. (1993). "From classical chirality to topologically chiral catenands and knots," in Supramolecular Chemistry I - Directed Synthesis and Molecular Recognition, eds J. Canceill, J.-C. Chambron, A. Collet, Ch. Dietrich-Buchecker, H. D. Durst, J.-P. Dutasta,
F. H. Kohnke, B. Lozach, J.-P. Mathias, S. Misumi, J.-P. Sauvage, J. F. Stoddart, D. A. Tomalia, and S. C. Zimmerman (Berlin; Heidelberg: Springer), 131-162. doi: $10.1007 / \mathrm{BFb} 0111283$

Chen, N., and Yan, B. (2018). Recent theoretical and experimental progress in circularly polarized luminescence of small organic molecules. Molecules 23:3376. doi: 10.3390/molecules23123376

Constable, E. C., Housecroft, C. E., Neuburger, M., Schonle, J., and Zampese, J. A. (2014). The surprising lability of bis $\left(2,2^{\prime}: 6^{\prime}, 2^{\prime \prime}\right.$-terpyridine)chromium(iii) complexes. Dalton Trans. 43, 7227-7235. doi: 10.1039/C4DT00200H

Cotter, D., Dodder, S., Klimkowski, V. J., and Hopkins, T. A. (2019). Circularly polarized luminescence of Sm (III) and Eu (III) complexes with chiral ligand (R/S)-BINAPO. Chirality 31, 301-311. doi: 10.1002/chir.23056

Coughlin, F. J., Westrol, M. S., Oyler, K. D., Byrne, N., Kraml, C., ZysmanColman, E., et al. (2008). Synthesis, separation, and circularly polarized luminescence studies of enantiomers of iridium(III) luminophores. Inorg. Chem. 47, 2039-2048. doi: 10.1021/ic701747j

Crassous, J. (2009). Chiral transfer in coordination complexes: towards molecular materials. Chem. Soc. Rev. 38, 830-845. doi: 10.1039/B806203J

Crassous, J. (2012). Transfer of chirality from ligands to metal centers: recent examples. Chem. Commun. 48, 9687-9695. doi: 10.1039/C2CC31542D

Dai, L., Lo, W.-S., Coates, I. D., Pal, R., and Law, G.-L. (2016). New class of bright and highly stable chiral cyclen europium complexes for circularly polarized luminescence applications. Inorg. Chem. 55, 9065-9070. doi: 10.1021/acs.inorgchem.6b01546

Dai, L., Zhang, J., Chen, Y., Mackenzie, L. E., Pal, R., and Law, G.-L. (2019). Synthesis of water-soluble chiral DOTA lanthanide complexes with predominantly twisted square antiprism isomers and circularly polarized luminescence. Inorg. Chem. 58, 12506-12510. doi: 10.1021/acs.inorgchem.9b01799

Dee, C., Zinna, F., Kitzmann, W. R., Pescitelli, G., Heinze, K., Di Bari, L., et al. (2019). Strong circularly polarized luminescence of an octahedral chromium(iii) complex. Chem. Commun. 55, 13078-13081. doi: 10.1039/C9CC06909G

Deng, M., Mukthar, N. F. M., Schley, N. D., and Ung, G. (2020). Yellow circularly polarized luminescence from C1-symmetrical copper(I) complexes. Angew. Chem. Int. Ed. 59, 1228-1231. doi: 10.1002/anie.201913672

Dhbaibi, K., Favereau, L., and Crassous, J. (2019). Enantioenriched helicenes and helicenoids containing main-group elements (B, Si, N, P). Chem. Rev. 119, 8846-8953. doi: 10.1021/acs.chemrev.9b00033

Di Pietro, S., and Di Bari, L. (2012). The structure of MLn(hfbc)4 and a key to high circularly polarized luminescence. Inorg. Chem. 51, 12007-12014. doi: 10.1021/ic3018979

Dickins, R. S., Howard, J. A. K., Lehmann, C. W., Moloney, J., Parker, D., and Peacock, R. D. (1997). Structural rigidity and luminescence of chiral lanthanide tetraamide complexes based on 1,4,7,10tetraazacyclododecane. Angew. Chem. Int. Ed. 36, 521-523. doi: 10.1002/anie. 199705211

Dickins, R. S., Howard, J. A. K., Maupin, C. L., Moloney, J. M., Parker, D., Riehl, J. P., et al. (1999). Synthesis, time-resolved luminescence, NMR spectroscopy, circular dichroism and circularly polarised luminescence studies of enantiopure macrocyclic lanthanide tetraamide complexes. Chem. Eur. J. 5, 1095-1105. doi: 10.1002/(sici)1521-3765(19990301)5:3 < 1095::aid-chem1095>3.0.co;2-c

Doistau, B., Collet, G., Bolomey, E. A., Sadat-Noorbakhsh, V., Besnard, C., and Piguet, C. (2018). Heteroleptic ter-bidentate Cr(III) complexes as tunable optical sensitizers. Inorg. Chem. 57, 14362-14373. doi: 10.1021/acs.inorgchem.8b02530

Doistau, B., Jiménez, J.-R., Guerra, S., Besnard, C., and Piguet, C. (2020). Key strategy for the rational incorporation of long-lived NIR emissive Cr(III) chromophores into polymetallic architectures. Inorg. Chem. 59, 1424-1435. doi: 10.1021/acs.inorgchem.9b03163

Donnay, E. G., Schaeper, J. P., Brooksbank, R. D., Fox, J. L., Potts, R. G., Davidson, R. M., et al. (2007). Synthesis and characterization of tris(heteroleptic) diimine complexes of chromium(III). Inorg. Chim. Acta 360, 3272-3280. doi: 10.1016/j.ica.2007. 03.055

Eliseeva, S. V., and Bünzli, J.-C. G. (2010). Lanthanide luminescence for functional materials and bio-sciences. Chem. Soc. Rev. 39, 189-227. doi: 10.1039/B905604C 
Emeis, C. A., and Oosterhoff, L. J. (1967). Emission of circularly-polarised radiation by optically-active compounds. Chem. Phys. Lett. 1, 129-132. doi: 10.1016/0009-2614(67)85007-3

Feringa, B. L. (2007). The art of building small: from molecular switches to molecular motors. J. Org. Chem. 72, 6635-6652. doi: 10.1021/jo070394d

Feringa, B. L., van Delden, R. A., Koumura, N., and Geertsema, E. M. (2000). Chiroptical molecular switches. Chem. Rev. 100, 1789-1816. doi: $10.1021 /$ cr9900228

Flamigni, L., Barbieri, A., Sabatini, C., Ventura, B., and Barigelletti, F. (2007). "Photochemistry and photophysics of coordination compounds: iridium," in Photochemistry and Photophysics of Coordination Compounds II, eds V. Balzani and S. Campagna (Berlin; Heidelberg: Springer Berlin Heidelberg), 143-203. doi: 10.1007/128_2007_131

Forster, L. S. (1990). The photophysics of chromium(III) complexes. Chem. Rev. 90, 331-353. doi: 10.1021/cr00100a001

Forster, L. S. (2002). Thermal relaxation in excited electronic states of $\mathrm{d} 3$ and $\mathrm{d} 6$ metal complexes. Coord. Chem. Rev. 227, 59-92. doi: $10.1016 /$ S0010-8545(01)00458-1

Fu, H. L.-K., Po, C., He, H., Leung, S. Y.-L., Wong, K. S., and Yam, V. W.-W. (2016). Tuning of supramolecular architectures of l-valinecontaining dicyanoplatinum(II) $2,2^{\prime}$-bipyridine complexes by metal-metal, $\pi$ $\pi$ stacking, and hydrogen-bonding interactions. Chem. Eur. J. 22, 11826-11836. doi: $10.1002 /$ chem. 201601983

Fucaloro, A. F., Forster, L. S., Rund, J. V., and Lin, S. H. (1983). 2E relaxation in mixed-ligand $\mathrm{Cr}(\mathrm{NH} 3) 6-\mathrm{nXn}$ complexes. J. Phys. Chem. 87, 1796-1799. doi: $10.1021 / \mathrm{j} 100233 \mathrm{a} 028$

Gálico, D. A., Marin, R., Brunet, G., Errulat, D., Hemmer, E., Sigoli, F. A., et al. (2019). Triplet-state position and crystal-field tuning in optomagnetic lanthanide complexes: two sides of the same coin. Chem. Eur. J. 25, 14625-14637. doi: 10.1002/chem.201902837

Gao, X., Qin, X., Yang, X., Li, Y., and Duan, P. (2019). (R)-Binaphthyl derivatives as chiral dopants: substituent position controlled circularly polarized luminescence in liquid crystals. Chem. Commun. 55, 5914-5917. doi: 10.1039/C9CC02253H

Gauthier, E. S., Abella, L., Hellou, N., Darquié, B., Caytan, E., Roisnel, T., et al. (2020). Long-lived circularly polarized phosphorescence in heliceneNHC rhenium(i) complexes: the influence of helicene, halogen, and stereochemistry on emission properties. Angew. Chem. Int. Ed. 59, 8394-8400. doi: 10.1002/ange.2020023878394

Gendron, F., Moore Ii, B., Cador, O., Pointillart, F., Autschbach, J., and Le Guennic, B. (2019). Ab initio study of circular dichroism and circularly polarized luminescence of spin-allowed and spin-forbidden transitions: from organic ketones to lanthanide complexes. J. Chem. Theory Comput. 15, 4140-4155. doi: 10.1021 /acs.jctc. 9 b00286

Geng, Y., Trajkovska, A., Culligan, S. W., Ou, J. J., Chen, H. M. P., Katsis, D., et al. (2003). Origin of strong chiroptical activities in films of nonafluorenes with a varying extent of pendant chirality. J. Am. Chem. Soc. 125, 14032-14038. doi: $10.1021 / \mathrm{ja} 037733 \mathrm{e}$

Gilot, J., Abbel, R., Lakhwani, G., Meijer, E. W., Schenning, A. P. H. J., and Meskers, S. C. J. (2010). Polymer photovoltaic cells sensitive to the circular polarization of light. Adv. Mater. 22, E131-E134. doi: 10.1002/adma.200903995

Golesorkhi, B., Guénée, L., Nozary, H., Fürstenberg, A., Suffren, Y., Eliseeva, S. V., et al. (2018). Thermodynamic programming of erbium(III) coordination complexes for dual visible/near-infrared luminescence. Chem. Eur. J. 24, 13158-13169. doi: 10.1002/chem. 201802277

Górecki, M., Carpita, L., Arrico, L., Zinna, F., and Di Bari, L. (2018). Chiroptical methods in a wide wavelength range for obtaining Ln3+ complexes with circularly polarized luminescence of practical interest. Dalton Trans. 47, 7166-7177. doi: 10.1039/ C8DT00865E

Goto, H. (2018). Liquid crystal auto-induction and amplification function for circularly polarized luminescence (CPL) with high gem-value, and dynamically controllable CPL devices. Mol. Cryst. Liq. Cryst. 669, 27-35. doi: 10.1080/15421406.2019.1569355

Gregolinski, J., Starynowicz, P., Hua, K. T., Lunkley, J. L., Muller, G., and Lisowski, J. (2008). Helical lanthanide(III) complexes with chiral nonaaza macrocycle. J. Am. Chem. Soc. 130, 17761-17773. doi: 10.1021/ja805033j
Guerchais, V., and Fillaut, J.-L. (2011). Sensory luminescent iridium(III) and platinum(II) complexes for cation recognition. Coord. Chem. Rev. 255, 2448-2457. doi: 10.1016/j.ccr.2011.04.006

Gunde, K. E., Credi, A., Jandrasics, E., von Zelewsky, A., and Richardson, F. S. (1997). Chiroptical absorption and luminescence spectra of a dissymmetric osmium(II)-polypyridyl complex containing an optically active bis(bipyridine)-type ligand of well-defined structural chirality. Inorg. Chem. 36, 426-434. doi: 10.1021/ic9609012

Han, J., Duan, P., Li, X., and Liu, M. (2017a). Amplification of circularly polarized luminescence through triplet-triplet annihilation-based photon upconversion. J. Am. Chem. Soc. 139, 9783-9786. doi: 10.1021/jacs.7b04611

Han, J., Guo, S., Lu, H., Liu, S., Zhao, Q., and Huang, W. (2018). Recent progress on circularly polarized luminescent materials for organic optoelectronic devices. Adv. Opt. Mater. 6:1800538. doi: 10.1002/adom.201800538

Han, J., Guo, S., Wang, J., Wei, L., Zhuang, Y., Liu, S., et al. (2017b). Circularly polarized phosphorescent electroluminescence from chiral cationic iridium(III) isocyanide complexes. Adv. Opt. Mater. 5:1700359. doi: 10.1002/adom.201700359

Harada, T., Nakano, Y., Fujiki, M., Naito, M., Kawai, T., and Hasegawa, Y. (2009). Circularly polarized luminescence of $\mathrm{Eu}(\mathrm{III})$ complexes with pointand axis-chiral ligands dependent on coordination structures. Inorg. Chem. 48, 11242-11250. doi: 10.1021/ic901663w

Hasenknopf, B., Micoine, K., Lacôte, E., Thorimbert, S., Malacria, M., and Thouvenot, R. (2008). Chirality in polyoxometalate chemistry. Eur. J. Inorg. Chem. 2008, 5001-5013. doi: 10.1002/ejic.200800759

Hellou, N., Srebro-Hooper, M., Favereau, L., Zinna, F., Caytan, E., Toupet, L., et al. (2017). Enantiopure cycloiridiated complexes bearing a pentahelicenic N-heterocyclic carbene and displaying long-lived circularly polarized phosphorescence. Angew. Chem. Int. Ed. 56, 8236-8239. doi: 10.1002/anie.201704263

Hembury, G. A., Borovkov, V. V., and Inoue, Y. (2008). Chirality-sensing supramolecular systems. Chem. Rev. 108, 1-73. doi: 10.1021/cr050005k

Herren, M., Horikoshi, H., and Morita, M. (1996). Photoluminescence of enantio-selectively formed chromium(III) double salts. Mol. Cryst. Liq. Cryst. Sci. Technol. A 286, 251-256. doi: 10.1080/105872596 08042294

Hilmes, G. L., Brittain, H. G., and Richardson, F. S. (1977). Optical activity of the 4A2.tautm. 2E transition in chromium(en)33+. Inorg. Chem. 16, 528-533. doi: 10.1021/ic50169a005

Huck, N. P. M., Jager, W. F., de Lange, B., and Feringa, B. L. (1996). Dynamic control and amplification of molecular chirality by circular polarized light. Science 273, 1686-1688. doi: 10.1126/science.273. 5282.1686

Ikeda, T., Hirano, K., and Haino, T. (2018). A circularly polarized luminescent organogel based on a $\mathrm{Pt}(\mathrm{ii})$ complex possessing phenylisoxazoles. Mater. Chem. Front. 2, 468-474. doi: 10.1039/C7QM00564D

Ikeda, T., Takayama, M., Kumar, J., Kawai, T., and Haino, T. (2015). Novel helical assembly of a $\mathrm{Pt}(\mathrm{ii})$ phenylbipyridine complex directed by metal-metal interaction and aggregation-induced circularly polarized emission. Dalton Trans. 44, 13156-13162. doi: 10.1039/C5DT01284H

Ionescu, A., Godbert, N., Ricciardi, L., La Deda, M., Aiello, I., Ghedini, M., et al. (2017). Luminescent water-soluble cycloplatinated complexes: structural, photophysical, electrochemical and chiroptical properties. Inorg. Chim. Acta 461, 267-274. doi: 10.1016/j.ica.2017. 02.026

Isaacs, M., Sykes, A. G., and Ronco, S. (2006). Synthesis, characterization and photophysical properties of mixed ligand tris(polypyridyl)chromium(III) complexes, $[\mathrm{Cr}(\mathrm{phen}) 2 \mathrm{~L}]^{3+}$. Inorg. Chim. Acta 359, 3847-3854. doi: $10.1016 /$ j.ica.2006.04.036

Isla, H., and Crassous, J. (2016). Helicene-based chiroptical switches. C. R. Chim. 19, 39-49. doi: 10.1016/j.crci.2015.06.014

Isla, H., Srebro-Hooper, M., Jean, M., Vanthuyne, N., Roisnel, T., Lunkley, J. L., et al. (2016). Conformational changes and chiroptical switching of enantiopure bis-helicenic terpyridine upon $\mathrm{Zn}^{2+}$ binding. Chem. Commun. 52, 5932-5935. doi: 10.1039/C6CC01748G

Ito, H., Sakai, H., Okayasu, Y., Yuasa, J., Mori, T., and Hasobe, T. (2018). Significant enhancement of absorption and luminescence dissymmetry factors in the far-red region: a zinc(II) homoleptic helicate formed by a 
pair of achiral dipyrromethene ligands. Chem. Eur. J. 24, 16889-16894. doi: 10.1002/chem.201804171

Jamieson, E. M. G., Modicom, F., and Goldup, S. M. (2018). Chirality in rotaxanes and catenanes. Chem. Soc. Rev. 47, 5266-5311. doi: 10.1039/C8CS00097B

Jamieson, M. A., Serpone, N., and Hoffman, M. Z. (1981). Advances in the photochemistry and photophysics of chromium(iii) polypyridyl complexes in fluid media. Coord. Chem. Rev. 39, 121-179. doi: 10.1016/S0010-8545(00)80513-5

Jiménez, J.-R., Doistau, B., Besnard, C., and Piguet, C. (2018). Versatile heteroleptic bis-terdentate $\mathrm{Cr}(\mathrm{iii})$ chromophores displaying room temperature millisecond excited state lifetimes. Chem. Commun. 54, 13228-13231. doi: 10.1039/C8CC07671E

Jiménez, J.-R., Doistau, B., Cruz, C. M., Besnard, C., Cuerva, J. M., Campaña, A. G., et al. (2019). Chiral molecular ruby $\left[\mathrm{Cr}(\mathrm{dqp})_{2}\right]^{3+}$ with long-lived circularly polarized luminescence. J. Am. Chem. Soc. 141, 13244-13252. doi: $10.1021 /$ jacs.9b06524

Kapturkiewicz, A. (2016). Cyclometalated iridium(III) chelates-a new exceptional class of the electrochemiluminescent luminophores. Anal. Bioanal. Chem. 408, 7013-7033. doi: 10.1007/s00216-016-9615-8

Kim, B.-C., Choi, H.-J., Lee, J.-J., Araoka, F., and Choi, S.-W. (2019). Circularly polarized luminescence induced by chiral super nanospaces. Adv. Funct. Mater. 29:1903246. doi: 10.1002/adfm.201903246

Kirk, A. D. (1981). Chromium(iii) photochemistry and photophysics. Coord. Chem. Rev. 39, 225-263. doi: 10.1016/S0010-8545(00) 80515-9

Kirk, A. D. (1999). Photochemistry and photophysics of chromium(III) complexes. Chem. Rev. 99, 1607-1640. doi: 10.1021/cr960111

Kitchen, J. A., Barry, D. E., Mercs, L., Albrecht, M., Peacock, R. D., and Gunnlaugsson, T. (2012). Circularly polarized lanthanide luminescence from langmuir-blodgett films formed from optically active and amphiphilic euiii-based self-assembly complexes. Angew. Chem. Int. Ed. 51, 704-708. doi: $10.1002 /$ anie. 201106863

Knof, U., and von Zelewsky, A. (1999). Predetermined chirality at metal centers. Angew. Chem. Int. Ed. 38, 302-322. doi: 10.1002/(sici)15213773(19990201)38:3<302::aid-anie302>3.0.co;2-g

Kögel, J. F., Kusaka, S., Sakamoto, R., Iwashima, T., Tsuchiya, M., Toyoda, R., et al. (2016). Heteroleptic [bis(oxazoline)](dipyrrinato)zinc(II) complexes: bright and circularly polarized luminescence from an originally achiral dipyrrinato ligand. Angew. Chem. Int. Ed. 55, 1377-1381. doi: 10.1002/anie. 201509411

Kono, Y., Hara, N., Shizuma, M., Fujiki, M., and Imai, Y. (2017). Complexes of $\mathrm{Eu}(\mathrm{iii})(\mathrm{hfa}) 3$ with a planar chiral $\mathrm{P}$ (iii) ligand (phanephos): solventsensitive sign inversion of circularly polarised luminescence. Dalton Trans. 46, 5170-5174. doi: 10.1039/C7DT00741H

Kotova, O., Kitchen, J. A., Lincheneau, C., Peacock, R. D., and Gunnlaugsson, T. (2013). Probing the effects of ligand isomerism in chiral luminescent lanthanide supramolecular self-assemblies: a europium "trinity sliotar" study. Chem. Eur. J. 19, 16181-16186. doi: 10.1002/chem.201303660

Kreidt, E., Arrico, L., Zinna, F., Di Bari, L., and Seitz, M. (2018). Circularly polarised luminescence in enantiopure samarium and europium cryptates. Chem. Eur. J. 24, 13556-13564. doi: 10.1002/chem.201802196

Kreidt, E., Dee, C., and Seitz, M. (2017). Chiral resolution of lanthanoid cryptates with extreme configurational stability. Inorg. Chem. 56, 8752-8754. doi: 10.1021/acs.inorgchem.7b01407

Kudernac, T., Ruangsupapichat, N., Parschau, M., Maciá, B., Katsonis, N., Harutyunyan, S. R., et al. (2011). Electrically driven directional motion of a four-wheeled molecule on a metal surface. Nature 479, 208-211. doi: $10.1038 /$ nature 10587

Kumar, J., Kawai, T., and Nakashima, T. (2017). Circularly polarized luminescence in chiral silver nanoclusters. Chem. Commun. 53, 1269-1272. doi: 10.1039/C6CC09476G

Kumar, J., Nakashima, T., and Kawai, T. (2015). Circularly polarized luminescence in chiral molecules and supramolecular assemblies. J. Phys. Chem. Lett. 6, 3445-3452. doi: 10.1021/acs.jpclett.5b01452

Leigh, D. A., and Pérez, E. M. (2006). "Dynamic chirality: molecular shuttles and motors," in Supramolecular Chirality, eds M. Crego-Calama and D. N. Reinhoudt (Berlin; Heidelberg: Springer Berlin Heidelberg), 185-208. doi: 10.1007/128_039
Leonard, J. P., Jensen, P., McCabe, T., O’Brien, J. E., Peacock, R. D., Kruger, P. E., et al. (2007). Self-assembly of chiral luminescent lanthanide coordination bundles. J. Am. Chem. Soc. 129, 10986-10987. doi: 10.1021/ja073049e

Leonzio, M., Melchior, A., Faura, G., Tolazzi, M., Zinna, F., Di Bari, L., et al. (2017). Strongly circularly polarized emission from water-soluble Eu(III)- and $\mathrm{Tb}$ (III)-based complexes: a structural and spectroscopic study. Inorg. Chem. 56, 4413-4421. doi: 10.1021/acs.inorgchem.7b00430

Lever, A. B. P. (1984). Inorganic Electronic Spectroscopy. Weinheim: Elsevier.

Li, L.-P., Yao, S.-Y., Ou, Y.-L., Wei, L.-Q., and Ye, B.-H. (2017). Diastereoselective synthesis and photophysical properties of bis-cyclometalated $\operatorname{Ir}(\mathrm{III})$ stereoisomers with dual stereocenters. Organometallics 36, 3257-3265. doi: 10.1021/acs.organomet.7b00406

Li, T.-Y., Jing, Y.-M., Liu, X., Zhao, Y., Shi, L., Tang, Z., et al. (2015). Circularly polarised phosphorescent photoluminescence and electroluminescence of iridium complexes. Sci. Rep. 5:14912. doi: 10.1038/srep14912

Li, T.-Y., Zheng, Y.-X., and Zhou, Y.-H. (2016). Iridium(iii) phosphorescent complexes with dual stereogenic centers: single crystal, electronic circular dichroism evidence and circularly polarized luminescence properties. Dalton Trans. 45, 19234-19237. doi: 10.1039/C6DT04030F

Li, X., Hu, W., Wang, Y., Quan, Y., and Cheng, Y. (2019). Strong CPL of achiral AIE-active dyes induced by supramolecular self-assembly in chiral nematic liquid crystals (AIE-N*-LCs). Chem. Commun. 55, 5179-5182. doi: 10.1039/C9CC01678C

Li, X.-Z., Zhou, L.-P., Yan, L.-L., Yuan, D.-Q., Lin, C.-S., and Sun, Q.-F. (2017). Evolution of luminescent supramolecular lanthanide $\mathrm{M}_{2 \mathrm{n}} \mathrm{L}_{3 \mathrm{n}}$ complexes from helicates and tetrahedra to cubes. J. Am. Chem. Soc. 139, 8237-8244. doi: 10.1021/jacs.7b02764

Lincheneau, C., Destribats, C., Barry, D. E., Kitchen, J. A., Peacock, R. D., and Gunnlaugsson, T. (2011). Lanthanide directed self-assembly synthesis and photophysical evaluation of chiral Eu(iii) luminescent "half-helicates." Dalton Trans. 40, 12056-12059. doi: 10.1039/C1DT11225B

Liu, D., Zhou, Y., Zhang, Y., Li, H., Chen, P., Sun, W., et al. (2018). Chiral BINAPO-controlled diastereoselective self-assembly and circularly polarized luminescence in triple-stranded europium(III) podates. Inorg. Chem. 57, 8332-8337. doi: 10.1021/acs.inorgchem.8b00986

Liu, M., Zhang, L., and Wang, T. (2015). Supramolecular chirality in self-assembled systems. Chem. Rev. 115, 7304-7397. doi: 10.1021/cr500671p

Lo, K. K.-W., Li, S. P.-Y., and Zhang, K. Y. (2011). Development of luminescent iridium(iii) polypyridine complexes as chemical and biological probes. New $\mathrm{J}$. Chem. 35, 265-287. doi: 10.1039/C0NJ00478B

Longhi, G., Castiglioni, E., Koshoubu, J., Mazzeo, G., and Abbate, S. (2016). Circularly polarized luminescence: a review of experimental and theoretical aspects. Chirality 28, 696-707. doi: 10.1002/chir.22647

Lu, G.-Z., Su, N., Li, Y., and Zheng, Y.-X. (2017). Efficient electroluminescence of platinum complexes containing pinene sterically hindered spacer. $J$. Organomet. Chem. 842, 39-46. doi: 10.1016/j.jorganchem.2017.05.011

Lunkley, J. L., Shirotani, D., Yamanari, K., Kaizaki, S., and Muller, G. (2008). Extraordinary circularly polarized luminescence activity exhibited by cesium tetrakis(3-heptafluoro-butylryl-(+)-camphorato) $\mathrm{Eu}(\mathrm{III})$ complexes in $\mathrm{EtOH}$ and $\mathrm{CHCl}_{3}$ solutions. J. Am. Chem. Soc. 130, 13814-13815. doi: $10.1021 / \mathrm{ja} 805681 \mathrm{w}$

Lunkley, J. L., Shirotani, D., Yamanari, K., Kaizaki, S., and Muller, G. (2011). Chiroptical spectra of a series of tetrakis((+)-3heptafluorobutylyrylcamphorato)lanthanide(III) with an encapsulated alkali metal ion: circularly polarized luminescence and absolute chiral structures for the $\mathrm{Eu}(\mathrm{III})$ and $\mathrm{Sm}(\mathrm{III})$ complexes. Inorg. Chem. 50, 12724-12732. doi: $10.1021 /$ ic201851r

Macé, A., Hellou, N., Hammoud, J., Martin, C., Gauthier, E. S., Favereau, L., et al. (2019). An enantiopure cyclometallated iridium complex displaying long-lived phosphorescence both in solution and in the solid state. Helv. Chim. Acta 102:e1900044. doi: 10.1002/hlca.201900044

Madaras, J. S., and Brittain, H. G. (1980). Induced optical activity in the terbium(III) complex of pyridine-2, 6-dicarboxylic acid through association with resolved tris(ethylenediamine)chromium(III). Inorg. Chem. 19, 3841-3842. doi: 10.1021/ic50214a051

Maeda, C., Ogawa, K., Sadanaga, K., Takaishi, K., and Ema, T. (2019). Chiroptical and catalytic properties of doubly binaphthyl-strapped chiral porphyrins. Chem. Commun. 55, 1064-1067. doi: 10.1039/C8CC09114E 
Malta, O. L., and Carlos, L. D. (2003). Intensities of $4 \mathrm{f}-4 \mathrm{f}$ transitions in glass materials. Quim. Nova 26, 889-895. doi: 10.1590/S0100-40422003000600018

Mamula, O., Lama, M., Stoeckli-Evans, H., and Shova, S. (2006). Switchable chiral architectures containing PrIII ions: an example of solvent-induced adaptive behavior. Angew. Chem. Int. Ed. 45, 4940-4944. doi: 10.1002/anie.200601939

Mamula, O., Lama, M., Telfer, S. G., Nakamura, A., Kuroda, R., Stoeckli-Evans, H., et al. (2005). A trinuclear euIII array within a diastereoselectively self-assembled helix formed by chiral bipyridine-carboxylate ligands. Angew. Chem. Int. Ed. 44, 2527-2531. doi: 10.1002/anie.200500094

Manguin, R., Pichon, D., Tarrieu, R., Vives, T., Roisnel, T., Dorcet, V., et al. (2019). A kinetic resolution strategy for the synthesis of chiral octahedral NHC-iridium(iii) catalysts. Chem. Commun. 55, 6058-6061. doi: 10.1039/C9CC02434D

Manson, N. B., and Shah, G. A. (1977). Coupling of $\mathrm{T}_{1 \mathrm{u}}$ and $\mathrm{T}_{2 \mathrm{u}}$ vibrations to the 2Eg to $4 \mathrm{~A} 2 \mathrm{~g}$ transition in $\mathrm{MgO}: \mathrm{V}^{2+}$ and $\mathrm{MgO}: \mathrm{Cr}^{3+}$. J. Phys. C Solid State Phys. 10, 1991-2003. doi: 10.1088/0022-3719/10/11/034

Mason, S. F. (1971). Optical rotatory power of co-ordination compounds. Part XV. Regional rules and electronic mechanisms for the optical activity of $\mathrm{d} \rightarrow \mathrm{d}$ transitions. J. Chem. Soc. A Inorg. Phys. Theor. 1971, 667-676. doi: $10.1039 / \mathrm{J} 19710000667$

Mason, S. F., and Seal, R. H. (1975). Complementation of the crystal field for dihedral optical activity. Chem. Commun. 1975, 331-333. doi: 10.1039/C39750000331

Mason, S. F., and Seal, R. H. (1976). The optical activity of cobalt(III) chelate diamine complexes. Mol. Phys. 31, 755-775. doi: 10.1080/00268977600100581

Mateos-Timoneda, M. A., Crego-Calama, M., and Reinhoudt, D. N. (2004). Supramolecular chirality of self-assembled systems in solution. Chem. Soc. Rev. 33, 363-372. doi: 10.1039/B305550G

Maupin, C. L., Dickins, R. S., Govenlock, L. G., Mathieu, C. E., Parker, D., Williams, J. A. G., et al. (2000). The measurement of circular polarization in the near-IR luminescence from chiral complexes of $\mathrm{Yb}(\mathrm{III})$ and $\mathrm{Nd}(\mathrm{III})$. J. Phys. Chem. A 104, 6709-6717. doi: 10.1021/jp000648y

Maupin, C. L., Parker, D., Williams, J. A. G., and Riehl, J. P. (1998). Circularly polarized luminescence from chiral octadentate complexes of $\mathrm{Yb}$ (III) in the near-infrared. J. Am. Chem. Soc. 120, 10563-10564. doi: 10.1021/ja982147k

Mazzeo, G., Fusè, M., Longhi, G., Rimoldi, I., Cesarotti, E., Crispini, A., et al. (2016). Vibrational circular dichroism and chiroptical properties of chiral $\operatorname{Ir}($ iii) luminescent complexes. Dalton Trans. 45, 992-999. doi: 10.1039/C5DT03642A

Metcalf, D. H., and Richardson, F. S. (1994). The determination of chiroptical dissymmetry factors and electric-vs. magnetic-dipole transition amplitude ratios from circularly polarized excitation and emission measurements on racemic $\mathrm{Eu}(\mathrm{dpa})^{33-}$ in aqueous solution. J. Alloys Compd. 207-208, 59-61. doi: 10.1016/0925-8388(94)90176-7

Metcalf, D. H., Snyder, S. W., Demas, J. N., and Richardson, F. S. (1990). Excitedstate racemization kinetics and chiroptical activity of a labile metal complex in aqueous solution. Time-resolved circularly polarized luminescence study of tris(dipicolinato)europate (3-) in water and deuterium oxide. J. Am. Chem. Soc. 112, 469-479. doi: 10.1021/ja00158a001

Mori, K. (2011). Bioactive natural products and chirality. Chirality 23, 449-462. doi: 10.1002/chir.20930

Morita, M., Eguchi, K., Shishikura, M., Nishikawa, H., and Inoue, M. (1984). Circularly polarized luminescense of (-)D-[Cr(R-pn $\left.)_{3}\right]^{3+}$ and related chiral chromium (III) complexes using a microcomputerbased digital spectrophotometer system. J. Lumin. 31-32, 558-560. doi: 10.1016/0022-2313(84)90059-0

Morita, M., Herren, M., Ansai, T., and Rau, D. (2000). Excited-state chiral discrimination of $\mathrm{Tb}(\mathrm{III})$ complexes of $\left(\mathrm{S}, \mathrm{S}^{\prime}\right)$ - and $\left(\mathrm{R}, \mathrm{R}^{\prime}\right)$-ethylenediamine$N, N^{\prime}$-disuccinic acid in circularly polarized luminescence and luminescence decay profiles. J. Lumin. 87-89, 976-979. doi: 10.1016/S0022-2313(99) 00498-6

Muller, G., Bünzli, J.-C. G., Riehl, J. P., Suhr, D., Zelewsky, A. v., and Mürner, H. (2002). First diastereoselective formation of lanthanide triple helical complexes with a terdentate chiral C2 symmetric ligand. Chem. Commun. 2002, 1522-1523. doi: 10.1039/B203691F

Neil, E. R., Fox, M. A., Pal, R., and Parker, D. (2016). Induced europium CPL for the selective signalling of phosphorylated amino-acids and O-phosphorylated hexapeptides. Dalton Trans. 45, 8355-8366. doi: 10.1039/C6DT01212D
Nobuhiro, A., Shinjiro, M., and Kazuyuki, H. (2001). Chirooptical control of liquid crystalline textures containing chromium complex by irradiation of circular polarized light. Chem. Lett. 30, 888-889. doi: 10.1246/cl.2001.888

Otto, S., Dorn, M., Förster, C., Bauer, M., Seitz, M., and Heinze, K. (2018). Understanding and exploiting long-lived near-infrared emission of a molecular ruby. Coord. Chem. Rev. 359, 102-111. doi: 10.1016/j.ccr.2018.01.004

Otto, S., Grabolle, M., Förster, C., Kreitner, C., Resch-Genger, U., and Heinze, K. (2015). [Cr(ddpd $\left.)_{2}\right]^{3+}$ : a molecular, water-soluble, highly NIR-emissive ruby analogue. Angew. Chem. Int. Ed. 54, 11572-11576. doi: 10.1002/anie.201504894

Oyler, K. D., Coughlin, F. J., and Bernhard, S. (2007). Controlling the helicity of 2,2'-bipyridyl ruthenium(II) and zinc(II) hemicage complexes. J. Am. Chem. Soc. 129, 210-217. doi: 10.1021/ja067016v

Park, G., Kim, H., Yang, H., Park, K. R., Song, I., Oh, J. H., et al. (2019). Amplified circularly polarized phosphorescence from co-assemblies of platinum(ii) complexes. Chem. Sci. 10, 1294-1301. doi: 10.1039/C8SC04509G

Parker, D., Dickins, R. S., Puschmann, H., Crossland, C., and Howard, J. A. K. (2002). Being excited by lanthanide coordination complexes: aqua species, chirality, excited-state chemistry, and exchange dynamics. Chem. Rev. 102, 1977-2010. doi: 10.1021/cr010452

Perkovic, M. W., Heeg, M. J., and Endicott, J. F. (1991). Stereochemical perturbations of the relaxation behavior of (2E)chromium(III). Ground-state xray crystal structure, photophysics, and molecular mechanics simulations of the quasi-cage complex $\left[4,4^{\prime}, 4^{\prime \prime}\right.$-ethylidynetris(3-azabutan-1-amine) $]$ chromium tribromide. Inorg. Chem. 30, 3140-3147. doi: 10.1021/ic00016a009

Pescitelli, G., Di Bari, L., and Berova, N. (2011). Conformational aspects in the studies of organic compounds by electronic circular dichroism. Chem. Soc. Rev. 40, 4603-4625. doi: 10.1039/C1CS15036G

Pescitelli, G., Di Bari, L., and Berova, N. (2014). Application of electronic circular dichroism in the study of supramolecular systems. Chem. Soc. Rev. 43, 5211-5233. doi: 10.1039/C4CS00104D

Petoud, S., Muller, G., Moore, E. G., Xu, J., Sokolnicki, J., Riehl, J. P., et al. (2007). Brilliant $\mathrm{Sm}, \mathrm{Eu}, \mathrm{Tb}$, and Dy chiral lanthanide complexes with strong circularly polarized luminescence. J. Am. Chem. Soc. 129, 77-83. doi: 10.1021/ja064902x

Ranganathan, R. S., Pillai, R. K., Raju, N., Fan, H., Nguyen, H., Tweedle, M. F., et al. (2002). Polymethylated DOTA ligands. 1. Synthesis of rigidified ligands and studies on the effects of alkyl substitution on acid-base properties and conformational mobility. Inorg. Chem. 41, 6846-6855. doi: 10.1021/ic025657v

Reiné, P., Justicia, J., Morcillo, S. P., Abbate, S., Vaz, B., Ribagorda, M., et al. (2018a). Pyrene-containing ortho-oligo(phenylene)ethynylene foldamer as a ratiometric probe based on circularly polarized luminescence. J. Org. Chem. 83, 4455-4463. doi: 10.1021/acs.joc.8b00162

Reiné, P., Ortuño, A. M., Resa, S., Álvarez de Cienfuegos, L., Blanco, V., Ruedas-Rama, M. J., et al. (2018b). OFF/ON switching of circularly polarized luminescence by oxophilic interaction of homochiral sulfoxidecontaining o-OPEs with metal cations. Chem. Commun. 54, 13985-13988. doi: 10.1039/C8CC08395A

Resa, S., Miguel, D., Guisán-Ceinos, S., Mazzeo, G., Choquesillo-Lazarte, D., Abbate, S., et al. (2018). Sulfoxide-induced homochiral folding of ortho-phenylene ethynylenes (o-OPEs) by silver(I) templating: structure and chiroptical properties. Chem. Eur. J. 24, 2653-2662. doi: 10.1002/chem.201704897

Réthoré, C., Avarvari, N., Canadell, E., Auban-Senzier, P., and Fourmigué, M. (2005). Chiral molecular metals: syntheses, structures, and properties of the AsF6-salts of racemic ( \pm )-, (R)-, and (S)-tetrathiafulvalene-oxazoline derivatives. J. Am. Chem. Soc. 127, 5748-5749. doi: 10.1021/ja0503884

Richardson, F. S. (1971). Optical activity of transition metal compounds. I. Sector rules for metal complexes of the pseudotetragonal class. J. Chem. Phys. 54, 2453-2468. doi: 10.1063/1.1675200

Richardson, F. S. (1979). Theory of optical activity in the ligand-field transitions of chiral transition metal complexes. Chem. Rev. 79, 17-36. doi: $10.1021 / \mathrm{cr} 60317 \mathrm{a} 003$

Richardson, F. S. (1980). Selection rules for lanthanide optical activity. Inorg. Chem. 19, 2806-2812. doi: 10.1021/ic50211a063

Rickhaus, M., Mayor, M., and Juríček, M. (2017). Chirality in curved polyaromatic systems. Chem. Soc. Rev. 46, 1643-1660. doi: 10.1039/C6CS00623J

Riehl, J. P., and Muller, G. (2004). "Circularly polarized luminescence spectroscopy from lanthanide systems," in Handbook on the Physics and Chemistry of Rare 
Earths, Vol. 34, eds K. A. Gschneidner, J.-C. Bunzli, and V. Pecharsky (North Holland: Elsevier), 289-357. doi: 10.1016/S0168-1273(04)34003-1

Riehl, J. P., and Richardson, F. S. (1986). Circularly polarized luminescence spectroscopy. Chem. Rev. 86, 1-16. doi: 10.1021/cr00071a001

Rikken, G. L. J. A., and Raupach, E. (1997). Observation of magneto-chiral dichroism. Nature 390, 493-494. doi: 10.1038/37323

Roose, J., Tang, B. Z., and Wong, K. S. (2016). Circularly-polarized luminescence (CPL) from chiral AIE molecules and macrostructures. Small 12, 6495-6512. doi: $10.1002 /$ smll.201601455

Ryu, C. K., and Endicott, J. F. (1988). Synthesis, spectroscopy, and photophysical behavior of mixed-ligand mono- and bis(polypyridyl)chromium(III) complexes. Examples of efficient, thermally activated excited-state relaxation without back intersystem crossing. Inorg. Chem. 27, 2203-2214. doi: $10.1021 /$ ic00286a002

Saleh, N., Moore II, B., Srebro, M., Vanthuyne, N., Toupet, L., Williams, J. A. G., et al. (2015a). Acid/base-triggered switching of circularly polarized luminescence and electronic circular dichroism in organic and organometallic helicenes. Chem. Eur. J. 21, 1673-1681. doi: 10.1002/chem.201405176

Saleh, N., Srebro, M., Reynaldo, T., Vanthuyne, N., Toupet, L., Chang, V. Y., et al. (2015b). Enantio-enriched CPL-active helicene-bipyridine-rhenium complexes. Chem. Commun. 51, 3754-3757. doi: 10.1039/C5CC00453E

Sánchez-Carnerero, E. M., Agarrabeitia, A. R., Moreno, F., Maroto, B. L., Muller, G., Ortiz, M. J., et al. (2015). Circularly polarized luminescence from simple organic molecules. Chem. Eur. J. 21, 13488-13500. doi: $10.1002 /$ chem.201501178

Sang, Y., Han, J., Zhao, T., Duan, P., and Liu, M. (2019). Circularly polarized luminescence in nanoassemblies: generation, amplification, and application. Adv. Mater. 2019:1900110. doi: 10.1002/adma.201900110

Sato, S., Yoshii, A., Takahashi, S., Furumi, S., Takeuchi, M., and Isobe, H. (2017). Chiral intertwined spirals and magnetic transition dipole moments dictated by cylinder helicity. Proc. Natl. Acad. Sci. U.S.A. 114, 13097-13101. doi: 10.1073/pnas.1717524114

Sawada, Y., Furumi, S., Takai, A., Takeuchi, M., Noguchi, K., and Tanaka, K. (2012). Rhodium-catalyzed enantioselective synthesis, crystal structures, and photophysical properties of helically chiral $1,1^{\prime}$-bitriphenylenes. J. Am. Chem. Soc. 134, 4080-4083. doi: 10.1021/ja300278e

Scarborough, C. C., Lancaster, K. M., DeBeer, S., Weyhermüller, T., Sproules, S., and Wieghardt, K. (2012). Experimental fingerprints for redox-active terpyridine in $\left[\mathrm{Cr}(\mathrm{tpy})_{2}\right](\mathrm{PF} 6)_{\mathrm{n}}(n=3-0)$, and the Remarkable Electronic Structure of $\left[\mathrm{Cr}(\mathrm{tpy})_{2}\right]^{1-}$. Inorg. Chem. 51, 3718-3732. doi: 10.1021/ic2027219

Schaffner-Hamann, C., von Zelewsky, A., Barbieri, A., Barigelletti, F., Muller, G., Riehl, J. P., et al. (2004). Diastereoselective formation of chiral triscyclometalated iridium (III) complexes: characterization and photophysical properties. J. Am. Chem. Soc. 126, 9339-9348. doi: 10.1021/ja048655d

Schellman, J. A. (1975). Circular dichroism and optical rotation. Chem. Rev. 75, 323-331. doi: 10.1021/cr60295a004

Schönle, J., Constable, E. C., Housecroft, C. E., and Neuburger, M. (2015a). Tuning peripheral $\pi$-stacking motifs in $\left\{\mathrm{Cr}(\operatorname{tpy})_{2}\right\}^{3}+$ domains (tpy $=2,2^{\prime}: 6^{\prime}, 2^{\prime \prime}$-terpyridine). Inorg. Chem. Commun. 53, 80-83. doi: 10.1016/j.inoche.2015.01.014

Schönle, J., Constable, E. C., Housecroft, C. E., Prescimone, A., and Zampese, J. A. (2015b). Homoleptic and heteroleptic complexes of chromium(III) containing $4^{\prime}$-diphenylamino-2,2' $: 6^{\prime}, 2^{\prime \prime}$-terpyridine ligands. Polyhedron 89, 182-188. doi: 10.1016/j.poly.2015.01.015

Schulte, T. R., Holstein, J. J., Krause, L., Michel, R., Stalke, D., Sakuda, E., et al. (2017). Chiral-at-metal phosphorescent square-planar Pt(II)-complexes from an achiral organometallic ligand. J. Am. Chem. Soc. 139, 6863-6866. doi: $10.1021 /$ jacs.7b03963

Seeber, G., Tiedemann, B. E. F., and Raymond, K. N. (2006). "Supramolecular chirality in coordination chemistry," in Supramolecular Chirality, eds M. CregoCalama and D. N. Reinhoudt (Berlin; Heidelberg: Springer Berlin Heidelberg), 147-183. doi: 10.1007/128_033

Serpone, N., Jamieson, M. A., Henry, M. S., Hoffman, M. Z., Bolletta, F., and Maestri, M. (1979). Excited-state behavior of polypyridyl complexes of chromium(III). J. Am. Chem. Soc. 101, 2907-2916. doi: 10.1021/ja00505a019

Seyler, K. L., Zhong, D., Klein, D. R., Gao, S., Zhang, X., Huang, B., et al. (2018). Ligand-field helical luminescence in a 2D ferromagnetic insulator. Nat. Phys. 14, 277-281. doi: 10.1038/s41567-017-0006-7
Shen, C., Anger, E., Srebro, M., Vanthuyne, N., Deol, K. K., Jefferson, T. D., et al. (2014). Straightforward access to mono- and bis-cycloplatinated helicenes displaying circularly polarized phosphorescence by using crystallization resolution methods. Chem. Sci. 5, 1915-1927. doi: 10.1039/C3SC53442A

Sheng, Y., Ma, J., Liu, S., Wang, Y., Zhu, C., and Cheng, Y. (2016). Strong and reversible circularly polarized luminescence emission of a chiral 1,8-naphthalimide fluorophore induced by excimer emission and orderly aggregation. Chem. Eur. J. 22, 9519-9522. doi: 10.1002/chem.201600891

Shi, L., Zhu, L., Guo, J., Zhang, L., Shi, Y., Zhang, Y., et al. (2017). Self-assembly of chiral gold clusters into crystalline nanocubes of exceptional optical activity. Angew. Chem. Int. Ed. 56, 15397-15401. doi: 10.1002/anie.201709827

Song, F., Xu, Z., Zhang, Q., Zhao, Z., Zhang, H., Zhao, W., et al. (2018). Highly efficient circularly polarized electroluminescence from aggregation-induced emission luminogens with amplified chirality and delayed fluorescence. $A d v$. Funct. Mater. 28:1800051. doi: 10.1002/adfm.201800051

Song, J., Wang, M., Xu, X., Qu, L., Zhou, X., and Xiang, H. (2019). 1D-helical platinum(ii) complexes bearing metal-induced chirality, aggregation-induced red phosphorescence, and circularly polarized luminescence. Dalton Trans. 48, 4420-4428. doi: 10.1039/C8DT03615B

Song, J., Wang, M., Zhou, X., and Xiang, H. (2018). Unusual circularly polarized and aggregation-induced near-infrared phosphorescence of helical platinum(II) complexes with tetradentate salen ligands. Chem. Eur. J. 24, 7128-7132. doi: $10.1002 /$ chem. 201801414

Sprafke, J. K., Kondratuk, D. V., Wykes, M., Thompson, A. L., Hoffmann, M., Drevinskas, R., et al. (2011). Belt-shaped $\pi$-systems: relating geometry to electronic structure in a six-porphyrin nanoring. J. Am. Chem. Soc. 133, 17262-17273. doi: 10.1021/ja2045919

Stomeo, F., Lincheneau, C., Leonard, J. P., O’Brien, J. E., Peacock, R. D., McCoy, C. P., et al. (2009). Metal-directed synthesis of enantiomerially pure dimetallic lanthanide luminescent triple-stranded helicates. J. Am. Chem. Soc. 131, 9636-9637. doi: 10.1021/ja9032204

Strickland, R. W., and Richardson, F. S. (1976). Optical activity of d-d transitions in copper(II) complexes of amino acids, dipeptides, and tripeptides. Dynamical coupling model. J. Phys. Chem. 80, 164-173. doi: 10.1021/j100543a017

Tamayo, A. B., Alleyne, B. D., Djurovich, P. I., Lamansky, S., Tsyba, I., Ho, N. N., et al. (2003). Synthesis and characterization of facial and meridional triscyclometalated iridium(III) complexes. J. Am. Chem. Soc. 125, 7377-7387. doi: $10.1021 / \mathrm{ja} 034537 \mathrm{z}$

Tanaka, H., Ikenosako, M., Kato, Y., Fujiki, M., Inoue, Y., and Mori, T. (2018b). Symmetry-based rational design for boosting chiroptical responses. Commun. Chem. 1:38. doi: 10.1038/s42004-0180035-x

Tanaka, H., Inoue, Y., and Mori, T. (2018a). Circularly polarized luminescence and circular dichroisms in small organic molecules: correlation between excitation and emission dissymmetry factors. ChemPhotoChem 2, 386-402. doi: $10.1002 /$ cptc. 201800015

Tanaka, H., Kato, Y., Fujiki, M., Inoue, Y., and Mori, T. (2018c). Combined experimental and theoretical study on circular dichroism and circularly polarized luminescence of configurationally robust D3-symmetric triple pentahelicene. J. Phys. Chem. A 122, 7378-7384. doi: 10.1021/acs.jpca.8b05247

Tanaka, S., Sato, K., Ichida, K., Abe, T., Tsubomura, T., Suzuki, T., et al. (2016). Circularly polarized luminescence of chiral $\mathrm{Pt}(\mathrm{pppb}) \mathrm{Cl}$ (pppbH=1-pyridyl-3(4, 5-pinenopyridyl)benzene) aggregate in the excited state. Chem. Asian J. 11, 265-273. doi: 10.1002/asia.201500985

Tang, X.-L., Wang, W.-H., Dou, W., Jiang, J., Liu, W.-S., Qin, W.-W., et al. (2009). Olive-shaped chiral supramolecules: simultaneous self-assembly of heptameric lanthanum clusters and carbon dioxide fixation. Angew. Chem. Int. Ed. 48, 3499-3502. doi: 10.1002/anie.200900838

Tanner, P. A. (2013). Some misconceptions concerning the electronic spectra of tri-positive europium and cerium. Chem. Soc. Rev. 42, 5090-5101. doi: $10.1039 / \mathrm{C} 3 \mathrm{CS} 60033 \mathrm{E}$

Taro, T., Iwao, O., and Makoto, M. (1991). Luminescence and circularly polarized luminescence of mononuclear and binuclear chromium(III) L-alaninato complexes. Bull. Chem. Soc. Jpn. 64, 2341-2348. doi: 10.1246/bcsj.64.2341

Tóth, É., Vauthey, S., Pubanz, D., and Merbach, A. E. (1996). Water exchange and rotational dynamics of the dimeric gadolinium(III) complex $\left[\mathrm{BO}\left\{\mathrm{Gd}(\mathrm{DO} 3 \mathrm{~A})\left(\mathrm{H}_{2} \mathrm{O}\right)\right\}^{2}\right]$ : a variable-temperature and -pressure $17 \mathrm{O}$ NMR study 1. Inorg. Chem. 35, 3375-3379. doi: 10.1021/ic951492x 
Train, C., Gruselle, M., and Verdaguer, M. (2011). The fruitful introduction of chirality and control of absolute configurations in molecular magnets. Chem. Soc. Rev. 40, 3297-3312. doi: 10.1039/C1CS15012J

Treiling, S., Wang, C., Förster, C., Reichenauer, F., Kalmbach, J., Boden, P., et al. (2019). Luminescence and light-driven energy and electron transfer from an exceptionally long-lived excited state of a non-innocent chromium(III) complex. Angew. Chem. Int. Ed. 58, 18075-18085. doi: 10.1002/anie.201909325

Tsubomura, T., Morita, M., and Ohkouchi, I. (1988). Luminescence of chronium(III) 1-alaninato and other related complexes. J. Lumin. 40-41, 268-269. doi: 10.1016/0022-2313(88) 90188-3

Uchida, T.-A., Nozaki, K., and Iwamura, M. (2016). Chiral sensing of various amino acids using induced circularly polarized luminescence from europium(III) complexes of phenanthroline dicarboxylic acid derivatives. Chem. Asian J. 11, 2415-2422. doi: 10.1002/asia. 201600798

Usuki, T., Uchida, H., Omoto, K., Yamanoi, Y., Yamada, A., Iwamura, M., et al. (2019). Enhancement of the photofunction of phosphorescent Pt(II) cyclometalated complexes driven by substituents: solid-state luminescence and circularly polarized luminescence. J. Org. Chem. 84, 10749-10756. doi: 10.1021/acs.joc.9b01285

van Leeuwen, T., Lubbe, A. S., Štacko, P., Wezenberg, S. J., and Feringa, B. L. (2017). Dynamic control of function by light-driven molecular motors. Nat. Rev. Chem. 1:0096. doi: 10.1038/s41570-017-0096

Vandiver, M. S., Bridges, E. P., Koon, R. L., Kinnaird, A. N., Glaeser, J. W., Campbell, J. F., et al. (2010). Effect of ancillary ligands on the DNA interaction of $\left.[\mathrm{Cr} \text { (diimine })_{3}\right]^{3+}$ complexes containing the intercalating dipyridophenazine ligand. Inorg. Chem. 49, 839-848. doi: 10.1021/ic9013619

Vasudevan, S., Smith, J. A., Wojdyla, M., McCabe, T., Fletcher, N. C., Quinn, S. J., et al. (2010). Substituted dipyridophenazine complexes of $\mathrm{Cr}$ (iii): synthesis, enantiomeric resolution and binding interactions with calf thymus DNA. Dalton Trans. 39, 3990-3998. doi: 10.1039/C000150C

Wada, S., Kitagawa, Y., Nakanishi, T., Gon, M., Tanaka, K., Fushimi, K., et al. (2018). Electronic chirality inversion of lanthanide complex induced by achiral molecules. Sci. Rep. 8:16395. doi: 10.1038/s41598-018-34790-0

Walton, J. W., Bari, L. D., Parker, D., Pescitelli, G., Puschmann, H., and Yufit, D. S. (2011). Structure, resolution and chiroptical analysis of stable lanthanide complexes of a pyridylphenylphosphinate triazacyclononane ligand. Chem. Commun. 47, 12289-12291. doi: 10.1039/C1CC14904K

Wang, C., Otto, S., Dorn, M., Kreidt, E., Lebon, J., Sršan, L., et al. (2017). Deuterated molecular ruby with record luminescence quantum yield. Angew. Chem. Int. Ed. 57, 1112-1116. doi: 10.1002/anie.201711350

Watanabe, K., and Akagi, K. (2014). Helically assembled $\pi$-conjugated polymers with circularly polarized luminescence. Sci. Technol. Adv. Mater. 15:044203. doi: 10.1088/1468-6996/15/4/044203

Woods, M., Kovacs, Z., Zhang, S., and Sherry, A. D. (2003). Towards the rational design of magnetic resonance imaging contrast agents: isolation of the two coordination isomers of lanthanide DOTA-type complexes. Angew. Chem. Int. Ed. 42, 5889-5892. doi: 10.1002/anie.200352234

Woody, R. W. (1995). Circular dichroism. Methods Enzymol. 246, 34-71. doi: 10.1016/0076-6879(95)46006-3

Wu, T., You, X.-Z., and Bour, P. (2015). Applications of chiroptical spectroscopy to coordination compounds. Coord. Chem. Rev. 284, 1-18. doi: 10.1016/j.ccr.2014.09.012

Yamaga, M., Marshall, A., O’Donnell, K. P., and Henderson, B. (1990). Polarized photoluminescence from $\mathrm{Cr}^{3+}$ ions in laser host crystals III. $\mathrm{ZnWO}_{4}$. J. Lumin. 47, 65-70. doi: 10.1016/0022-2313(90)90060-O

Yan, L.-L., Tan, C.-H., Zhang, G.-L., Zhou, L.-P., Bünzli, J.-C., and Sun, Q.-F. (2015). Stereocontrolled self-assembly and self-sorting of luminescent europium tetrahedral cages. J. Am. Chem. Soc. 137, 8550-8555. doi: $10.1021 /$ jacs.5b03972

Yan, Z.-P., Liao, K., Han, H.-B., Su, J., Zheng, Y.-X., and Zuo, J.-L. (2019a). Chiral iridium(iii) complexes with four-membered Ir-S-P-S chelating rings for highperformance circularly polarized OLEDs. Chem. Commun. 55, 8215-8218. doi: 10.1039/C9CC03915E

Yan, Z.-P., Luo, X.-F., Liao, K., Lin, Z.-X., Wu, Z.-G., Zhou, Y.-H., et al. (2018). The Taiji and Eight Trigrams chemistry philosophy of chiral iridium(iii) complexes with triplex stereogenic centers. Dalton Trans. 47, 4045-4048. doi: 10.1039/C8DT00264A

Yan, Z.-P., Luo, X.-F., Liu, W.-Q., Wu, Z.-G., Liang, X., Liao, K., et al. (2019b). Configurationally stable platinahelicene enantiomers for efficient circularly polarized phosphorescent organic light-emitting diodes. Chem. Eur. J. 25, 5672-5676. doi: 10.1002/chem.201900955

Yang, D., Han, J., Liu, M., and Duan, P. (2019). Photon upconverted circularly polarized luminescence via triplet-triplet annihilation. Adv. Mater. 31:1805683. doi: 10.1002/adma.201805683

Yang, L., Zelewsky, A. v., Nguyen, H. P., Muller, G., Labat, G., and StoeckliEvans, H. (2009). Stereoselective synthesis of cyclometalated iridium(III) complexes: characterization and photophysical properties. Inorg. Chim. Acta 362, 3853-3856. doi: 10.1016/j.ica.2008.10.011

Yang, X., Han, J., Wang, Y., and Duan, P. (2019). Photon-upconverting chiral liquid crystal: significantly amplified upconverted circularly polarized luminescence. Chem. Sci. 10, 172-178. doi: 10.1039/C8SC03806F

Yang, Y., da Costa, R. C., Fuchter, M. J., and Campbell, A. J. (2013). Circularly polarized light detection by a chiral organic semiconductor transistor. Nat. Photon. 7:634. doi: 10.1038/nphoton.2013.176

Yeung, C.-T., Yim, K.-H., Wong, H.-Y., Pal, R., Lo, W.-S., Yan, S.-C., et al. (2017). Chiral transcription in self-assembled tetrahedral Eu4L6 chiral cages displaying sizable circularly polarized luminescence. Nat. Commun. 8:1128. doi: 10.1038/s41467-017-01025-1

Zamora, A., Vigueras, G., Rodríguez, V., Santana, M. D., and Ruiz, J. (2018). Cyclometalated iridium(III) luminescent complexes in therapy and phototherapy. Coord. Chem. Rev. 360, 34-76. doi: 10.1016/j.ccr.2018.01.010

Zare, D., Doistau, B., Nozary, H., Besnard, C., Guenee, L., Suffren, Y., et al. (2017b). CrIII as an alternative to ruII in metallo-supramolecular chemistry. Dalton Trans. 46, 8992-9009. doi: 10.1039/C7DT01747B

Zare, D., Suffren, Y., Nozary, H., Hauser, A., and Piguet, C. (2017a). Controlling lanthanide exchange in triple-stranded helicates: a way to optimize molecular light-upconversion. Angew. Chem. Int. Ed. 56, 14612-14617. doi: 10.1002/anie.201709156

Zercher, B., and Hopkins, T. A. (2016). Induction of circularly polarized luminescence from europium by amino acid based ionic liquids. Inorg. Chem. 55, 10899-10906. doi: 10.1021/acs.inorgchem.6b01343

Zhang, G., Gil-Ramírez, G., Markevicius, A., Browne, C., Vitorica-Yrezabal, I. J., and Leigh, D. A. (2015). Lanthanide template synthesis of trefoil knots of single handedness. J. Am. Chem. Soc. 137, 10437-10442. doi: 10.1021/jacs.5b07069

Zhang, J., Liu, Q., Wu, W., Peng, J., Zhang, H., Song, F., et al. (2019). Realtime monitoring of hierarchical self-assembly and induction of circularly polarized luminescence from achiral luminogens. ACS Nano 13, 3618-3628. doi: $10.1021 /$ acsnano.9b00218

Zhang, M.-M., Dong, X.-Y., Wang, Z.-Y., Li, H.-Y., Li, S.-J., Zhao, X., et al. (2019). AIE triggers the circularly polarized luminescence of atomically precise enantiomeric copper(I) alkynyl clusters. Angew. Chem. Int. Ed. n/a. doi: 10.1002/anie.201908909

Zhang, X.-P., Chang, V. Y., Liu, J., Yang, X.-L., Huang, W., Li, Y., et al. (2015). Potential switchable circularly polarized luminescence from chiral cyclometalated platinum(II) complexes. Inorg. Chem. 54, 143-152. doi: 10.1021/ic5019136

Zhang, X.-P., Wang, L.-L., Qi, X.-W., Zhang, D.-S., Yang, Q.-Y., Shi, Z.-F., et al. (2018). Pt...Pt interaction triggered tuning of circularly polarized luminescence activity in chiral dinuclear platinum(ii) complexes. Dalton Trans. 47, 10179-10186. doi: 10.1039/C8DT02277A

Zhao, J., Zhang, T., Dong, X.-Y., Sun, M.-E., Zhang, C., Li, X., et al. (2019). Circularly polarized luminescence from achiral single crystals of hybrid manganese halides. J. Am. Chem. Soc. 141, 15755-15760. doi: $10.1021 /$ jacs.9b08780

Zhou, G., Wong, W.-Y., and Yang, X. (2011). New design tactics in OLEDs using functionalized 2-phenylpyridine-type cyclometalates of iridium(III) and platinum(II). Chem. Asian J. 6, 1706-1727. doi: 10.1002/asia. 201000928

Zhou, Y., Li, H., Zhu, T., Gao, T., and Yan, P. (2019). A highly luminescent chiral tetrahedral $\mathrm{Eu}_{4} \mathrm{~L}_{4}\left(\mathrm{~L}^{\prime}\right)_{4}$ cage: chirality induction, chirality memory, and circularly polarized luminescence. J. Am. Chem. Soc. 141, 19634-19643. doi: $10.1021 /$ jacs.9b07178 
Zinna, F., Arrico, L., and Di Bari, L. (2019). Near-infrared circularly polarized luminescence from chiral $\mathrm{Yb}$ (iii)diketonates. Chem. Commun. 55, 6607-6609. doi: 10.1039/ $\mathrm{C} 9 \mathrm{CC} 03032 \mathrm{H}$

Zinna, F., and Di Bari, L. (2015). Lanthanide circularly polarized luminescence: bases and applications. Chirality 27, 1-13. doi: 10.1002/ chir.22382

Zinna, F., Pasini, M., Galeotti, F., Botta, C., Di Bari, L., and Giovanella, U. (2017). Design of lanthanide-based OLEDs with remarkable circularly polarized electroluminescence. Adv. Funct. Mater. 27:1603719. doi: 10.1002/adfm. 201603719
Conflict of Interest: The authors declare that the research was conducted in the absence of any commercial or financial relationships that could be construed as a potential conflict of interest.

Copyright (๑) 2020 Doistau, Jiménez and Piguet. This is an open-access article distributed under the terms of the Creative Commons Attribution License (CC BY). The use, distribution or reproduction in other forums is permitted, provided the original author(s) and the copyright owner(s) are credited and that the original publication in this journal is cited, in accordance with accepted academic practice. No use, distribution or reproduction is permitted which does not comply with these terms. 